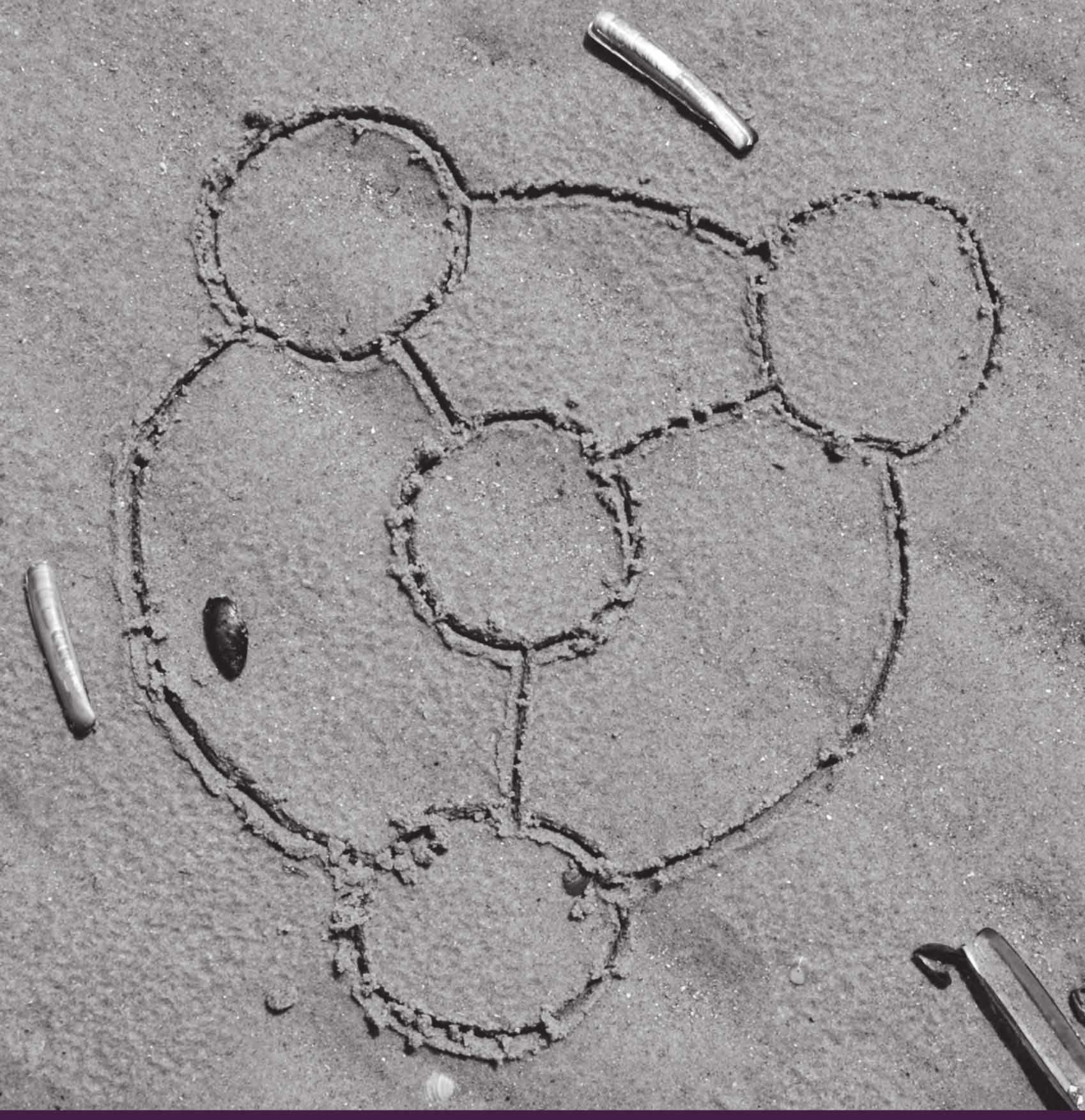

\title{
STRUCTURING USER-CENTRED PRODUCT DEVELOPMENT PROCESSES
}

Frederik Hoolhorst 


\section{STRUCTURING USER-CENTRED PRODUCT DEVELOPMENT PROCESSES}


Dissertation committee:

Prof. dr. F. Eising

Prof. dr. ir. F.J.A.M. van Houten

Dr. ir. M.C. van der Voort

Prof. A. Bernard

Prof. dr. ir. C.H. Dorst

Prof. ir. D.J. van Eijk

Prof. dr. ir. R. ten Klooster

Prof. dr. ir. P.P.C.C. Verbeek
University of Twente, Chairman/secretary

University of Twente, Promoter

University of Twente, Assistant-promoter

Ecole Centrale de Nantes, France

University of Technology Sydney, Australia

Delft University of Technology

University of Twente

University of Twente

ISBN 978-90-365-3401-7

DOI $\quad 10.3990 / 1.9789036534017$

(C) Frederik Hoolhorst, 2012

Cover design by Frederik Hoolhorst and Jesyca Hakstege

Photography by Bert Hoolhorst

Printed by PrintPartners Ipskamp BV, Enschede, The Netherlands

All rights reserved. No part of this publication may be reproduced, stored in a retrieval system or transmitted, in any form or by any means, electronic, mechanical, photocopying, recording or otherwise, without the prior written permission of the author. 


\title{
STRUCTURING USER-CENTRED PRODUCT DEVELOPMENT PROCESSES
}

\section{PROEFSCHRIFT}

\author{
ter verkrijging van \\ de graad van doctor aan de Universiteit Twente, \\ op gezag van de rector magnificus, \\ prof. dr. H. Brinksma \\ volgens besluit van het College voor Promoties \\ in het openbaar te verdedigen op \\ vrijdag 14 september 2012 om 14:45 uur
}

door

Frederik Willem Bertrandus Hoolhorst geboren op 3 mei 1979 te Eeklo, België 
Dit proefschrift is goedgekeurd door de promotor

Prof. dr. ir. F.J.A.M. van Houten

en de assistent-promotor

Dr. ir. M.C. van der Voort

The author gratefully acknowledges the support of the Innovation-Oriented Research Programme 'Integral Product Creation and Realisation (IOP IPCR)' of the Netherlands Ministry of Economic Affairs, Agriculture and Innovation. 
To my grandmothers, Maria van den Broecke-Lamyns and Eleonore Hoolhorst-Hartmann 


\section{Preface}

During my graduation at the Delft University of Technology I developed an interest in research. Slowly, but surely, it became a wish to become a PhD student. Particularly, the opportunity to gain a more in-depth insight into a topic in which I was personally interested seemed a challenge to me. Finally, after working as a product developer for two years, I was given the opportunity to make this wish come true. In June 2007, I started as a PhD student at the University of Twente within the IOP-IPCR Design for Usability research program. It became my task to develop a method that systematically supports product development teams in specifying a detailed usercentred plan of approach for a specific project. Now, the result of this research can be found in this dissertation. Although the execution of a $\mathrm{PhD}$ assignment is an individual challenge, it requires the support of many people. A number of people I met as a $\mathrm{PhD}$ student provided me this support and generously shared their insights and experience with me. I would like to acknowledge these people, without whom this dissertation would never have existed.

First of all my gratitude goes to my promoter Fred van Houten and my assistantpromoter Mascha van der Voort. I deeply thank you for the opportunity, the trust and freedom you have given me to make my personal wish come true: spending some years on a PhD project. To my assistant-promoter Mascha van der Voort I would like to extend my sincere thanks for never giving up on me. You supported me when needed from day one. And support was needed from time to time ... Within many discussions you inspired me and forced me to critically reflect on my ideas and research results.

Developing a method that is directly applicable in product development practice was one of the goals of my research. Gaining a good insight into the characteristics and needs of the product development practice is required in order to achieve this goal. The dialogue with the product development practice was essential for gaining such an insight. For this reason I would like to acknowledge all product development practitioners who participated in my workshops: Willem-Mees, Jasper, Erik, Wilfred, Céline, Mario, Bas, Estella, Hans, Hub, Jacqueline, Jan, Jan Hendrik, Edward, Jo, Abbie, Ximera and Barbara. Thank you for the time and effort you spend in showing me something of your daily product developing practice. Your critical remarks on my ideas and results have been of great value for quality of my research.

Within the past five years I enjoyed being a part of the group of Design, Production and Management. The tutoring of Industrial Design Engineering students I performed 
was a fun, rewarding and learning experience for me. Furthermore, coffee breaks and lunches with colleagues were often a welcome change to the sometimes difficult research activities. In here a special thanks goes to all the people that have shared room N-211 with me over the years. To phrase one of you: "Our crowded and lively office was not always the best catalyst for productivity, but always a strong motivation to come to work." I really enjoyed our conversations and entertaining actions. Bedankt, bedankt, bedankt! Ik zal dit nooit, nooit, nooit vergeten!

Last, but certainly not least, I would like to thank my parents. You have been there for me from the moment I was born. I love you dearly and consider myself lucky to be raised up by such parents. Your endless love, support and confidence made it possible to become the person I want to be.

Enschede, 3 August 2012

Frederik Hoolhorst 


\section{Summary}

Within the last decades, product development industry has found itself facing a general increase in product use problems. These problems originate from a mismatch between the actual functionality that the product provides and the afforded productuser interaction versus the user's expectations regarding both aspects. At the same time increased competition made markets shift from a technology push to a market pull situation. This involves that, to be successful on the market, the importance of developing products that meet users' expectations has increased. However, developing products that meet users' expectations remains challenge and asks for an effective and efficient organisation of the product development process.

Past efforts to increase the product development processes' effectiveness and efficiency particularly resulted in a large amount of user-centred product development methods. Unfortunately most of these methods do not offer sufficient support to product development teams since they do not:

- Discuss how use relates to other design aspects or how these methods can be used next to other product development methods

- Explain how they can be adapted to the specific approach needs of the product development project at hand.

Therefore this research, which existed out of four phases, focused on supporting product development teams in specifying a detailed plan of approach for a specific product development project.

The first research phase consisted out of a literature research which provided insight regarding the state of the art in product development methodology in order to gain a better understanding of the problem area. This literature research resulted in a development statement and overview of criteria regarding the support that needed to be developed during this research. According to the development statement and criteria there is a need for a method that supports product development teams in specifying a detailed and univocal user-centred plan of approach for the product development process. The user-centred plan of approach should be based on the design brief and take all aspects within and outside the organisation that influence product's use characteristics (and therefore the execution of the product development process) into account.

The second research phase focused on a verification of the development statement and overview of criteria in product development practice. This research phase existed out of two case studies, which additionally provided insight into the expected 
circumstances under which the method would be used. Based on the results of these case studies the method is expected to be particularly useful within complex product development assignments in which product use is seen as a key aspect to take into account during the product development process. In here complex refers to assignments that are divided into sub-assignments, in which a large number of design aspects need to be considered during the product development process' (usually long) lead time. These assignments are generally executed by large, complex-structured, multidisciplinary teams.

Based on the insights of the literature research and case studies, the product development support was developed in close collaboration with some industrial partners within the third phase of the research. This phase resulted in the method that supports product development teams in explicitly specifying a detailed user-centred plan of approach for product development based on the specific characteristics of the assignment as well as the development context: the UCD Kick-off method. Input for the method is a design brief describing desired basic product functionality, the main characteristics of its user, process and project constraints and the core development team. Output of the method is a detailed user-centred plan of approach describing project stakeholders, product's intended use characteristics, intermediate development results, selected product development methods, development activities, input per development activity and allocation of resources. The method is characterised by the following four iterative steps to define a user-centred plan of approach that specifies these aspects.

\section{Stakeholder mapping}

The lack of a complete overview of project stakeholders is an important aspect that causes use problems. Therefore the method, by means of templates which were developed during this research, supports in making a complete overview and specification of project stakeholders (including the product's users). It furthermore supports in prioritising their interests.

\section{Product characteristics and intermediate results}

A detailed insight into the desired product characteristics as well as the needed intermediate results of the development process is required in order to define a usercentred plan of approach. Furthermore contextual conditions, such as available time and budget, influence the specification of the user-centred product development process. This method focuses on making a detailed overview of product characteristics, scheduled intermediate development results and contextual conditions. 


\section{Development method selection}

Product developers tend to stick to development methods they are familiar with without questioning if these development methods fit the intended development results. The developed method therefore supports in explicitly exploring and selecting appropriate and feasible development methods which lead to the desired development results.

\section{Development method specification}

Only selecting a development method does not guarantee that intended development results will be achieved during the product development process. Further specification of the actual application of the selected development method is needed. Therefore the method supports in describing required development activities, required input per activity, development techniques and allocation of resources.

The fourth phase of the research focused on validation and evaluation of the method in close cooperation with the product development practice. These validation and evaluation existed out of several loops in which (1) the method's viability was checked, (2) criteria regarding the format in which the support is made available were formulated and (3) finally the method was incorporated into its actual format. This phase resulted in a workshop manual, the UCD Kick-off tool, which supports in executing a series of workshops in which product development teams apply the method that was developed. Execution of this series of workshops enables product developers to jointly specify a detailed user-centred plan of approach.

This research therefore resulted in a method that supports product development teams in specifying a detailed plan of approach that, next to user-centred, is specific for their product development assignment, their team as well as the development context. An evaluation study revealed that the UCD Kick-off method and accompanying UCD Kick-off tool are assessed to be applicable in and of added value to product development practice. 


\section{Samenvatting (Summary in Dutch)}

De industrie heeft in de afgelopen decennia een algemene toename van het aantal gebruiksproblemen met producten waargenomen. Deze problemen worden veroorzaakt doordat de daadwerkelijke functionaliteit die het product biedt en de daadwerkelijk geboden product-gebruiker-interactie niet aansluiten bij de verwachtingen die gebruikers ten aanzien van deze beide aspecten hebben. Tegelijkertijd zijn afzetmarken, onder druk van een toegenomen concurrentie, verschoven van een 'technology push' naar een 'market pull' situatie. Dit heeft er toe geleid dat het steeds belangrijker is geworden om producten te ontwikkelen die aan de gebruiksverwachting van de gebruikers voldoen. Echter, het ontwikkelen van dergelijke producten is niet gemakkelijk en vereist een effectieve en efficiënte organisatie van het productontwikkelingproces (proces).

In het verleden zijn vele pogingen ondernomen om het proces effectiever en efficiënter te maken. Deze hebben voornamelijk geresulteerd in een grote hoeveelheid (gebruiker-gerichte) productontwikkelingmethodes (methodes). Helaas bieden de meeste van deze methodes in de ontwerppraktijk onvoldoende ondersteuning. Dit komt doordat ze niet:

- Aangeven hoe het aspect 'productgebruik' is gerelateerd aan andere ontwerpaspecten of hoe de betreffende methode samen met andere methodes toegepast kan worden.

- Uitleggen hoe ze aangepast kunnen worden aan de omstandigheden waarin de specifieke ontwerpopdracht uitgevoerd dient te worden.

Dit onderzoek richtte zich daarom op het ondersteunen van productontwikkelingteams (team) in het specificeren van een gedetailleerd plan van aanpak voor een specifieke ontwerpopdracht.

De eerste fase van het onderzoek bestond uit een literatuuronderzoek. Dit onderzoek leidde tot een beter inzicht in de stand van de wetenschap op het gebied van ontwerpmethodologie en het onderzoeksveld. Het literatuuronderzoek heeft uiteindelijk geresulteerd in een ontwikkelingsvisie en een overzicht met criteria met betrekking tot de ontwerpondersteuning die gedurende dit onderzoek ontwikkeld diende te worden. Volgens deze ontwikkelingsvisie en criteria is er behoefte aan een methode die ontwerpteams ondersteunt in het specificeren van een gedetailleerd en eenduidig gebruiker-gericht plan van aanpak voor het proces. Dit plan van aanpak dient gebaseerd te zijn op de omschrijving van de ontwerpopdracht. Bovendien dient de methode tijdens het specificeren van dit plan van aanpak rekening te houden met 
alle factoren die invloed hebben op het productgebruik (en daardoor ook op de uitvoering van het ontwerpproces). Het gaat hierbij zowel om invloedsfactoren van binnen als ook van buiten de productontwikkelingsorganisatie.

In de tweede onderzoeksfase zijn de ontwikkelingsvisie en de geformuleerde criteria aan de hand van twee casestudy's geëvalueerd in de ontwerppraktijk. Deze casestudy's gaven bovendien inzicht in de verwachting met betrekking tot de omstandigheden waaronder de methode toegepast zou kunnen worden. De methode zal naar verwachting vooral toegepast worden tijdens de uitvoering van complexe ontwerpopdrachten. De uitvoering van deze opdrachten vereist extra aandacht voor de gebruikaspecten van het product. De term 'complex' verwijst hier naar ontwerpopdrachten die bestaan uit verschillende deelopdrachten. Dergelijke ontwerpopdrachten worden doorgaans uitgevoerd door grote, multidisciplinaire ontwerpteams die worden gekenmerkt door een complexe organisatiestructuur. Bovendien dient tijdens het proces, naast aandacht voor het gebruik van het product, ook aandacht besteedt te worden aan een groot aantal andere ontwerpaspecten. De doorlooptijd van deze ontwerpopdrachten is over het algemeen lang.

De methode is ontwikkeld tijdens de derde onderzoeksfase. Dit is gedaan in samenwerking met verschillende industriële partners op basis van de resultaten van het literatuuronderzoek en de beide casestudy's. De ontwikkeling resulteerde in de UCD Kick-off methode: een methode die teams ondersteunt in het specificeren van een gedetailleerd gebruiker-georiënteerd plan van aanpak. Dit plan van aanpak is gebaseerd op de specifieke eigenschappen van de ontwerpopdracht en de productontwikkelingsomgeving (omgeving). De omschrijving van de ontwerp-opdracht dient als uitgangspunt voor het toepassen van de UCD Kick-off methode. Deze beschrijft op zijn minst de vereiste basisfunctionaliteit van het te ontwerpen product, de belangrijkste kenmerken van de gebruiker, en de randvoorwaarden voor het proces. Bovendien beschrijft deze omschrijving het kernteam. Dit kernteam bestaat uit de productontwikkelaars die tijdens het gehele proces betrokken blijven. Het toepassen van de UCD Kick-off methode leidt tot een gedetailleerd gebruiker-georiënteerd plan van aanpak. Deze beschrijft: de stakeholders, de voorgenomen gebruikseigenschappen van het te ontwerpen product, de milestones, methodes die toegepast zullen worden, productontwikkelingsactiviteiten (activiteiten) die uitgevoerd zullen worden en de vereiste input voor iedere activiteit. Bovendien laat deze zien hoe resources over het proces worden gealloceerd. De UCD Kick-off methode is opgebouwd uit de volgende vier iteratieve stappen.

\section{Stakeholder mapping}

Het gebrek aan een compleet overzicht van de stakeholders is een belangrijke oorzaak voor gebruiksproblemen. Daarom biedt de UCD Kick-off methode ondersteuning in 
het beschrijven en het maken van een hiërarchisch overzicht van alle stakeholders (inclusief gebruikers). Dit doet zij aan de hand van enkele templates.

\section{Bepalen van producteigenschappen en tussenliggende ontwerpresultaten}

Een goed inzicht in de vereiste eigenschappen van het te ontwerpen product en de milestones is noodzakelijk om een gebruiker-georiënteerd plan van aanpak te kunnen maken. Daarnaast beïnvloeden factoren uit de omgeving, zoals beschikbare tijd en budget, de loop van het proces. De UCD Kick-off methode ondersteunt dan ook op het maken van een gedetailleerde productspecificatie, specificeren van milestones alsook het specificeren van de voorwaarden die de omgeving aan het proces stelt.

\section{Selecteren van ontwerpmethodes}

Productontwikkelaars hebben de neiging om terug te vallen op voor hen bekende methodes. Dit doen ze zonder zich af te vragen of het toepassen van deze methodes op een adequate manier leidt tot de voorgenomen resultaten. De UCD Kick-off methode ondersteunt in het expliciet zoeken naar en selecteren van methodes die op een adequate manier leiden tot de voorgenomen resultaten.

\section{Specificeren van ontwerpmethodes}

Het enkel selecteren van methodes garandeert niet dat de voorgenomen resultaten ook daadwerkelijk behaald worden tijdens het proces. Hiervoor is het noodzakelijk om de wijze waarop geselecteerde methodes toegepast zullen worden te specificeren. Dit wordt door de UCD Kick-off methode ondersteund. De methode ondersteunt hierin het beschrijven van de vereiste activiteiten die tijdens het ontwerpproces uitgevoerd dienen te worden en de input die nodig is om deze uit te voeren. Daarnaast ondersteunt de UCD Kick-off methode voor iedere activiteit in (1) het specificeren van de ontwerptechnieken die toegepast dienen te worden en (2) het toekennen van de benodigde resources om de activiteit uit te kunnen voeren.

In de vierde onderzoeksfase is de UCD Kick-off methode gevalideerd en geëvalueerd. Dit is gedaan in samenwerking met verschillende industriële partners. De validatie en evaluatie van de UCD kick-off methode richtten zich op (1) het verkrijgen van inzicht in de daadwerkelijke levensvatbaarheid van de UCD Kick-off methode, (2) het formuleren van criteria betreffende het format waarin de UCD Kick-off methode beschikbaar moet worden voor de ontwerppraktijk en (3) het daadwerkelijk toegankelijk maken van de methode voor de ontwerppraktijk. Deze onderzoeksfase resulteerde in een workshophandleiding: de UCD Kick-off tool. Deze workshophandleiding ondersteunt in het uitvoeren van een aantal workshopsessies waarin het team de UCD Kick-off methode toepast. Het uitvoeren van deze workshop sessies maakt het voor ontwerpteams mogelijk om gezamenlijk een gedetailleerd gebruikergeoriënteerd plan van aanpak te specificeren. 
Het onderzoek heeft geresulteerd in een methode en tool die teams ondersteunt in het specificeren van een gedetailleerd, gebruiker-georiënteerd plan van aanpak. Dit plan van aanpak is specifiek geformuleerd voor de ontwerpopdracht die gedaan moet worden, het team dat deze opdracht uitvoert en de ontwerpomgeving waarin de opdracht wordt uitgevoerd. Uit een evaluatiestudie blijkt bovendien dat de UCD Kickoff methode en tool naar verwachting een toegevoegde waarde hebben voor de ontwerpspraktijk. Bovendien blijkt uit deze studie de UCD Kick-off tool naar verwachting toepasbaar is in de ontwerppraktijk. 


\section{Table of Contents}

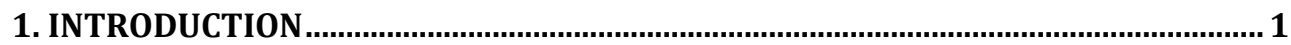

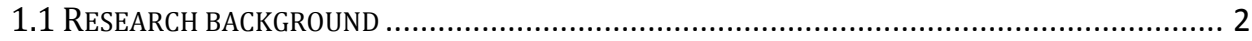

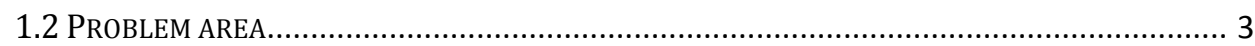

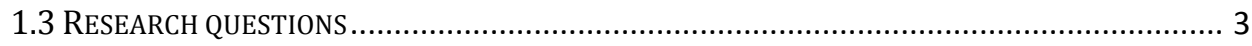

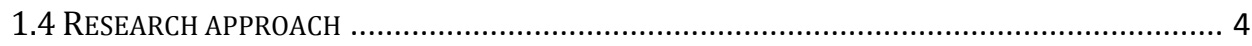

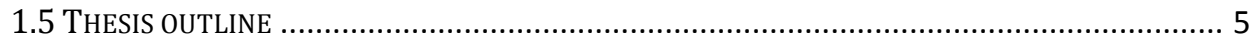

2. USER-CENTRED PRODUCT DEVELOPMENT METHODS......................................... 7

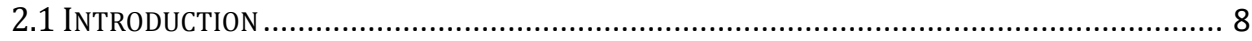

2.2 PRODUCT DEVELOPMENT METHODOLOGIES, METHODS, TECHNIQUES AND TOOLS .................. 9

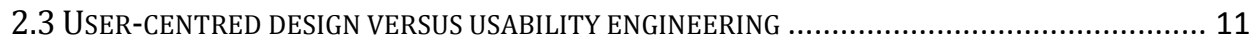

2.4 METHODS' FOCUS WITHIN THE PRODUCT INNOVATION PROCESS ...................................... 12

2.5 USE-CENTRED METHODS FOR THE 'STRICT' PRODUCT DEVELOPMENT PHASE. ...................... 14

2.6 HOW TO SUPPORT THE USER-CENTRED PRODUCT DEVELOPMENT PROCESS? ......................... 15

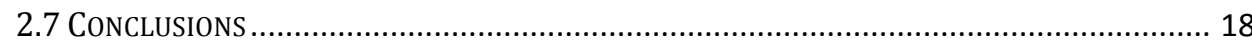

\section{INFLUENCE OF THE PRODUCT DEVELOPMENT ASSIGNMENT, TEAM AND} CONTEXT ON THE USER-CENTRED PRODUCT DEVELOPMENT PROCESS...............21

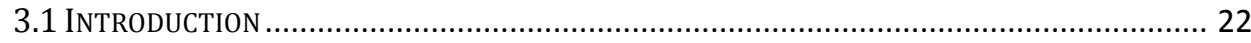

3.2 PRODUCT DEVELOPMENT PROJECT: ITS INFLUENCE ON THE USER-CENTRED PRODUCT

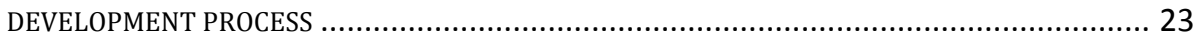

3.3 PRODUCT DEVELOPMENT TEAM: HOW IT APPROACHES PRODUCT DEVELOPMENT PROJECTS. 25

3.4 PRODUCT DEVELOPMENT CONTEXT: ITS INFLUENCE ON THE USER-CENTRED PRODUCT

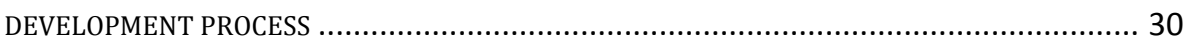

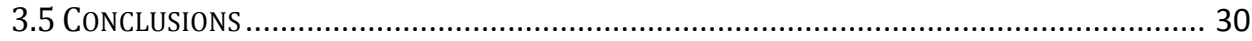

4. INSIGHTS FROM THE PRODUCT DEVELOPMENT PRACTICE ................................33

4.1 INTRODUCTION

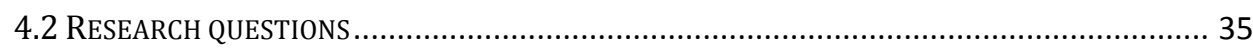

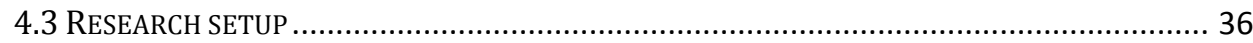

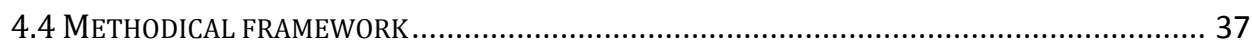

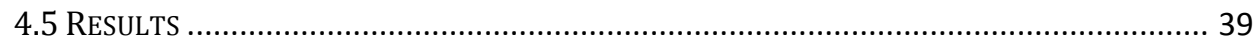

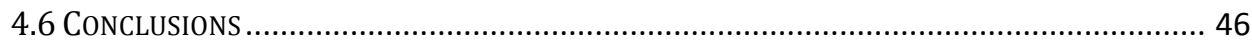

5. AN IMPACT MODEL REGARDING PRODUCT USE................................................49 


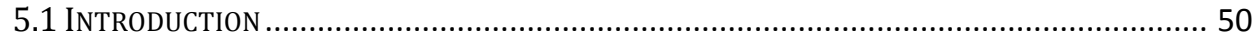

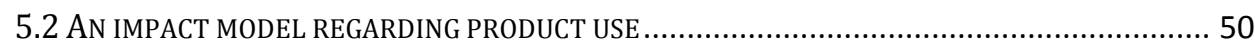

5.3 DETAILING THE IMPACT MODEL REGARDING PRODUCT USE ............................................. 54

6. SPECIFYING STAKEHOLDERS FOR USER-CENTRED PRODUCT DEVELOPMENT

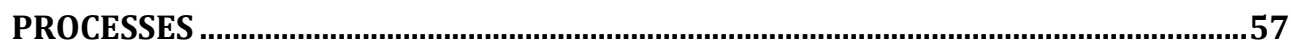

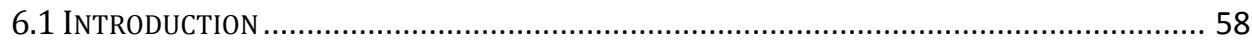

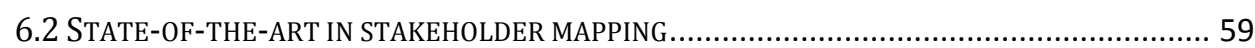

6.3 TEMPLATES FOR SPECIFYING STAKEHOLDERS REGARDING USER-CENTRED PRODUCT

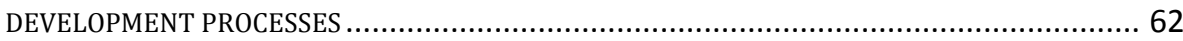

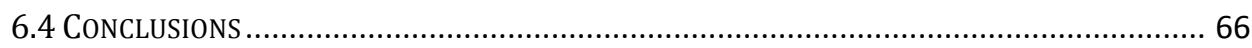

7. A METHOD THAT SUPPORTS IN SPECIFYING A USER-CENTRED PLAN OF

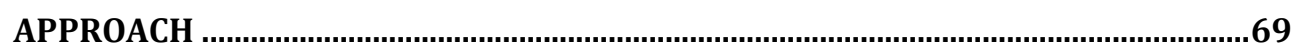

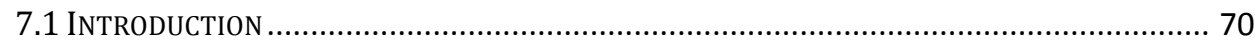

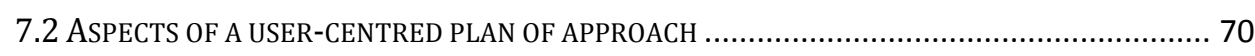

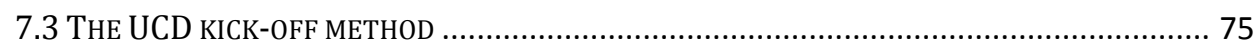

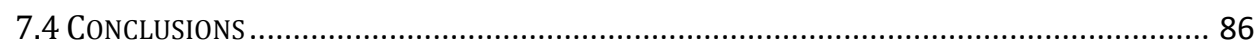

8. VALIDATION AND EVALUATION OF THE UCD KICK-OFF METHOD AND TOOL 89

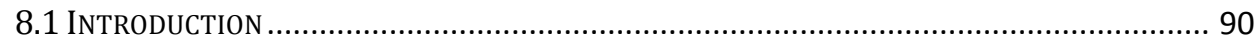

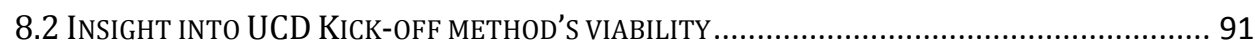

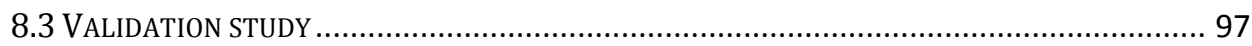

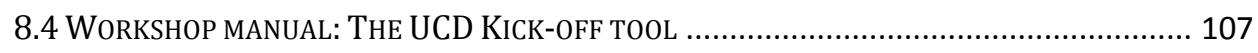

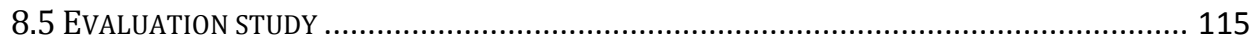

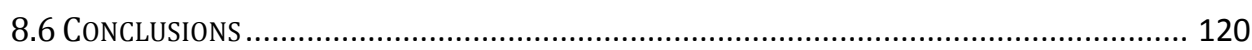

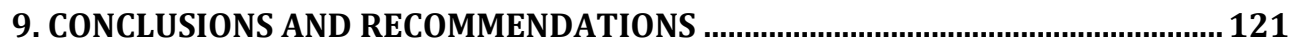

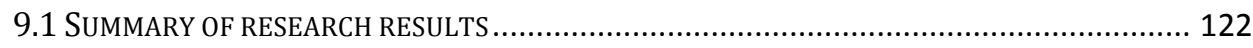

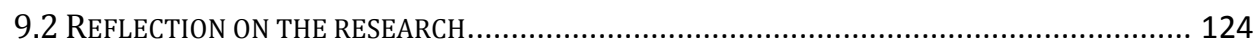

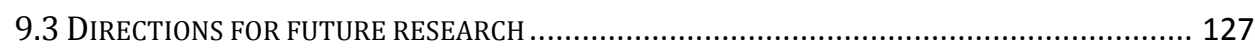

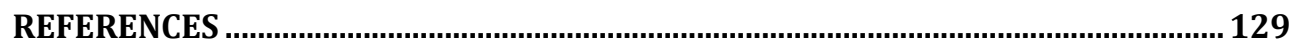




\section{1}

\section{Introduction}

\subsection{Research background}

Within the last decades, product development industry has found itself facing a general increase in product use problems (Den Ouden 2006). These problems originate from a mismatch between the actual functionality that the product provides and the afforded product-user interaction versus the user's expectations regarding both aspects. Even though their products function technically well, manufacturers are due to this mismatch, confronted with growing numbers of dissatisfied customers and customer service costs. At the same time increased competition made markets shift from a technology push to a market pull situation. This involves that, to be successful on the market, the manufacturer's products have to meet their users' expectations. Vanka (2008) states that several trends however make it increasingly difficult for manufacturers to develop products that meet user expectations.

Firstly, users increasingly ask for products that can be used under a wide variety of circumstances in order to achieve a wide variety of goals. In reaction manufacturers develop complex products that are intended to provide a large amount of functions and are part of a larger system that exist out of multiple hardware products, software and/or services. This increased complexity easily results in a deteriorating user product interaction and thereby actual failure of user expectations.

Secondly, developing products that meet user's expectations requires an extended understanding of the actual user, the actual use goals and actual use situations. However, gaining such an understanding is not easy since markets become increasingly more diverse and divergent due to market globalisation. This involves that products have to satisfy a wide scope of users. Moreover, new products let users discover unexpected use possibilities. They therefore influence user's actual use behaviour as well as their expectations regarding these products (Verbeek 2005).

Thirdly, increased competition forces manufacturers to decrease the time-to-market in order to offer state-of-the-art products to their customers. This requires that 
product development teams develop products as efficiently and effectively as possible, leaving limited time and resources to explore the product's use.

These trends make that the importance of the product's use characteristics in product development is more and more recognised. Where in the past product use often was seen as an afterthought, nowadays it is increasingly seen as a key-driver in the product development process. However, developing products that meet the wide variety of use needs of all potential users remains a challenge.

\subsection{Problem area}

This research focuses on supporting product development teams in developing products that meet the wide range of use expectations of its potential users. Past efforts by both design research and product development practice particularly resulted in a large amount of user-centred product development methods. Unfortunately most of these methods do not offer sufficient support to product development teams. There are two main reasons for this.

Firstly, studied user-centred product development methods focus exclusively on product use, e.g. Bailey (1996) or Shneiderman (1992). However, in product development practice, multiple product aspects need to be considered at the same time in order to develop a successful product. Unfortunately most user-centred product development methods do not discuss how product use relates to other product aspects or how they can be used next to other product development methods.

Secondly, studied methods are generic. This means that they are developed in order to be applicable to a wide range of product development assignments. In here they prescribe how a generic product development process (or a part of it) on an abstract level looks like in terms of its main process steps and milestones. However, each product development project has its unique characteristics which influence the execution of the product development process and therefore requires a dedicated approach. Unfortunately, most methods do not explain how they can be adapted to the specific approach need of the product development project.

Therefore this research focuses on supporting product development teams in specifying a detailed plan of approach for a specific product development project. In here the support focuses on product use, but does not exclude other relevant product aspects that need to be considered during the product development process.

\subsection{Research questions}

The main objective of this research was to develop a validated product development support that systematically supports product development teams in specifying a 
detailed user-centred plan of approach. The following main research questions were formulated in order to develop such a support:

1) Which literature based criteria for a systematic support in specifying usercentred plans of approach can be formulated?

2) Does product development practice recognise the need for a systematic support in specifying a user-centred plan of approach?

3) Under which circumstances is the support expected to be used by product development practice?

4) What kind of systematic support in specifying a user-centred plan of approach should be provided?

5) In what format should such a support be made available in order to be directly applicable in product development practice?

\subsection{Research approach}

The research was conducted as part of the IOP-IPCR Design for Usability research project. The above formulated research questions were answered by means of a combination of literature and practice based studies. The research approach existed out of the following four phases.

\section{Phase 1 - Literature research}

The research started with a literature research which provided insight regarding the state of the art in product development methodology in order to gain a better understanding of the problem area. The research particularly provided insight into the necessity for further specification of product development methods towards a detailed user-centred plan of approach as well as the influence of the product development assignment, product development team and product development context on the product development approach. These insights resulted in an identified need, expressed in a development statement and an overview of criteria regarding the to-be-developed support.

\section{Phase 2 - Practice based research}

Verification of the identified need in product development practice is required. After all, the need for a product development support that is identified based on literature research does not necessarily have to be recognised by product development practice. To this aim, the second part of the research existed out of two case studies, which additionally provided insight into the expected circumstances under which the support would be used.

\section{Phase 3 - Design support development}

Based on the insights of the literature research and case studies, the product development support was developed in multiple iterative cycles. Each iteration 
incorporated a reflection step, in which experts out of the product development practice and design research were asked to reflect on the latest development state of the support. Their remarks and recommendations served as input for the next development iteration. This phase resulted in a proposed method that supports in specifying a user-centred plan of approach.

\section{Phase 4 - Validation and evaluation}

Developing a support that is directly applicable in product development practice is one of the main objectives of this research. Validation and evaluation of the support in close cooperation with the product development practice was therefore pursued. It existed out of several loops in which (1) the support's viability was checked, (2) criteria regarding the format in which the support is made available were formulated and (3) finally the method was incorporated into its actual format. This phase resulted in a workshop manual that supports in executing a series of workshops in which product development teams apply the method. Execution of this series of workshops results in a detailed user-centred plan of approach.

\subsection{Thesis outline}

Based on the research approach, this thesis is organised in 9 chapters. Chapter 2 and 3 describe the results of the literature research performed to formulate criteria for a systematic support in specifying user-centred plans of approach. In here Chapter 2 (1) elaborates on the characteristics of existing product development methods, (2) explains why further specification of user-centred plans of approach is needed in order to apply them in product development practice and finally (3) formulates in a development statement the identified need for a support in specifying user-centred plans of approach. This statement among others states that the characteristics of the product development assignment, product development team and product development context influence the execution of the product development process. Chapter 3 provides further insight into how these characteristics influence the execution of this process.

Chapter 4 discusses the results of the two case studies that were carried out in order to verify the identified need for a support in specifying user-centred plans of approach in product development practice. It furthermore provides insight into the circumstances under which such a support is expected to be used.

According to Chapter 2 there are many aspects insight and outside the product development organisation that have an influence on product use characteristics and therefore need to be considered while specifying a user-centred plan of approach. Chapter 5 discusses an impact model regarding product use that provides insight into these aspects and their influence. 
Within a product development project, there are multiple parties that can influence the execution of the product development process, the so called stakeholders. Chapter 6 explains the necessity of mapping stakeholders in the plan of approach specification process and provides templates that support in this activity.

All knowledge and insights that was gained in Chapters 2 to 6 resulted in a method that supports in specifying user-centred plans of approach. Chapter 7 introduces the characteristics of this method and discusses its steps and sup-steps. Together with the product development practice the support's viability was checked and the format in which the method should be made available for product development practice was determined. Chapter 8 provides insight in the method's validation and evaluation process and the resulting workshop format. Finally, Chapter 9 will reflect on the findings of this research and deliver recommendations for future work. 
$x^{1}, \mathrm{~s}, y^{-1}$

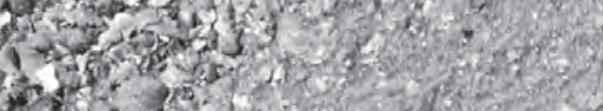

6.1.62 $3=0$

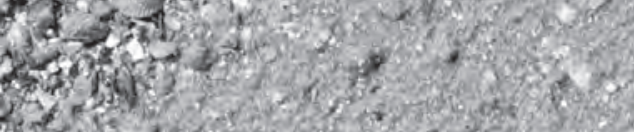

(2)

at:

$30,2,5$

?.1.

(2. 7.32

- $x+2.23$

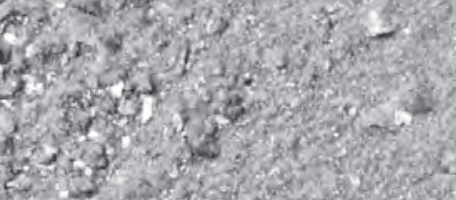

(3).

W. 50 - $=$

ex+

13

and

$f^{3} 3^{2} x^{2}$

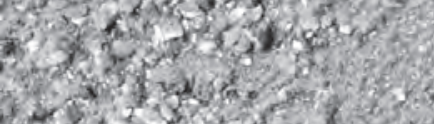
nexes. 6 n.t.t? - 05.709 7.t2n

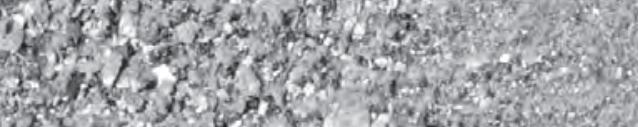
3.t. 72 (1) $2 \times 15=210$
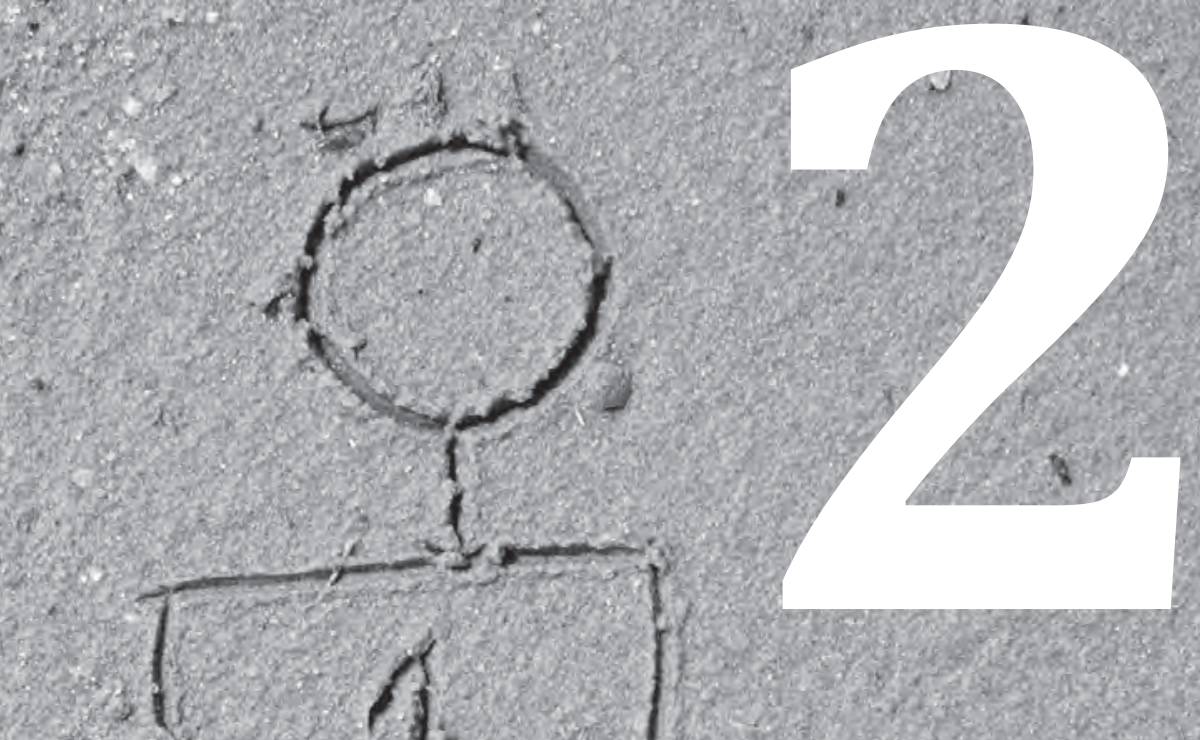

and on 


\section{User-centred Product Development Methods}

\subsection{Introduction}

This research focuses on supporting product development teams in dealing with product use aspects. Past efforts by both design research and product development practice resulted in a wide variety of (product use related) product development methods. Only a fraction of them is actually applied in product development practice. It is therefore important to demonstrate that there is a need for another use related product development method. This chapter clarifies the need for such a method based on design research literature.

As a first step it is important to identify what a method actually is as well as in what a method distinguishes itself from a product development methodology, product development technique and product development tool. Therefore this chapter first discusses the meaning and characteristics of these terms.

Use centred product development as a term comprises the full range of usability engineering to user-centred design. Where user-centred design takes all user's product needs and wishes into account, usability engineering only focuses on improving the usability of user interfaces. When developing a new product development method, it is important to determine whether this method should focus on user-centred design or restrict to usability engineering. Determining this will be done by means of a more elaborate discussion of and reflection on both terms.

Focussing on product use during product development is part of product innovation process. This process exists out of several phases. Most existing use centred product development methods focus on specific phases of this product innovation process. When developing a product use related product development method one should address the following questions: 
1) Which phases of the product innovation process should the development method support?

2) Should the new development method support the entire phase(s) or just a specific (product use related) product development activity?

Sections 2.4 and 2.5 will address these questions.

When developing a product development method, it is not only important to determine which phases of the product innovation process should be supported or whether this method should focus on user-centred design or usability engineering. Determining in what way the use focused product development method should support product development teams in dealing with the aspect product use is just as important. Section2.6 will reflect on this issue. Based on the results of the questions raised above, this chapter ends with a literature based development statement regarding the need for a new use centred product development method.

\subsection{Product development methodologies, methods, techniques and tools}

This research aims at developing a new method that supports product development teams in dealing with product's use aspects. It is necessary to define what a method is in order to do so. Within design research the terms product development methodology, product development method, product development technique and product development tool are often randomly used. Therefore this section discusses the meaning and characteristics of these terms to define their meaning within this research.

\section{Product development methodology}

A product development methodology is a set of methods which are used within a certain discipline (Roozenburg and Eekels 1996). Methodologies describe the philosophy behind a method or set of methods. The philosophy can relate to for example:

- The nature in which a method approaches the design problem: e.g. concurrent engineering, waterfall methodology, reverse engineering or top-down design, bottom-up design or scenario-based design;

- The focus of the product development process: e.g. usability, user-centred design, sustainability, product reliability, manufacturability or maintenance;

- Etc.

Of course it is possible to combine several philosophies into one methodology.

\section{Product development method}

A product development method is a set of any procedures, techniques, aids or tools, based on a methodology, for product development that attempt to bring rational, 
diachronically procedures into product development processes (Hubka 1983; Cross 1994; Evbuomwan and Sivaloganathan 1996; Roozenburg and Eekels 1996). Nemeth (2004) emphases that product development methods intend to lead the product developer into areas of discovery. It is up to the product developer to understand the strengths and limitations of methods and to be opportunistic while using methods in order to discover insights into problems and solutions.

Two different types of methods can be distinguished, i.e. algorithmic methods and heuristic methods. The use of algorithmic methods always results into un-discussable, unambiguous results; heuristic methods at the other hand stimulate in obtaining results. However, in here success is not guaranteed and results often have an ambiguous character. Most product development methods are heuristic methods. Newell (1983) states that product development methods generally have the following typical characteristics:

- The use of a method is noticeable.

- Methods are general. This means that they are applicable to more than one single kind of product development assignment.

- Methods are rational procedures. Following the methodical steps enlarges the chance at success. However, this success is not guaranteed.

- A method describes a specific procedure; many other procedures which lead to success are conceivable.

Since multiple similarities between most diverse disciplines (like mechanical engineering, software engineering, architecture, product design, policy design, etc.) exist, it should be emphasised that that many product development methods are not specifically designed to be used within one product development discipline only (Roozenburg and Eekels 1996). Furthermore they can be applied within multiple stages of the product development process.

\section{Product development technique}

According the Open University (2011), a product development technique is concerned with the manner in which a (part of a) product development method is executed, such as observing users, sketching product solutions or use.

\section{Product development tool}

According the Open University (2011), a tool for product development practice is usually a facility, used in carrying out a product development method, phase, step or sub-step. Tools can appear as digital (e.g. software, video data), physical (e.g. camera, sketching devices), abstract (e.g. diagrams) or a combination of it.

\section{Research focus}

As stated in Chapter 1, this research will focus on the development of a (heuristic) method that supports in dealing with product use aspects during the product 
development process. This method will be placed in a format that is as accessible and applicable as possible in product development practice.

\subsection{User-centred design versus usability engineering}

Use centred product development as a term comprises the full range of user-centred design to usability engineering (Van Kuijk 2010). When identifying a need for a new use centred product development method, it is important to determine whether this method should focus on user-centred design or restrict to usability engineering. Determining this will be done by means of a more elaborate discussion of and reflection on both terms.

Vredenburg et al. (2002) describe user-centred design as an iterative and multidisciplinary product development process in which users are actively involved (with the aim for a clear understanding of user and task requirements). In usercentred design product quality should be verified taking user groups needs, wishes, characteristics and abilities as a starting point (Vredenburg, Isensee et al. 2002). Gould and Lewis (1985) mention that user-centred design (or human-centred design) aims at improving products by means of following a product development method that is based on the following four principles:

1) Know who the user group is;

2) Incorporate current knowledge of users in the early stage of the product development process;

3) Evaluate: confront users repeatedly with early prototypes for evaluation purposes;

4) Iteration: re-design as often as necessary.

These principles have also found their way in ISO 9241: a standard for human-centred design processes for interactive systems (ISO 1998).

Usability engineering can be seen as a part of user-centred design. Where usercentred design methods take into account user group's needs and wishes in a wide sense, usability engineering methods focus on improving the usability of products' user interfaces. In here, just as in user-centred design, usability engineering takes user testing, prototyping and a systematic, iterative way of development as key elements (Nielsen 1992; Butler 1996).

Although usability is an important aspect of product use, only focusing on usability during the product development process does not automatically result in a product that is successful in the market. This also counts for user-centred design. After all, the success of a product depends on many aspects. However, focusing on user-centred product development at least enlarges the opportunity to develop a successful product since it covers users' wide range of (use) needs and expectations, e.g. 
usability. Therefore this research will focus on the development method that focuses on product use, but also allows the inclusion of focus on other product aspects in the plan of approach.

\subsection{Methods' focus within the product innovation process}

As shown in figure 2.1, the product innovation process exists out of several phases, namely (1) strategy formulation, (2) design brief formulation, (3) strict development, (4) introduction and (5) product in use. Although Van Kuijk (2010) argues that product use aspects should be taken into account during the entire product innovation cycle, it does not automatically mean that the method that will be develop needs to support all phases of the product innovation process. Therefore, as a second step in determining the need for a new user-centred product development method, it is important to determine on which phase or phases of the product innovation process such a method should focus. This section discusses a classification of methods (see figure 2.1) which is comparable to Van Kuijk's classification of methods for product development (Van Kuijk 2010) in order to do this. However, where Van Kuijk's classification distinguishes the categories (1) product innovation methods, (2) methods for product development and (3) design methods; this categorisation distinguishes a fourth category, namely DfX methods. Adding this category enables to better address the scope of user-centred product development methods regarding the product innovation process.

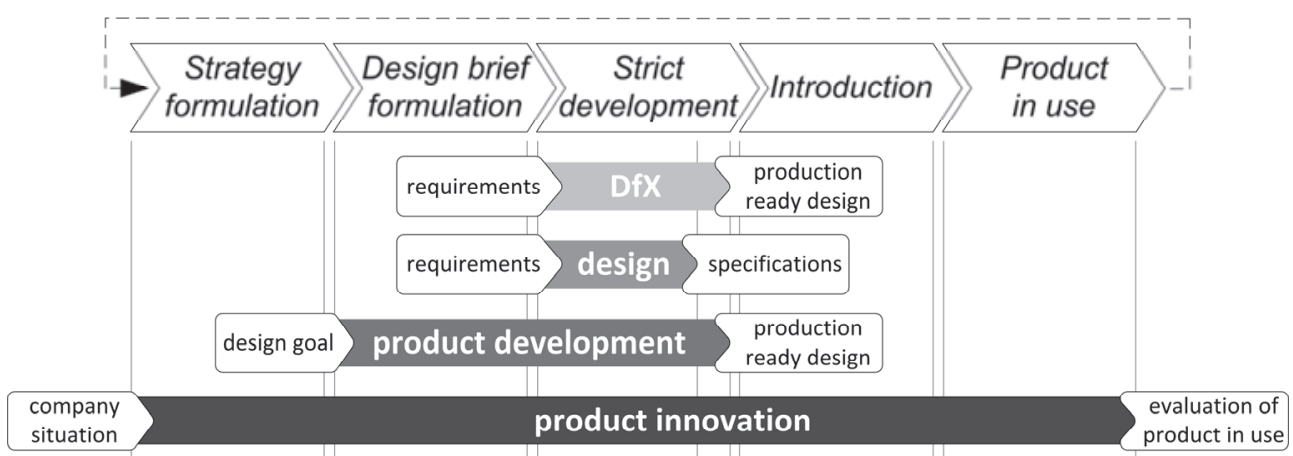

Figure 2.1 - Classification of product development methods regarding the phases of the product innovation process distinguishing (1) product innovation methods, (2) methods for product development, (3) design methods and (4) DfX methods.

\section{Product innovation methods}

Product innovation methods refer to the repeating cycle of conceiving a company strategy, generating product ideas based on that strategy, creating designs, and producing, distributing and selling products, as well as collecting feedback once the 
products are in use, and then (possibly) starting the whole process from the start (Roozenburg and Eekels 1996; Buijs and Valkenburg 2005).

The Delft Innovation Model of Buijs and Valkenburg (2005) is a well-known example of a method which is often used to illustrate the characteristics of product innovation methods and had the advantage of (1) stressing the generation-wise approach to product development that is common in electronic consumer goods industry, (2) explicitly including a phase in which the product is in use, and (3) explicitly including evaluation and iterations, which are important in user-centred design as well as usability engineering (Nielsen 1992; ISO 1999; Vredenburg, Isensee et al. 2002; Van Kuijk 2010).

\section{Methods for product development}

Roozenburg and Eekels (1996) as well as Buijs and Valkenburg (2005) state that it is important to distinguish product development methods and methods for 'strict' product development. In here they agree with Ullrich and Eppinger (1995) and define product development methods as methods which prescribe the activities that start with the perception of a product market opportunity and end in the production and market introduction of a product. Methods for 'strict' product development at the contrary prescribe product innovation activities which start with the product development assignment and end with a production-ready design. Many of them have been developed within the last decades. Well known methods are Pugh (1978), Asimov (1964), French (1971), Van den Kroonenberg (1998), Tjalve (1979), Roth (1982), Koller (1976), VDI 2221 (1985), Pahl \& Beitz (1986), Andreassen \& Hein (1985), Roozenburg \& Eekels (1996), Ullman (1992) and Ullrich \& Eppinger (1995). However, although used terminology and phase arrangement of each individual product development method might differ, most methods for product development prescribe similar product development activities or results to achieve during the product development process (Roozenburg and Eekels 1996; Buijs and Valkenburg 2005).

\section{Design methods}

Figure 2.1 shows that design methods can be seen as a subset of methods for product development. Roozenburg and Eekels (1996) define design methods as methods for 'reasoning from function to form': finding a suitable spatial and physical-chemical arrangement for the product and all of its parts so that the desired function is fulfilled. Within the Delft Innovation Model (Buijs and Valkenburg 2005), product design is done in the phase which is called 'Strict development'. Just as methods for 'strict' product development, design methods take the design brief (which provides an overview of overview of the desired set of main product functions) as a starting point. In several prescriptive steps, this set of desired product properties is translated into a 
spatial form and behaviour which fulfil the certain requirements (Luckman 1984). However, where methods for 'strict' product development also support product's optimisation to production, most design methods stop supporting product development teams after materialisation. In here materialisation refers to the phase that focuses on technical detailing of the initial design proposal's construction towards a functional prototype. At this stage, the product is not ready yet for production and market introduction.

\section{DfX methods}

DfX stands for 'Design for X', where X refers to a specific product aspect, e.g. DfU stands for design for usability. DfX methods can be seen as a subset of methods for product development or design methods. They are based on knowledge and guidelines regarding a specific product aspect and support product developers in addressing that specific product aspect during product development. Just as methods for 'strict' product development, most DfX methods take the design brief as a starting point. However, where most design methods stop after the materialisation phase, most DfX methods take the market introduction as an end point (Van Kuijk 2010). In this thesis DfX refers to DfU, i.e. methods for user-centred product development or usability engineering and thus refers to methods which explicitly support product developers taking the use aspect into account during in product development.

Concluding from this classification, most user-centred product development methods particularly focus on the 'strict development' phase of the product innovation process. After all, a product is developed during these phases and product development teams therefore here have most influence on products' use characteristics (Van Kuijk 2010).

However, the use related product aspects and results which are gained in other phases of the product innovation process have direct or indirect influence on the 'strict development' phase (see figure 2.1). Through here these phases also influence the choice and way of application of user-centred product development methods. Therefore this research will focus at the development of a user-centred product development method that (1) focuses on the strict development phase of the product innovation process and (2) takes the product use related results that have been realised in other phases of the product innovation process into account.

\subsection{Use-centred methods for the 'strict' product development phase}

There is a considerable variety in use centred methods that focus on the strict development phase of the product innovation process (Vredenburg, Mao et al. 2002; Van Kuijk 2010). These methods can be divided into two categories. The first category consists of methods that support the entire 'strict' product development phase, e.g. 
Bailey (1996) and Blanchard \& Fabrycky (1990). The second category consists of methods that support just a specific product development activity, e.g. Kahn \& Prail (1994) and Bias (1991).

As stated in section 1.1, increased competition forces manufacturers to decrease the time-to-market. This requires a user-centred product development process that is executed as effective, efficient and coherent as possible. As a consequence it is important that product development activities are coherently geared to one another. A method could contribute to the coherence between these activities. Therefore this research will focus on the development of a method that supports the entire 'strict' development phase.

Well known methods that support the entire 'strict' user-centred product development process are Bailey (1996), Blanchard \& Fabrycky (1990), Dix et al. (1993), Meister (1987), Shneiderman (1992), ISO (1999), Nielsen (1992) and Kreifeldt (1992). These methods prescribe a set of relatively similar product development activities and/or results divided over relatively similar phases: analysis, concept development, materialisation and optimisation (Wickins, Gordon et al. 1998). The analysis phase focuses on gaining insights into the product's future use(s). These insights result into product development specifications regarding product use. The concept development phase aims at exploring solutions for the product development problem. It results in a base design proposal that meets the formulated product use specifications. The design materialisation phase focuses on technical detailing of the base design proposal's construction. Regarding product use, diverse use tests give better insight into the product's use performance. Finally the design is made ready for production during the optimisation phase. Within this phase it is important to check if the production model preserves the intended degree of use performance as the final prototype. Whether these methods adequately support the user-centred product development process will be discussed in the next section.

\subsection{How to support the user-centred product development process?}

Sections 2.3 to 2.5 discussed which aspects of product use a new product development method should focus on and which part of the product innovation process such a method should support. In order to identify the need for a new user-centred product development method, it is important to additionally determine how such a method should provide support to product development teams. In here it is important to be aware of the fact that the discussed user-centred product development methods are developed to be generic. This involves that they are applicable to a wide variety of product development projects which are executed by a wide variety of product 
developers in a varying design context (Dorst 2008). This generic character of current user-centred product development methods has two main consequences.

Firstly, the discussed user-centred product development methods prescribe how an efficient product development process in general should look like. In here the methods only give guidance with respect to the main process steps and milestones (Dorst 2008; Van Kuijk 2010). It is up to the product development team to adapt the method to the specific project and to determine which product development activities exactly need to be performed during the product development process in order to achieve these milestones. Determination of these product development activities is currently not supported by user-centred product development methods.

Secondly, although not surprising, the user-centred product development methods only focus on product use aspects. However, in product development practice, product development teams often need to consider multiple product development aspects at the same time. They often apply additional product development methods next to the user-centred product development method to consider these other product development aspects. Nevertheless, some of these product development aspects might have a relation with product use aspects or influence them. Product development teams therefore have to be aware of these relations and consider how to apply the chosen user-centred product development method next to other product development methods. Relating and combing methods regarding multiple product development aspects is currently not supported by most user-centred product development methods.

Based on both discussed consequences it is legitimate to conclude that these usercentred product development methods describe how a generic user-centred product development process (or a part of it) on an abstract level looks like in terms of its main process steps and milestones. The project development team needs to adapt the user-centred product development methods in such a way that all their steps and milestones are specific for the product development project at hand before it is possible to apply them during the product development process. This involves that the product development team needs to specify which product development activities exactly need to be performed during the product development process as well as how these activities need to be performed (Christiaans 1992; Dorst 2008; Hoolhorst and Voort 2009). Adapting and specifying these user-centred product development methods will result in a user-centred plan of approach. Such a plan of approach provides a complete and detailed insight in how a product development project will be exactly will be executed. A plan of approach provides an overview of (PMI 2000; Kerzner 2001): 
- The main characteristics of the product that needs to be developed (in terms of a product vision and product conditions);

- Milestones that need to be achieved during the product development process;

- All product development activities.

It furthermore specifies per product development activity:

- When it needs to be executed;

- Which techniques and tools should be used for it execution;

- Resources that are available for execution in terms of budget, equipment and facilities;

- Who will execute the product development activity as well as their role.

Defining a plan of approach that addresses these aspects has two main advantages. Firstly it provides a complete overview of the intended user-centred product development process and through this overview enlarges the change to develop a product that meets the intended use characteristics (Shewhart 1939; Deming 1986; Kerzner 2001; Van Kuijk 2010). Secondly it provides insight into a project's organisational feasibility before the product development process actually is started (Kerzner 2001). In here the term organisational feasibility refers to the question: To what extent are the available resources (time, budget, equipment, facilities, people) expected to be sufficient to develop a product that meets the intended use characteristics? These are seen as the main advantages of a plan of approach with respect to a user-centred product development method. Specifying a detailed plan of approach is however not easy, since it faces two challenges.

The first challenge is to make the user-centred plan of approach complete and univocally understandable for the entire product development team. Particular in cases were a large, multidisciplinary product development team collaborates in a project, product development team members currently often have an un-univocal or incomplete overview of the user-centred plan of approach (Van Kuijk 2010). The lack of a detailed and accessible overview of the approach will, based on the productprocess relation (Cross, Christiaans et al. 1996; Cross 2006), most certainly not lead to a product design that meets the intended use characteristics (Van Kuijk 2010; Van Eijk, Van Kuijk et al. 2012).

The second challenge is to take the specific characteristics of the product development assignment, team and context into account when specifying a user-centred plan of approach, since these aspects sketch boundary conditions for the execution of product development process (Dorst, 2008). In here the term product development context refers to the environment in which the product development team executes the product development project. It is not always easy to gain insight into the characteristics of these aspects since it is not always clear which characteristics are 
relevant to take into account. However, exclusion of the characteristics of these aspects might result in an inefficient, ineffective or incoherent plan of approach.

Specifying a plan of approach is an important and challenging activity which belongs to project management. Most existing project management methodologies, such as PRINCE 2 (Hedeman and Vis van Heemst 2005) or PMBoK (PMI 2004) stress this. Furthermore most of them discuss items to define in a plan of approach and provide principles or aspects to take into account when defining such a plan of approach. However, none of them provides methods or tools which support in systematically defining such a plan of approach. Practice based research shows that until now usercentred plans of approach are defined based on experience (Van Kuijk, 2010). There are no methods to support product development teams in defining a univocal, effective and complete plan of approach. This research therefore focuses at the development of a method that supports product development teams in specifying a detailed and univocal user-centred plan of approach. In here the method takes the boundary conditions that are sketched by the product development project as well as specific needs and characteristics of the product development team and context into account.

\subsection{Conclusions}

This chapter focused on identifying the need for a new product use centred product development method based on design research literature. The need that was identified based on this research is represented in the following development vision.

\section{Development statement:}

Develop a method that supports product development teams in specifying a detailed and univocal user-centred plan of approach. Such a plan of approach describes how to approach the project during the entire strict development phase of the product innovation process. In here the method focuses on addressing product use, but does not automatically exclude addressing other product aspects (which might have influence on product use).

Defining a user-centred plan of approach will be based on a design brief. This design brief at least describes the product's basic functionality and the main characteristics of its users. Additionally product use related characteristics of the following aspects are acknowledged to have influence on the user-centred plan of approach:

- The product development assignment as well as the specific characteristics and needs of the product development team and product development context; 
- The other phases of the product innovation process: 'strategy formulation', 'design brief formulation', 'introduction' and 'product in use'.

The method should therefore support product developers in taking these aspects into account while specifying a dedicated user-centred plan of approach for a specific product development project.

In order to support taking the product use related characteristics of above mentioned aspects into account, it should be clear which aspects of the product development project, product development team and product development context have influence on the user-centred plan of approach. Therefore Chapter 3 elaborates on these aspects and formulates additional criteria for the method. Furthermore aspects of the phases 'strategy formulation', 'design brief formulation', 'introduction' and 'product in use' of the product innovation process that have influence on product use should be identified. This is done in Chapter 5 by means of introducing an impact model that discusses aspects which need to be considered while organising the user-centred company organisation at large and specifying user-centred product development processes in specific.

Additionally it is important to emphasise that above formulated development vision is based on design research literature. However, the new product use focused product development method should fit the needs of product development practice in order to be effective. Verification of the identified need in product development practice is therefore required. Chapter 4 discusses a research that was conducted in product development practice to reveal product developers' opinion regarding the expected usefulness and possible added value of a tool that meets the formulated development vision. 


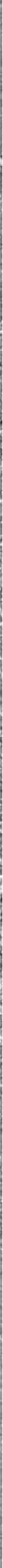




\section{3}

\section{Influence of the Product Development Assignment, Team and Context on the User-centred Product Development Process}

\subsection{Introduction}

A development statement regarding a new user-centred product development method was formulated in Chapter 2 based on the results of an extensive literature research. According to this statement, such a method should support product development teams in specifying a detailed and univocal user-centred plan of approach for their projects. Such a user-centred plan of approach should among other things be based on the specific characteristics of the product development assignment as well as the specific characteristics and needs of the product development team and product development context. However, in order to take these characteristics and needs into account, aspects of the product development assignment, product development team and product development context that could have influence on the user-centred product development process and thus also on the user-centred plan of approach should be identified. This chapter in addition discusses lessons that can be learnt from this identification for the development of a method that supports in specifying a usercentred plan of approach.

Section 3.2 goes further into the characteristics of product development assignments. It starts discussing the advantages and limitations of product portfolios, platforms and generations on the product development freedom during product development processes. The section furthermore states that product development assignments are wicked and ill-defined and addresses the consequences of these characteristics for the product development processes. 
Section 3.3 focuses on product development teams. It starts discussing the multidisciplinary character of nowadays product development teams. It continues by discussing the nature in which product developers and product development teams approach product development problems. Classifications of possible product development approaches and the characteristics of the user-centred design cycle are part of this discussion. The section furthermore addresses the consequences of product developers' experience on the user-centred product development process.

Section 3.4 goes further into the influence of the product development context on the user-centred product development process. It appoints entities of which a product development exists and argues that product developers should have insight into these entities when specifying a user-centred plan of approach.

Finally section 3.5 draws conclusions regarding the possible influence of product development assignment, the product development team and product development context on the user-centred product development process and formulates criteria for a method that supports in specifying user-centred plan of approach and acknowledges these influences.

\subsection{Product development project: Its influence on the user- centred product development process}

\section{Portfolios, platform and generations}

Although companies strive to reduce complexity of developing and managing their products, they want to offer buyers an optimal variety of products (Jiao, Simpson et al. 2007). Companies therefore resort to develop products based on platforms: Components and sub-systems shared across a family of products (Sawhney 1998; Sundgren 1999; Krishnan and Gupta 2001) or multiple product generations (Buxton 2007). Platforms are applied for four reasons and offer several advantages. Firstly companies want to spread risks. Most companies do not rely on one single product for their survival and offer a variety of products to ensure that buyers find the product they like. Secondly an extensive product portfolio has a positive effect on the perceived reliability of a brand, product quality or market share (Person, Schoormans et al. 2008). Thirdly, expanding product lines gives the opportunity to explore market opportunities. Fourthly, product platforms reduce development risk, system complexity and an enhanced flexibility and responsiveness to market developments and manufacturing processes (Sawhney 1998). This involves that over product generations, it enables manufacturers both (1) improving product's and product platform's quality as well as (2) keeping product and product platforms up-to-date with the latest market and product trends. Besides the advantages that the use of (a combination of) product platforms brings along, there is also the following possible 
disadvantage. Using product platforms might restrict the solution space for a product that meets the intended use specification (Van Kuijk 2010). Product development teams need to be aware of these restricted solution space as early as possible in order to be able to deal with it during the user-centred product development process. Therefore it is important that a method that supports the product development team in specifying a user-centred plan of approach helps to gain insight into (1) how chosen (combination of) product platforms restrict the solution space regarding the intended product use as well as (2) how to deal with this restricted solution space during the user-centred product development process e.g. in terms of collaborations between product development team members, decision taking or the sequence of (usercentred) product development activities.

\section{Wicked product development assignment}

Product development project's assignments are wicked, because assignments interrelate with the product development solution (Rittel and Webber 1973). It is not possible to think about the product development assignment without referring to the product development solution and conversely. This means that the assignment evolves and becomes more specified as the product development solution arises during the product development process. Because of this, it is hard to predict when a product development assignment has been completed at the start of a product development project. However, to reduce product development project's lead time it is important to get grip on its user-centred plan of approach as early as possible (Kerzner 2001). In addition the co-evolution of the assignment interrelates with the product development process (Cross, Christiaans et al. 1996; Cross 2006). To be able to define an appropriate user-centred plan of approach it is therefore important to have a precise vision regarding the solution direction (and therefore also of the assignment) as early as possible in the project. A method that supports product development teams in specifying a user-centred plan of approach should therefore support in specifying relevant design problem's aspects as well as generating visions regarding the solution at the same time.

\section{Ill defined product development assignments}

At the start product development, projects, and therefore also design briefs, are illdefined (Rittel and Webber 1973; Simon 1973; MacCormac 1976; Restrepo and Christiaans 2003; Dorst 2006). They consist of ambiguous and incomplete descriptions. At this stage often little relevant information about the stakeholders and their interests in the product development project is known. The design brief also give little insight into stakeholders' ideas regarding the solution direction for the project. Furthermore information regarding the boundary conditions on the product development approach needs to become clear. Regarding product use specifically, at this stage the product development project often poorly specifies (1) who will use the 
product, (2) why they will use the product, (3) under which conditions they will use the product and (4) what impact the product is expected to have on the user and environment in which it is used. A method that supports product development teams in specifying a user-centred plan of approach should therefore first aim at clarifying these product development project's aspects during the product development process.

\subsection{Product development team: How it approaches product development projects}

\section{Multidisciplinary product development teams}

A product development team exists out of a collection of individuals developing a product (Ulrich and Eppinger 2004). A lot of products (e.g. consumer electronics) are, due to their complexity, developed by a large multidisciplinary (global) product development team (Hoolhorst and Voort 2009; Van Kuijk 2010). To illustrate this: even to address the use aspect, product development already requires a wide variety of disciplines (ISO 1999; Van Kuijk 2010). Based on the roles subscribed by the ISO standard for large systems (ISO 1999), Van Kuijk (2010) mentions that the following six roles should be represented within a user-centred product development process (1) product manager, (2) marketing specialist, (3) industrial designer, (4) interaction designer, (5) usability specialist and (6) development engineer (see table 3.1).

\begin{tabular}{|c|c|c|}
\hline Role & Role description & Also known as (aliases) \\
\hline Product manager & $\begin{array}{l}\text { Coordinates product } \\
\text { development, sets the priorities } \\
\text { for the market }\end{array}$ & $\begin{array}{l}\text { Project manager, customer- } \\
\text { marketing manager }\end{array}$ \\
\hline Marketing specialist & $\begin{array}{l}\text { Collects market information, } \\
\text { defines marketing strategies }\end{array}$ & $\begin{array}{l}\text { Marketing manager, market } \\
\text { intelligence manager, marketer, } \\
\text { sales manager }\end{array}$ \\
\hline Industrial designer & $\begin{array}{l}\text { Develop the physical appearance } \\
\text { of the product }\end{array}$ & Product designer \\
\hline Interaction designer & $\begin{array}{l}\text { Develop the user interface of the } \\
\text { product }\end{array}$ & $\begin{array}{l}\text { User interface designer, user } \\
\text { experience designer, visual } \\
\text { designer }\end{array}$ \\
\hline Usability specialist & $\begin{array}{l}\text { Collects user information, } \\
\text { evaluates the usability of } \\
\text { products }\end{array}$ & $\begin{array}{l}\text { Usability tester, user } \\
\text { experience specialist }\end{array}$ \\
\hline Development engineer & $\begin{array}{l}\text { Responsible for technological and } \\
\text { production aspects }\end{array}$ & $\begin{array}{l}\text { Mechanical engineer, software } \\
\text { engineer, product engineer, } \\
\text { electronics engineer }\end{array}$ \\
\hline
\end{tabular}

Table 3.1 - Development roles relevant for studying usability in product development (Van Kuijk 2010).

Furthermore product development teams commonly exist out of a core team which includes representatives of all departments and disciplines involved and an extended 
team (ISO 1999; Van Kuijk 2010). Where the core team exists out of a fixed group of product developers who are involved during the project's entire lead time, the extended team only gets involved during specific parts of the product development process. The extended team's size and composition varies based on the required skills regarding a specific product development process activity.

Managing these large, multidisciplinary product development teams is a challenging task since each team member has its own vision on the product development assignment, the role and meaning of product use within this product development project, the solution direction and the product development approach. Within managing large multidisciplinary product development teams it is therefore important to:

- Manage and tune product development activities among product development team members;

- Make sure that product development teams have a univocal, complete and detailed view on the product development assignment, the role of product use, the solution direction and the overview of the approach.

A method that supports in specifying a user-centred plan of approach should therefore support in managing and tuning product development activities among the team members. Furthermore the method should support product development teams in having a univocal, complete and detailed view on the product development project, the role of product use, the solution direction and the overview of the approach.

\section{Solution versus problem focused development approach}

Product developers adopt different product development approaches depending on their rate of affinity and knowledge regarding the product development assignment. Cross (2006) subdivides product development approaches into solution focused product development approaches and problem focused product development approaches. Analysis of product development practice shows that product developers generally adopt a solution focused product development approach (Cross 2006). Solution focused product development approaches exist out of many iterative steps, also known as '(user-centred) basic design cycles' (Roozenburg and Eekels 1996). While using a solution focused product development approach, product developers continuously jump between the temporary solution and the (changing) product development assignment until they achieve a satisfying design solution and a clear view on the product development assignment. However, particularly in cases in which they have little experience or have little pre-knowledge of a certain topic, product developers tend to adopt a problem focused product development approach (Lloyd and Scott 1994; Restrepo and Christiaans 2003; Restrepo 2004; Cross 2006). Here they explore all facets of the product development assignment in advance and start creating solutions as soon as they have completed the survey of the product 
development assignment. Nevertheless in product development practice, product developers tend to adopt a product development approach that is neither purely solution focused nor purely problem focused since they are usually not fully inexperienced. In general, to make the product development process as efficient and effective as possible, product developers will strive for a solution focused product development approach. Product developers will only first explore aspects of the product development assignment that are expected to be relevant and in which they have insufficient insight. A supporting method that focuses on specifying user-centred plans of approach should therefore support in gaining insight into which aspects need to be explored and when they need to be explored during the user-centred product development process.

\section{User-centred design cycle}

In every phase of the product development process alternatives are explored and choices have to be made. In here, product developers follow a pattern of the following stages of thought throughout the product innovation process' phases: divergence, transformation and convergence (Finger and Dixon 1989; Evbuomwan and Sivaloganathan 1996). The product development process as a whole can be represented as a sequence of divergence, transformation and convergent sub-phases (Roozenburg and Eekels 1996) or as going through a series of problem solving cycles (Cross and Roozenburg 1993). Roozenburg and Eekels (1996) have tried to represent this kind of problem solving by means of the basic design cycle. Van Kuijk (2010) specified this basic design cycle towards a cycle that focuses on dealing with usercentred product development assignment: the user-centred design cycle (see figure 3.1).

The user-centred design cycle does not represent the process of developing a product or a product development method. It is a representation of problem solving that can be applied during all phases of product innovation, and therefore can be seen as a universal building block for entire the user-centred product development process.

The user-centred design cycle integrates the basic design cycle (Roozenburg and Eekels 1996) with user involvement (Grudin 1991; Lauesen 1997; Vredenburg, Isensee et al. 2002). This means that users give input in all phases of the basic design cycle. Van Kuijk mentions that active user involvement is not possible in some cases. However, in those cases product developers still have to anticipate product use; for instance by means of methods which anticipate use, but do not include users as 'user representation'. An example of such method is expert evaluation. 


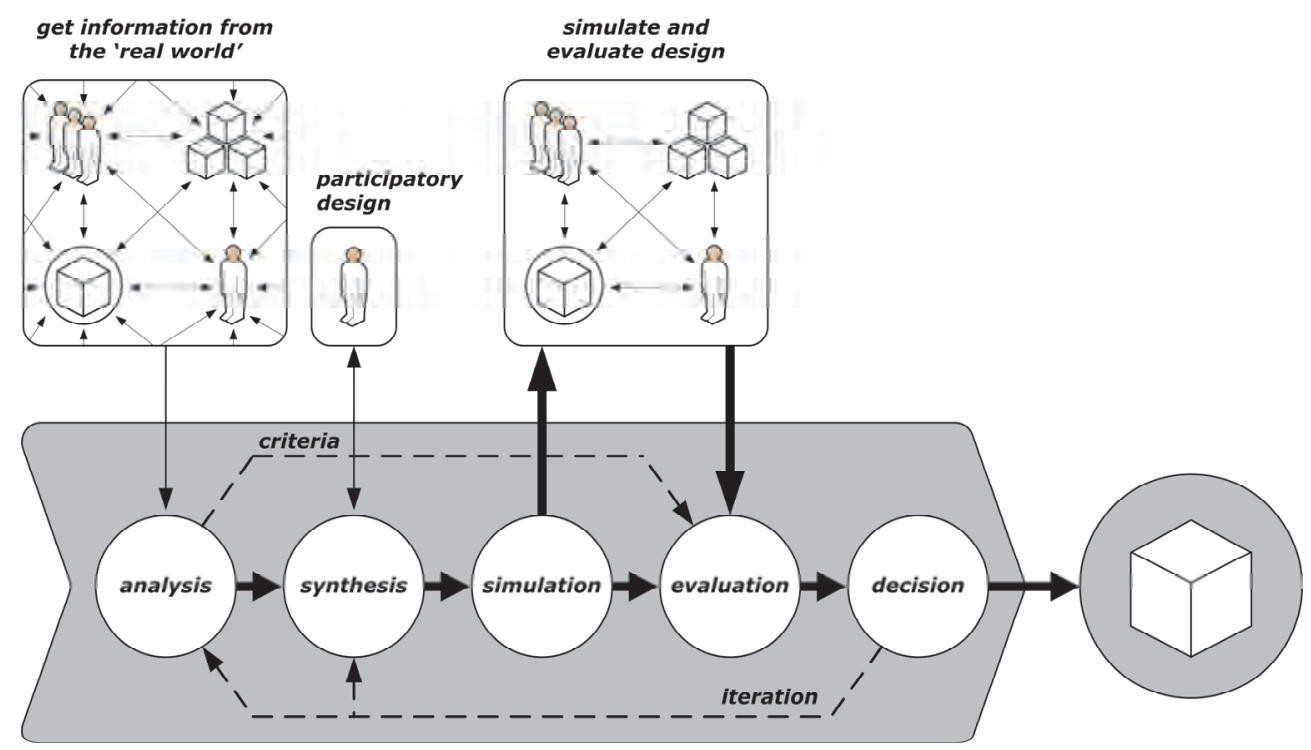

Figure 3.1 - The user-centred design cycle: A combination of the Basic design cycle (Roozenburg and Eekels 1996) and the framework for human-product interaction.

Combining the basic design cycle with user involvement and user representation results in a problem solving cycle that starts with gathering information from the 'real world' and defining a frame of reference for the future solution with respect to product use. This involves that product developers investigate user groups (e.g. needs, behaviour or anthropometrics), the environments in which the product will be used (e.g. at home, in the car or in hospital) and the circumstances under which the product will be used by these user groups in these use environments. It continues with participation of users in synthesising solutions. Most user-centred product development methods focus on user involvement in analysis and evaluation (Gulliksen, Boivie et al. 2006). However, in product development practice, product developers do apply (user-centred) techniques for actual creation of the product with respect to its behaviour. These techniques can support to reflect on solutions and therefore offers the possibility for iteratively exploring new ideas (e.g. use scenarios (Carroll 2000) or task analysis (Preece, Sharp et al. 2007)). Other support which facilitates generating design solutions can be found in existing use knowledge regarding product use (e.g. guidelines, heuristics or personas) (Van Kuijk 2010). Simulation of future use is performed by means of simulating the future product (by means of a mock-up or prototype), users, physical and non-physical use environment and use situations. The simulation of use is evaluated afterwards and a decision is made whether the result is acceptable and meets the frame of reference. It is important to mention that the user-centred design cycle's simulation and evaluation 
phase cannot be seen completely separated since the way of simulating and evaluating design solutions influence each other.

Due to the universal character of the user-centred design cycle, a method that focuses on specifying user-centred plans of approach should support product development teams in planning a sequence of user-centred design cycles throughout the usercentred product development process. Furthermore it should support in specifying product development activities for each phase of the user-centred design cycle for all phases of the product development process.

\section{Experience in user-centred product development}

Dorst (2008) discusses that product development experience influences the approach of product development assignments in two ways. Firstly, the rate of product development experience influences the way in which product developers apply (usercentred product development) methods. Where inexperienced product developers tend to hold on to learned methods and follow the prescribed phases and steps literally; experienced product developers tend to adjust methods, based on earlier experiences, to the specific characteristics of their task and/or, the context in which the task needs to be performed. This involves that product developers, depending on their experience, have different needs regarding product development methods. Although for this research the product development team's task, i.e. specifying a usercentred plan of approach - hardly differ, the context in which such a user-centred plan of approach needs to be specified might vary. Therefore, depending on product developer's rate of experience, a method that supports in specifying a user-centred plan of approach should provide product developers both the opportunity for following steps of the method literally as well as the opportunity for adjusting particular steps to the context in which the plan of approach needs to be specified.

Secondly, product developers define the scope of the product development assignment differently based on their experience. Where inexperienced product developers tend to narrow down the product development assignment's scope, experienced product developers tend to extend the domain in which they work and search for new product development approaches. It is often more effective to extend the domain of the assignment since product developers often learn from other (product development) disciplines. Inexperienced product developers might not be aware of the possibilities for extending the product development assignment's domain or they face problems in dealing with extended product development assignment domains. Therefore a method that supports product development teams in specifying a user-centred plan of should support product developers in exploring the possibilities for extending the product development assignment's scope. 


\subsection{Product development context: Its influence on the user- centred product development process}

The product development context is the environment in which product development teams execute product development projects. This environment exists out of physical and non-physical aspects. Physical aspects refer to all the facilities that product development teams have at their disposal during a product development project, e.g. use test laboratories, workshops, software or tools. Non-physical aspects refer to the regulations and protocols with respect to a company's policy, strategy and organisation that product development teams need to take into account during a product development project, e.g. regarding communication, decision taking, information management or design review (Peters, Rooney et al. 1999).

Since the amount of facilities that can be used is limited and regulations and protocols need to be taken into account, product development teams have restrictions in the way they execute a user-centred product development process. The product development context therefore sketches boundary conditions regarding such a usercentred product development process and product development teams need to take these into account when specifying a user-centred plan of approach (Van Kuijk 2010).

A method that focuses on specifying a user-centred plan of approach should therefore support product development teams in gaining insight into characteristics of the product development context in which they need to execute the product development project. The method should furthermore support product development teams in gaining insight into the boundary conditions which this product development context raises regarding their user-centred product development process. Finally the method should support product development teams in taking these boundary conditions into account while defining a user-centred plan of approach.

\subsection{Conclusions}

Several aspects of the product development assignment, product development team and product development context have influence on how the user-centred product development process can be executed. These aspects need to be taken into account when specifying a user-centred plan of approach for a product development project. This chapter therefore addressed which aspects of the assignment, product development team and product development context are relevant to take into account when specifying a user-centred plan of approach as well as how these aspects can influence the product development process. It furthermore discussed lessons that can be learnt from this discussion regarding the development of a method that supports in specifying a user-centred plan of approach. These lessons can be translated into the following criteria regarding such a method. 
A method that focuses on specifying user-centred plans of approach should support product development teams in:

- Obtaining a univocal, complete and detailed view on the product development project, the role of product use, the solution direction and the overview of the approach.

- Specifying relevant aspects of the product development problem that need to be taken into account during the user-centred product development process

- Generating a vision regarding the design solution in co-evolution with the specification of the product development problem and vice versa.

- Gaining insight in how chosen (combination of) product platforms restrict the solution space regarding the intended product use as well as

- How to deal with this restricted solution space during the user-centred product development process.

- Exploring the possibilities for extending the product development assignment's scope.

- Determining (1) who will use the product, (2) why they will use the product, (3) under which conditions they will use the product and (4) what impact the product is expected to have on the user and environment in which it is used.

- Gaining insight into the characteristics of the product development context in which the product developers need to execute the product development project as well as

- The boundary conditions which this product development context sketches regarding their user-centred product development process.

- Taking these boundary conditions of the product development context into account while defining a user-centred plan of approach.

- Planning a sequence of user-centred design cycles throughout the user-centred product development process.

- Specifying product development activities for each phase of the user-centred design cycle.

- Managing and tuning user-centred product development activities among the team members.

- In both following the steps of the method literally as well as adjusting particular steps to the context in which the plan of approach needs to be specified.

The need for a method that focuses on specifying a user-centred plan of approach as well as above discussed additional criteria regarding such a method are formulated based on the results of literature research. However, the new user-centred product development method should fit the needs of product development practice in order to be effective. Verification is therefore required. The next chapter will therefore 
elaborate on the performed verification of the identified need in product development practice. 


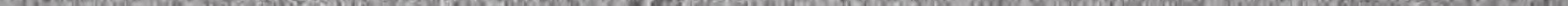




\section{4}

\section{Insights from the Product Development Practice}

\subsection{Introduction}

The previous two chapters identified the need for a method that supports product development teams in specifying a user-centred plan of approach. This need was determined based on the results of literature research. However, since such a method should fit the needs of product development practice in order to be effective, verification of the identified need in product development practice is required. This chapter discusses a research that (1) addressed this verification of the identified need and (2) explored the circumstances under which the method is expected to be used.

In order to achieve these goals, it was important to gain insight into the following topics:

- Product developers' opinion regarding the expected usefulness and possible added value of a method that meets the identified need;

- Characteristics of user-centred product development assignments as they exist in product development practice;

- Composition and organisation of user-centred product development teams as they exist in product development practice.

The research consisted of two case studies that were performed in collaboration with two industrial partners in order to gain insight into above enounced topics. The first industrial partner was a multinational which develops, manufactures and sells printer copier systems for the professional market. The second industrial partner was a midsize design agency whose employees have experience in the development of userfocussed, mainly healthcare, products. Due to the divergence in product development expertise of both industrial partners, the composition of their product development team as well as the characteristics of the context in which both partners develop products, it was possible to gain a broader view and insight regarding above enounced topics. 
The case studies existed out of two main activities. The first main activity focused on the verification of the identified need for a method that supports in specifying usercentred plans of approach (see section 2.7). In here, by means of a homework assignment and a group discussion, product developers were asked to evaluate a conceptual framework which reflects this identified need. The evaluation provided the opportunity to gain insight into product developers' opinion regarding the expected usefulness and possible added value of such a method.

The second activity within the case studies focused on a gaining insight into the circumstances under which the method is expected to be used. For this purpose the characteristics of two product development assignments that was carried out recently by the industrial partners were analysed, i.e. respectively the development of a user interface for a printer and the development of a healthcare hoist. Here the case studies provided the opportunity to make retrospective reconstructions and evaluations of the user-centred product development processes of both assignments. In particular, interviews and evaluated reconstructions gave insight into the specific characteristics of the product development assignment and the composition of the product development teams.

The next sections discuss the case studies in more detail. Section 4.2 gives an overview of research questions that needed to be answered by means of the case studies. Section 4.3 elaborated on the goals and the setup of the case studies. Section 4.4 discusses a framework for a method that supports in specifying a user-centred plan of approach. This framework was used as input for the workshop. Finally sections 4.5 and 4.6 respectively discuss and conclude on the results of the case studies with respect to the defined research questions.

\subsection{Research questions}

The aim to verify the identified need for a method that supports product development teams in specifying a user-centred plan of approach as well as to explore the circumstances under which the method is expected to be used was translated into the following research questions:

1) Is the need for a method that supports in specifying user-centred plans of approach recognised in product development practice?

1.1) How are plans of approach currently defined in product development practice?

1.2) To what level of detail are user-centred plans of approach specified in product development practice?

1.3) To what extend do product developers expect that a method that supports in specifying a user-centred plan of approach has added value? 
2) Under which circumstances is a method that supports in specifying usercentred plans of approach expected to be used?

2.1) For what kind of product development assignments is the method expected to have added value?

2.2) Within what kind of product development teams is the method expected to be valuable?

2.3) Under which product development contextual circumstances is the method expected to be valuable?

\subsection{Research setup}

Two case studies were performed to achieve the discussed goals and answer the research questions. The main part of these case studies existed out of a workshop at both participating companies. Participants to these workshops were employees of the respective companies. Within the workshop at the multinational the group of participants existed out of employees of the department responsible for the development of the printer's housing and user interface. The participants of the midsize design agency consisted of two experienced all-round industrial design engineers.

Interviews were held as a preparation to the workshops. With respect to the participating multinational, the head of the design department and a usability engineer were interviewed; for the participating design agency a project manager was interviewed. The interviews focused on organisation of the respective product development processes. Both interviews provided a first insight into the characteristics of the assignments that were carried out within both companies as well as the composition and organisation of their product development teams.

The workshops each existed out of the following three parts:

- Part 1: Verification of the framework for a method that supports in systematically defining user-centred plans of approach;

- Part 2: Retrospective study with respect to the user-centred product development process of the product development case;

- Part 3: Discussion with respect to the daily product development practice within the companies (with respect to use aspects).

The first part existed out of a discussion in which participants verified a framework for a method that supports in specifying user-centred plans of approach. This discussion was preceded by an individual homework assignment in order to prepare the workshop participants on this discussion. Within this homework assignment, workshop participants verified the framework for such a method individually by means of answering several questions. The most interesting answers and propositions regarding these questions were used as input for the discussion in the form of 
statements in order to make this discussion as effective and efficient as possible. During the discussion participants were asked to elaborate and reflect on the statements. This discussion provided deeper insight into workshop participants' opinion regarding the expected usefulness and added value of a method that supports in specifying user-centred plans of approach.

The second and third part of the workshop focused on gaining insight into the circumstances under which the method is expected to be used. Part 2 existed out of an exercise which particularly prepared the workshop participants for a discussion which was held in the third workshop part. The exercise existed out of a retrospective reconstruction of the user-centred product development process for the product development case. In here participants were asked to make an overview of the case's entire user-centred product development process on a large piece of paper by indicating:

- The product development phases that could be distinguished within the process;

- The user-centred product development activities that were performed as well as their interrelations;

- Who were involved in these user-centred product development activities as well as their roles;

- The characteristics of the results that were achieved during the user-centred product development process.

The exercise triggered workshop participants to think about the characteristics of the assignments they were used to work on as well as the organisation and composition of their product development teams.

Part 3 existed out of a discussion the regarding composition and organisation of product development teams within the participating companies as well as the characteristics of the assignments that these teams execute. The retrospective reconstructions in part 2 provided insight into the characteristics of only one specific assignment as well as the organisation and composition of only one specific team. In order to assess how generic the provided overviews were, workshop participants were asked to discuss to which extent the reviewed cases are representative for other cases. This discussion resulted in a deeper insight into the characteristics of assignments and the composition of product development teams at the two companies.

\subsection{Methodical framework}

Participants were asked to indicate their expectations regarding the method based on the reflection on a framework. This framework was a translation of the identified need for a method that supports in specifying user-centred plans of approach. The 
framework was developed to explain participants what kind of method was intended to be developed, rather than it had to be seen as an end result of the research.

The framework exists out of several steps. The first step (step 1a and step 1b) focuses at exploring the characteristics of the product development assignment and the product development context. Regarding the product development assignment product developers explore what is known about the stakeholders, their interests in the product development project and their vision towards possible solution directions. Furthermore exploration of the role of usability within the product development project is an important activity. Regarding the product development context product developers determine the available time, the people who can be involved within the project and the resources which can be used to solve the product development problem. Furthermore product developers need to explore the formal (inter) -corporate procedures regarding topics as (use focused) product development strategy, internal and external communication as well as information management.

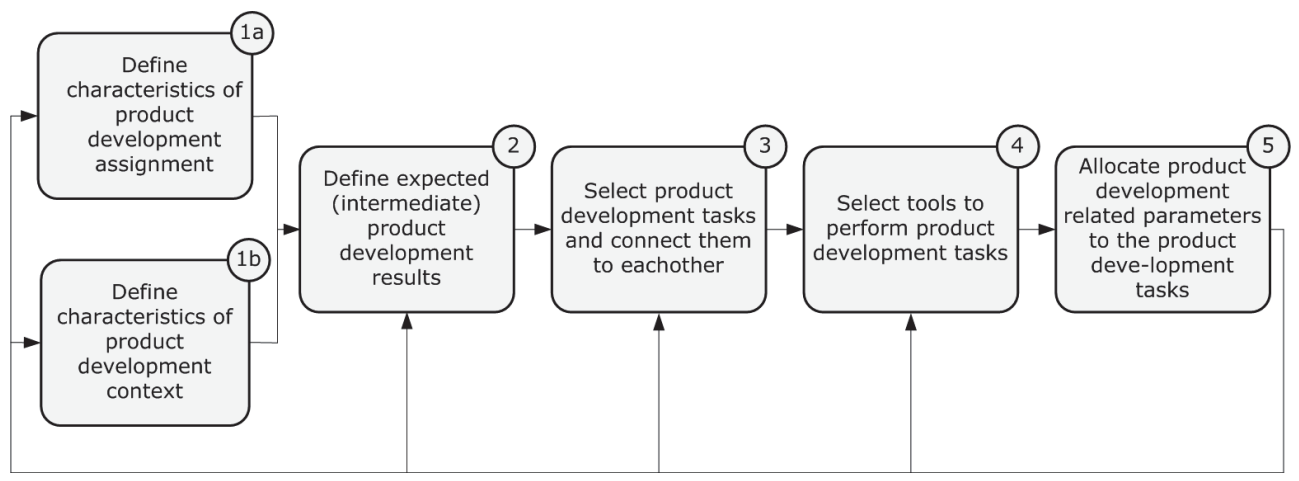

Figure 4.1 - Framework of a method that supports in systematically defining usercentred plans of approach.

The second step focuses on (1) defining the characteristics of the most promising product development solution for the product development assignment and (2) defining the characteristics of the intermediate product development results which should lead to this product development solution. In here product developers have to consider the opportunities and limitations which the product development assignment and the product development context provide to solve the (use related) product development problem.

The third and fourth step focus on determining what to do to achieve the defined (intermediate) results (i.e. development tasks) as well as determining how to achieve these (intermediate) results by selecting the right tools and techniques. Furthermore also product developers also draw relations between (user-centred) product 
development activities. In here product developers need to consider the opportunities and limitations that are provided by the context in which the assignment needs to be performed.

The final step focuses at assigning the product development context parameters to the earlier defined (user-centred) product development tasks. Here product developers determine who to involve in the design process and what their role will be. They also determine the time and the resources that will be available for the user-centred product development tasks. Furthermore product developers determine how internal as well as external communication will take place as well as how to manage (product development) information during the product development process. In here product developers need to consider the formal (inter-) corporate procedures regarding these topics.

\subsection{Results}

This section presents the results regarding the verification of the identified need for a method that supports product development teams in specifying a user-centred plan of approach as well as the exploration of the circumstances under which the method is expected to be used based on the defined research questions.

\section{Research question 1: Is the need for a method that supports in specifying user- centred plans of approach recognised in product development practice?}

During the workshops, workshop participants of both companies confirmed that plans of approach are made for each product development assignment. These are usually specified by a project manager based on the corporate product development method. The plans of approach are generally updated several times during the product development process. For example, the product development documentation of the hoist case shows that the plan of approach for this case was updated more than six times. However, updating user-centred plans of approach is considered to be a complex activity. This is particularly the case for plans of approach that exist out of a large amount and variety of product development activities that interrelated with each other. These interrelations can cause a lack of overview on the plan of approach's updating process. A method that supports in specifying a user-centred plan of approach is therefore considered useful and to have added value if it supports in systematically updating plans of approach during the product development process.

Plans of approach that are specified at both participating companies, are usually not as detailed as intended by the methodical framework that is discussed in section 4.3 The plans of approach that were made at the design agency for the hoist case for example only provided an overview of the main product development activities that needed to be executed. These activities were specified on an abstract level that is 
hardly understandable for outsiders, e.g. as 'Risk management' or 'Concept design'. The plans of approach specified per product development activity when the activity needed to be executed, which team members had to execute the activity and the amount of hours that could be spend on its execution. During the workshop at the multinational, participants stated that plans of approach that were formulated at their company usually have a similar level of detail as those at the design agency. These plans of approach do not specify how a product development activity exactly has to be executed, how product development activities relate to each other or what results exactly has to be achieved during the product development process. Participants of both companies indicated that further specification of product development activities and results was done by the team members who had to execute a specific activity. Unfortunately, these specifications were usually not documented nor communicated to the complete product development team. As one of the workshop participants said: "Specifying activities is usually done on the flow. We collectively consider the steps we think we need to take, the methods we want to apply, facilities and equipment we need, etcetera". During the workshop at the multinational participants admitted that team members often do not have a good overview on the plan of approach, because of its lack of detail. As a result they do not have good insight into what they are exactly expected to contribute during the product development process. One of the participants formulated: "Sometimes, at the start of the project, I only can guess how my product development activities relate to others. At that stage I do not completely know which results I am exactly supposed to deliver, why they are needed or who will use them. In that case I first have to find out what I am exactly supposed to do". In here the method could provide added value. Participants of the workshop at the multinational stated the method could provide better insight into what is expected from them during the product development process in terms of results and activities as well as what they can expect from other sub-teams since its use results in a more detailed plan of approach. Furthermore they expect that the method could provide added value in cases for which it is not known how to execute the product development assignment. One of the participants during the workshop at the multinational stated: "Sometimes you get stuck in the development process. Methods you are familiar with do not lead to the required results and you do not know how to solve the problem. I can imagine that a method like this could support me to explore alternative methods and approaches for my problem". Participants of the workshop at the design agency also expect the method to have added value. During the workshop one of the participants stated this: "It is important to avoid use risks during the design process. These use risks relate to insights - which are of course the intermediate results - that need to be gained during the design process regarding product's use characteristics. Not gaining these insights can lead to taking wrong decisions during the design process. As a consequence these wrong decisions result in a product that does not meet user's expectation regarding its use behaviour. Your method might help us to gain an overview of these use 
risks as well as the insights and results that need to be achieved during the product development process. This helps us and our clients to gain insight into the importance of the product use aspect at the start of the project". Concluding from this quote, the method is expected to have additional added value since it can support in gaining insight in as well as reducing use risks during the product development process.

\section{Results regarding research question 2: Under which circumstances is a method that supports in specifying user-centred plans of approach expected to be used?}

\section{Assignments}

Participants of the workshop at the multinational indicated that the development of printer-copier systems is classified into root, branch and leave assignments. This classification is based on the following aspects: assignment's concreteness, amount of design freedom, innovativeness and amount of use risks. Based on the discussion during the workshop, an overview of the characteristics of root, branch and leave assignments was composed (see table 4.1).

\begin{tabular}{|c|c|c|}
\hline Root & Branch & Leave \\
\hline $\begin{array}{l}\text { There is a need on the market, } \\
\text { but no product is available which } \\
\text { fulfils this need. }\end{array}$ & $\begin{array}{l}\text { There is a product on the market. } \\
\text { This product needs major } \\
\text { adjustments to enlarge its life } \\
\text { span. }\end{array}$ & $\begin{array}{l}\text { There is a product on the market } \\
\text { which is suffering small usability } \\
\text { problems. }\end{array}$ \\
\hline $\begin{array}{l}\text { Product development } \\
\text { assignment regarding product } \\
\text { use (risks) is vague. Limited } \\
\text { information about its users and } \\
\text { use situations and thereby about } \\
\text { the desired use characteristics of } \\
\text { the product is available. }\end{array}$ & $\begin{array}{l}\text { The product development } \\
\text { assignment is concrete. The } \\
\text { product's users and use } \\
\text { situations are known. Product's } \\
\text { use related shortcomings are } \\
\text { known. }\end{array}$ & $\begin{array}{l}\text { The product development } \\
\text { assignment is concrete. } \\
\text { Product's use related } \\
\text { imperfections/bugs are known. }\end{array}$ \\
\hline $\begin{array}{l}\text { Product developers have a lot of } \\
\text { design freedom since most } \\
\text { hardware components need to } \\
\text { be developed from scratch. } \\
\text { There is room for negotiation } \\
\text { regarding solution directions. }\end{array}$ & $\begin{array}{l}\text { The solution space is limited } \\
\text { since most hardware and/or } \\
\text { software components have been } \\
\text { developed already. A solution } \\
\text { direction needs to fit in the } \\
\text { limited solution space. }\end{array}$ & $\begin{array}{l}\text { The solution space is very } \\
\text { limited. Product development } \\
\text { adjustments are often limited to } \\
\text { developing software updates. }\end{array}$ \\
\hline $\begin{array}{l}\text { There is a focus on making the } \\
\text { product development } \\
\text { assignment more concrete by } \\
\text { exploring use needs and risks } \\
\text { during the early stages of the } \\
\text { product development process. } \\
\text { Results of these explorations are } \\
\text { communicated to other product } \\
\text { development teams. }\end{array}$ & $\begin{array}{l}\text { There is a focus on exploring the } \\
\text { limitations of the solution space } \\
\text { during the early phases of the } \\
\text { product development project. }\end{array}$ & $\begin{array}{l}\text { Limited time available for an } \\
\text { exploration of the solution space. } \\
\text { A solution needs to be found } \\
\text { quickly since the product is } \\
\text { already on the market. }\end{array}$ \\
\hline
\end{tabular}




\begin{tabular}{|c|c|c|}
\hline $\begin{array}{l}\text { The early phases of the product } \\
\text { development process focus on } \\
\text { developing promising use } \\
\text { concepts. In here promising } \\
\text { refers to a concept which fits } \\
\text { best to the user's needs and is } \\
\text { expected to avoid use risks } \\
\text { during further development } \\
\text { activities }\end{array}$ & $\begin{array}{l}\text { The user interface already exists. } \\
\text { There is a focus on modifying the } \\
\text { existing user interfaces. } \\
\text { Modifications are based on } \\
\text { proven use/technology } \\
\text { (concepts). }\end{array}$ & $\begin{array}{l}\text { The product development } \\
\text { process focuses at solving the } \\
\text { use problem by means of a } \\
\text { minimum of minor software } \\
\text { adjustments. }\end{array}$ \\
\hline $\begin{array}{l}\text { Product's use concept or parts of } \\
\text { it are extensively tested. There is } \\
\text { sufficient time available for use } \\
\text { tests Product developers need to } \\
\text { ensure themselves that the use } \\
\text { concept fits best to the user's } \\
\text { needs (use risk reduction). }\end{array}$ & $\begin{array}{l}\text { Compared to Root assignments, } \\
\text { there is less time available to test } \\
\text { adjustments regarding the user } \\
\text { interfaces since hardware } \\
\text { components already have been } \\
\text { developed. The use concept of } \\
\text { the interface already has been } \\
\text { proved in earlier product } \\
\text { development assignments. }\end{array}$ & $\begin{array}{l}\text { Available time for use testing is } \\
\text { very limited. The product is } \\
\text { already on the market. }\end{array}$ \\
\hline
\end{tabular}

Table 4.1 - Characteristics of Root, Branch and Leave assignments.

Despite whether the development assignment for a specific printer-copier system is indicated as root, branch or leave, most printer-copier systems are complex products for which a complex organisation of the product development process is inevitable. After all, it included a wide variety of product development tasks which need to be performed by a large multidisciplinary product development team. During the interview, the head of the design department explained that assignments are therefore divided into sub-assignments on functional component level, i.e. userinterface, paper transport or printer head. These sub-assignments, in turn, are divided into several work packages in order to make the product development process manageable. Nevertheless, as one of the workshop participants indicated, dividing assignments into sub-assignment often causes problems at the stage where product development results of the individual sub-assignments and work packages need to be integrated. During the workshop he gave the following example of such a problem: "The printer's user-interface software and hardware were developed separately. Product developers discovered in a late stage of the development process that both were instrumented with a green button. In this case only one green button would have been sufficient since both buttons had the same functionality. Above all, both green buttons were positioned next to each other". During the workshop, another participant indicated: "This problem was most probably caused by a lack of communication between both sub-teams during the product development process. The available plan of approach for this project only stated collaborating product development activities between both sub-teams at the end of the process. This problem could most likely be prevented if both teams had collaborated throughout the product development process". Both quotes 
illustrate that the collaboration between sub-teams was neither efficient nor effective during this product development process. It resulted in use problems that could have been avoided when sub-teams collaborated earlier in the product development process and were more aware of each others activities. In contrary to the multinational, product development teams at the design agency are, on behalf of clients, involved in the development of a wide variety of products. During the interview the design agency's project manager indicated the difficulty to categorise product development assignments. However, during the workshop at the design agency, one of the participants stated that the following aspects of the assignment influence the required complexity and lead time of the product development process as well as the rate of attention that is paid to product use during the product development process:

- Client's expectations regarding the maturity of the design: Clients do not always ask to develop a product that is ready for production. For example in some cases clients only ask to analyse the assignment or to develop a product concept. The expectations regarding the design's maturity have direct influence on the product development process' complexity since it influences the amount and variety of product aspects that need to be considered during the process and therefore also the assignment's lead time and the amount and variety of activities that need to be executed during the process.

- Importance of the product use aspect: Although the design agency's corporate product development method imposes multiple use tests in several of its product development phases, there is not always a focus on product use during the product development process. For some product development assignments focusing on other product development aspects might have priority. A workshop participant explained that the importance of the product use aspect and the rate to which attention is paid to it depends on:

o The risks and opportunities regarding product use aspects in the project

o The product developer's capability to oversee use risks during the product development project. This ability particular depends on product developer's analytic capacities, product development capacities, level of knowledge about the product's use and affinity with the product

o The client's vision on (the importance of) product use aspects for the product's success in the market.

This involves that the more product use influences the product's success in the market, the more the client recognises the importance of incorporating the product use aspect in de development process, and the less product developers oversee the use risk, the more attention is paid to product use aspects during the product development process. This observation also holds for the multinational. Although here 
product developers do not have to deal with clients, participants from the multinational indicated during the workshop that they spend more time on product use aspects in case it is hard for them to oversee use risks.

Overall, the workshops indicated that a method that systematically supports in specifying a user-centred plan of approach is particularly useful within complex assignments in which product use is seen as a key aspect to take into account during the product development process. In here the term 'complex' refers to assignments that are divided into sub-assignments, in which a large amount of design aspects need to be taken into account and which product development process' lead time is expected to be long. For assignments which meet these characteristics generally a large amount and variety of interrelating product development activities need to be executed and a wide variety of results need to be achieved during the product development process. All these activities and results need to be specified in a plan of approach. Specifying such a large amount of activities and results in a plan of approach is a challenge, because it is not easy keep overview on the activities and results that need to be specified as well as their interrelations. A method that systematically supports in this is therefore considered to be useful.

\section{Team}

During the interview, the head of the multinational's design department stated that printer-copiers are extremely complex products to develop. They exist out of many different components which all need to be developed and integrated with each other towards a complete functioning system that fulfils the (use) needs and expectations of its user. Knowledge and expertise out of wide variety of disciplines is required in order to develop these printer-copiers. Therefore developing them in large and multidisciplinary development teams is inevitable. In the interview, the head of the multinational's design department indicated that a printer-copier's product development team usually exists out of 150 to 200 persons. He furthermore explained that an R\&D manager, who is responsible for the development of the entire printer copier, leads the development team. This R\&D manager also stays in contact with the other departments within the company that are indirectly involved in the development of the printer-copier, e.g. manufacturing and logistics, services, product management, etc.

The head of the multinational's design department furthermore stated that, in order to make the large product development team manageable, it is divided into a large amount of sub-teams which can be divided in two categories. The first category exists out of sub-teams which are responsible for the development of the individual printercopier components, e.g. its user-interface. The second category exists out of sub-teams which are responsible for the integration of the components towards a complete 
printer-copier. Because of the large amount of sub-teams as well as the size and multidisciplinary of the entire product development team, it is hardly possible for the R\&D manager to steer all members of sub-teams directly. Therefore each sub-team has a team leader who is responsible for the results of the sub-team. This team leader stays in close contact with the R\&D manager and steers the sub-team.

Furthermore a sub-team usually has a multidisciplinary composition. To illustrate this: the retrospective reconstruction of the user-interface's product development process during the workshop showed that the following disciplines were involved in the development of the printer's user-interface: visual designer, interaction designer, industrial designer, usability engineer, system integrator and a software engineer. The composition of a sub-team is generally based on the knowledge and expertise that are required for the execution of sub-teams development tasks.

In contrast with the participating multinational, the product development team's composition and organisation at the participating design agency in general is less complicated. Here assignments are usually performed by a small team. Teams usually exist out of two or three all-round industrial design engineers and mechanical engineers. These teams operate independently in executing the complete assignment for the client. However, there are situations in which the organisation and composition of the design agency's product development team also become more complex. These cover situations where product developers of the design agency cooperate with external product developers or teams in case knowledge or expertise is required which is not available within the design agency. The design case for which its product development process was reconstructed during the workshop is an example of such case. In here the hoist's framework and user-interface were developed internal, whereas the hoist's software and electronics were developed by an external agency.

The case studies revealed insight into the composition and organisation of the product development teams in the product development practice of the two participating companies. Based on the discussions during the workshops it can be concluded that particularly for members of a large, multidisciplinary and complex structured product development teams it is important to have a complete and detailed plan of approach since it can be difficult for them to determine what is exactly expected from them during the product development project. However, for those who are responsible for the specification of the plan of approach it can be difficult to define such a plan of approach. It involves that they have to specify a large amount and big variety of (interrelating) product development activities and results, which holds the challenge to keep overview of these activities and results as well as on the aspects that need to be specified for each of them. A method that supports in specifying such a plan of 
approach in a structured way might support them to keep this overview during the specification process.

\section{Context}

The multinational's head of the design department and the design agency's project manager both stated during the interview that their company applies a corporate product development method for each assignment. These corporate development methods are stage gate methods that divide the product development process into several phases. Both methods furthermore prescribe results that need to be achieved at the end of each of these phases. However, the level of detail to which these results are formulated is very low: e.g. in terms as 'proven interface concept' or 'functional UI prototype'. Further specification of these corporate product development methods in a plan of approach is needed in order to effectively apply them to an assignment. During the interviews, the head of the design department as well as the project manager stated that specification of these plans of approach is based on the corporate product development method. A method that supports in specifying a user-centred plan of approach should therefore enable such plan of approach based on available corporate product development methods.

\subsection{Conclusions}

Based on the two conducted case studies it can be concluded that the need for a method that supports in specifying detailed user-centred plans of approach is recognised by design practice. The application of such a method results in a detailed user-centred plan of approach. Due to this high level of detail, design practitioners expect the added value of such a method to be fourfold, i.e. such method is expected to:

- Provide better insight into what is expected from product developers during the product development process in terms of results and activities;

- Provide better insight into what product developers can expect from other subteams since its use results in a more detailed plan of approach;

- Inspire product developers when they do not know how to execute the product development assignment;

- It can support in gaining insight in as well as reducing use risks during the product development process.

Furthermore, such a method is particularly expected to be useful within complex product development assignments in which product use is seen as a key aspect to take into account during the product development process. In here complex refers to assignments that are divided into sub-assignments, in which a large amount of design aspects need to be considered during the product development process' (usually long) 
lead time. These assignments are generally executed by large, complex-structured, multidisciplinary teams.

However, a method with the proposed characteristics can only be applied successfully when product developers take all influences on product use into account when specifying a user-centred plan of approach. As described in Chapter 2, product use is not only influenced during the strict product development phase, but by several aspects of the phases 'strategy formulation', 'design brief formulation', 'introduction' and 'product in use' of the product innovation process as well. Chapter 5 discusses a product use impact model that addresses the aspects which need to be considered while organising the user-centred company organisation at large and specifying usercentred product development process in specific. 


\section{$x^{2}+2 x \cdot x$}




\section{5}

\section{An Impact Model Regarding Product Use}

\subsection{Introduction}

The previous chapters identified the need for a method that systematically supports product development teams in specifying a user-centred plan of approach. When specifying a user-centred plan of approach, such a method should among others support in considering the aspects that influence the product's use characteristics during the product development process. However, this is only possible when it is clear which aspects exactly need to be considered.

This chapter therefore discusses an impact model regarding product use. According to this model, aspects on multiple levels within and outside the product development organisation have influence on product use characteristics in product development in general and the product development process in particular. This chapter introduces the methodology, the identified levels as well as the corresponding aspects that influence product use characteristics.

\subsection{An impact model regarding product use}

Figure 5.1 shows the impact model regarding product use (Van Kuijk, Hoolhorst et al. 2010).

Design research literature as well as product development practice based research (see Chapters 2 to 4) show that the product's level of use is not only determined during strict product development. Developing products which fit the use needs of their users is a result from other, higher level, (organisational) factors as well.

The model shows an overview of levels within the product development organisation which have influence on the product's use characteristics and addresses aspects that have influence on these characteristics. From outside inward, the following levels can be distinguished: context, company, project/team and process. The influence on 
product use comes from outside in. The influence on product use is the biggest in the centre, where the product development process takes place. To address product use at a certain level, the impact on product use of the outer levels should first be identified.

Each level has several main aspects that have influence on product's use characteristics. The next sections discuss these aspects for each of the distinguished levels.

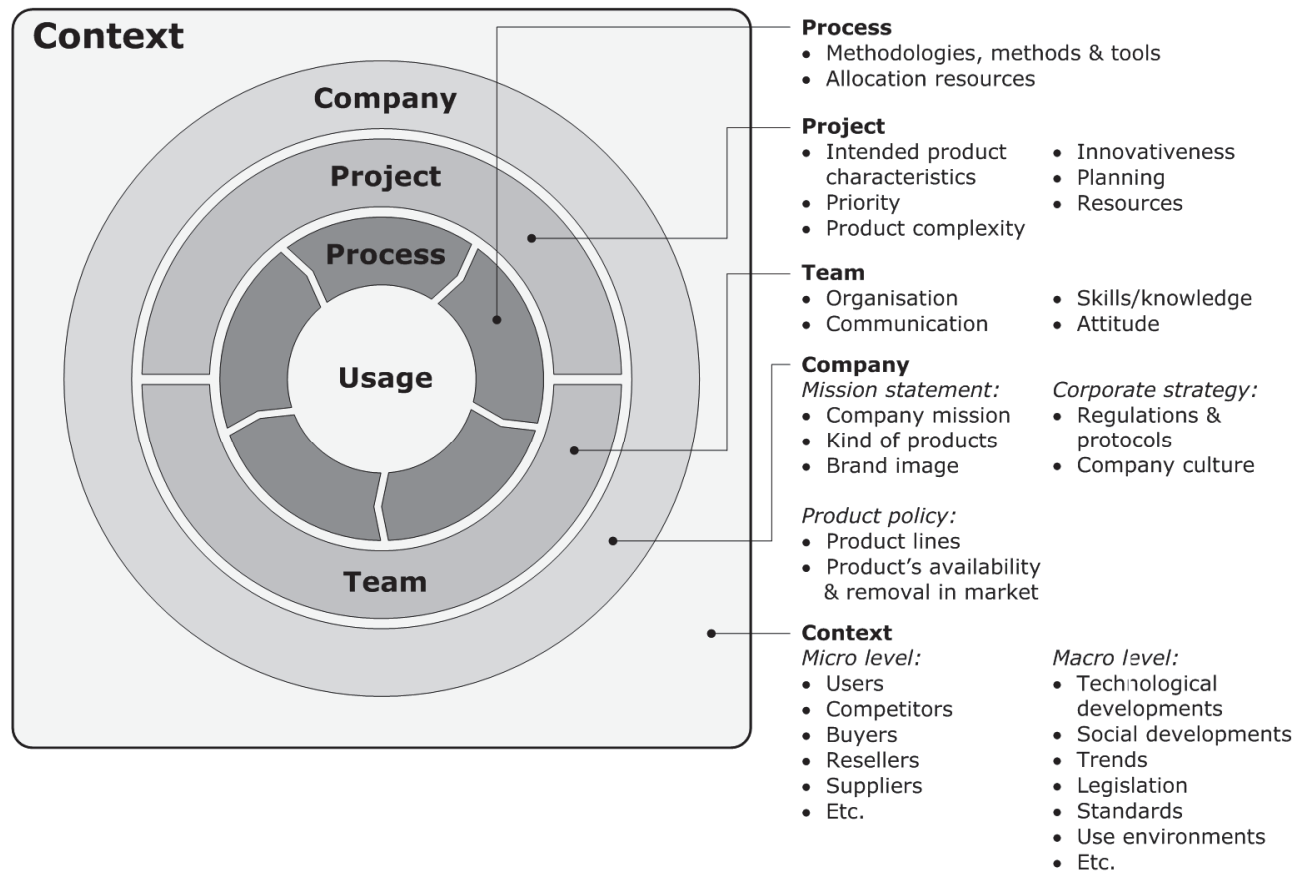

Figure 5.1 - Impact model regarding product use representing levels and aspects within the organisation which have influence on product's use.

\section{Context level}

The context level represents society. Within this society two, mutually influencing sub-levels can be distinguished, namely micro level and macro level. Context on micro level consists of all parties within society, i.e. individual persons or groups of people as well as all public and non-public bodies. Examples of such parties are users, competitors, buyers, resellers or suppliers. Context on macro level consists of all developments and regulations within society which are initiated or created by parties on micro level. Examples of these developments and conditions are trends, technological and social developments, legislation, standardisation or (use) environments. 
Parties on micro level have specific, sometimes conflicting, goals and use specific products which support in achieving these goals. These products have to meet specific needs, e.g. use needs, in order to be useful in achieving these specific goals. Furthermore, parties on micro level might have to take developments and regulations into account while achieving their goals. These developments and regulations therefore sketch preconditions regarding use for the specific products in which these parties on micro level have interests. Example: Someone wants to travel to Berlin (goal) and wants to drive by car (product) in order to get there. However, it is only allowed to travel by car when this car meets all the governmental safety regulations (regulations on macro level). These safety regulations e.g. prescribe that a car must be equipped with indicators. In here, the safety regulation thus sketches a precondition for the car, namely the fact that it must be equipped with indicators.

When developing a usable product, teams have to be aware of (1) parties that might have interests in this product, (2) the (conflicting) goals these parties have to achieve with this product, (3) the use needs that the product needs to fulfil as well as (3) the preconditions which are sketched by developments and regulations in society regarding product use.

\section{Company level}

Companies try to benefit from the product needs of parties on context level. Therefore they develop, produce and market products which fulfil (use) needs of the parties on context level and try to distinguish themselves from competitors. However, companies also should organize themselves in such a way that they are able to develop, manufacture and market these products in a successful way (Buijs and Valkenburg 1997). In here the following aspects, which are usually defined by upper management, have influence on product use characteristics:

- Mission statement: A mission statement prescribes the company's main mission and in that indirectly also the way in which it distinguishes itself from competitors. It furthermore mentions what kind of products it will develop, produce and market to accomplish this main mission. In here, regarding use, products are described in terms of their use aim, their intended use impact, and brand image as well as to which market or group of users they are sold.

- Product policy: A product policy prescribes which product lines a company distinguish to meet its mission statement. Furthermore it prescribes which products will be developed and manufactured per product line as well as when these products will become available and are removed from the market. Regarding product use, a product policy roughly prescribes product's main use circumstances, main functionality, its focus users and their use goals.

- Corporate strategy: A corporate strategy prescribes the way in which the product policy will be executed. It prescribes on a high level the approaches for 
developing, manufacturing and marketing of company's products that meet the user's needs, e.g. regarding usability. In addition it prescribes the organisation structure (e.g. of the usability department and upper management) which enables the company to develop, manufacture and market products according to these approaches. Furthermore the corporate strategy lays down regulations, protocols and a vision on the company culture for product development, manufacturing and marketing products, e.g. regarding product development models or decision taking.

Companies should be aware of the (use) needs on micro context level as well as the developments and conditions on macro context level in order to define a mission statement, product policy and corporate strategy which will lead to high-level usability for their products.

\section{Project/team level}

On project/team level the company's mission statement, product policy and corporate strategy are translated towards concrete product development projects. In here, the following aspects influence product use characteristics:

- Product specification: What specific product needs to be developed, what are aspects of the product that have priority (e.g. in terms of functionality, focus aspects during product development process, product complexity and innovativeness)?

- Planning: When should the product be available? This sketches a precondition regarding the amount of time and effort that can be used for use-related product development activities.

- Resources: Which resources are available for product development activities?

This level also incorporates the assembly and organisation of a core product development team which will execute the concrete product development project as well as the definition of the way in which communication will take place during the project's lead time. Selecting team members takes place based on expected need of skills, knowledge and attitude during the product development process.

\section{Process}

The process level focuses on the actual development of the product. The following aspects on process level have an influence on product's use characteristics:

- Results: Which results need to be achieved during the product development process in order to develop a product that meets the intended use characteristics?

- Methodologies, methods and tools: Which product development methodologies, methods and tools are applied during the product development process (e.g. for user-centred product development activities), when are these methodologies, 
methods and tools applied during the product development process as well as how are they applied in terms of development activities.

- Allocation of resources: Which resources are available during the product development process (e.g. for user-centred product development activities) in terms of time, budget, equipment and people skills or knowledge.

\subsection{Detailing the impact model regarding product use}

This chapter discussed an impact model regarding product use. According to this model there are aspects on four levels of the product development organisation that need to be considered when defining a user-centred plan of approach. The discussed levels influence each other outside-in.

It is possible to detail this model by means of developing multiple methods which support the transition between different levels of the model (see figure 5.2). However, this research will restrict to the development of a method that supports the transition from project-team level to process level, i.e. to a method that supports in specifying a user-centred plan of approach. Focus on the development of such a method was chosen, since product use is most influenced on process level (Den Ouden 2006; Van Kuijk 2010). At this level the product development team actually develops the product itself and product's use characteristics are established. When specifying such a usercentred plan of approach, this method supports in addressing the discussed aspects that influence product's use characteristics on each of the higher model levels.

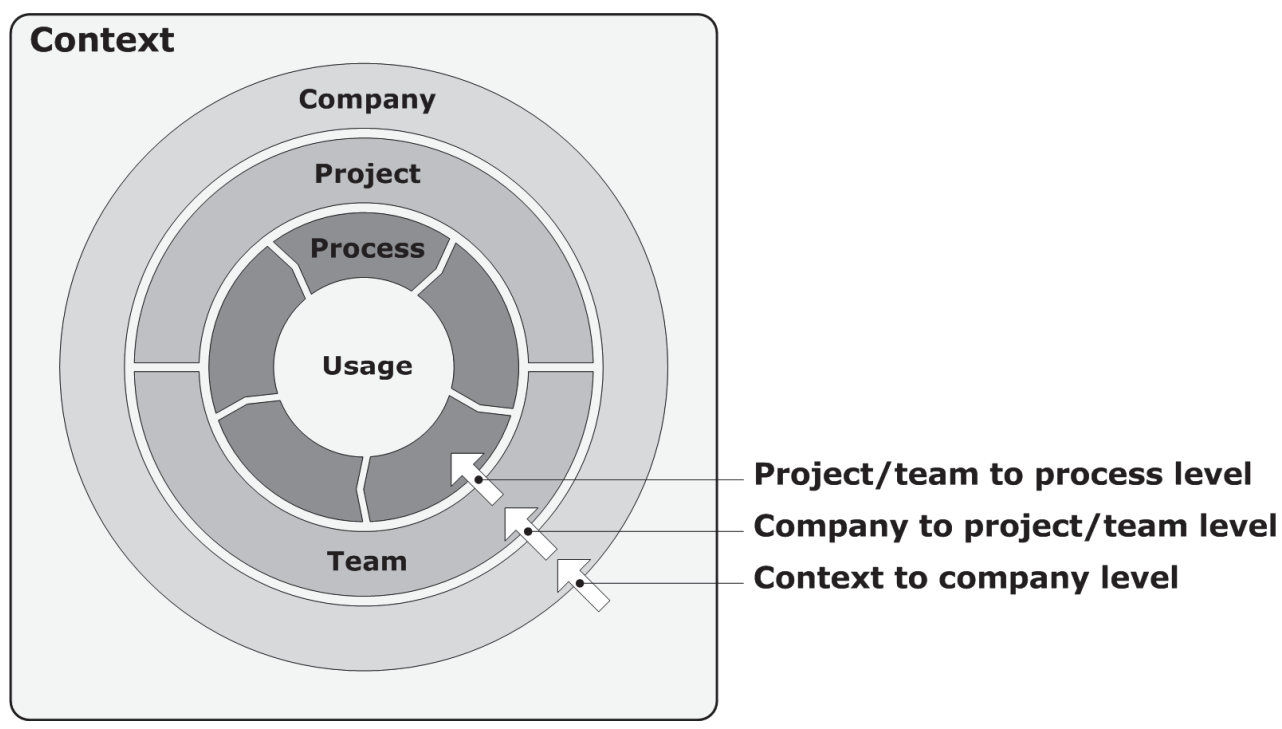

Figure 5.2 - Overview of transitions between levels of the model which could be supported by a method. 
Chapter 7 introduces a method that supports product development teams in specifying a user-centred plan of approach in terms of intended characteristics of the product that need to be developed, milestones and product development activities. This method takes an identification of all relevant stakeholders to the product development project as a base for defining user-centred plans of approach. These stakeholders are all parties on context, company and project/team level that are affected by the outcome of the project or can influence the product development process. In order to base a user-centred plan of approach on an identification of stakeholders, it is necessary to know how stakeholders can be identified. Therefore Chapter 6 first focuses on stakeholder mapping. The chapter gives insight into the definition of stakeholder mapping in relation to product development. It furthermore discusses how to specify stakeholders in order to be useful in specifying user-centred product development processes. 


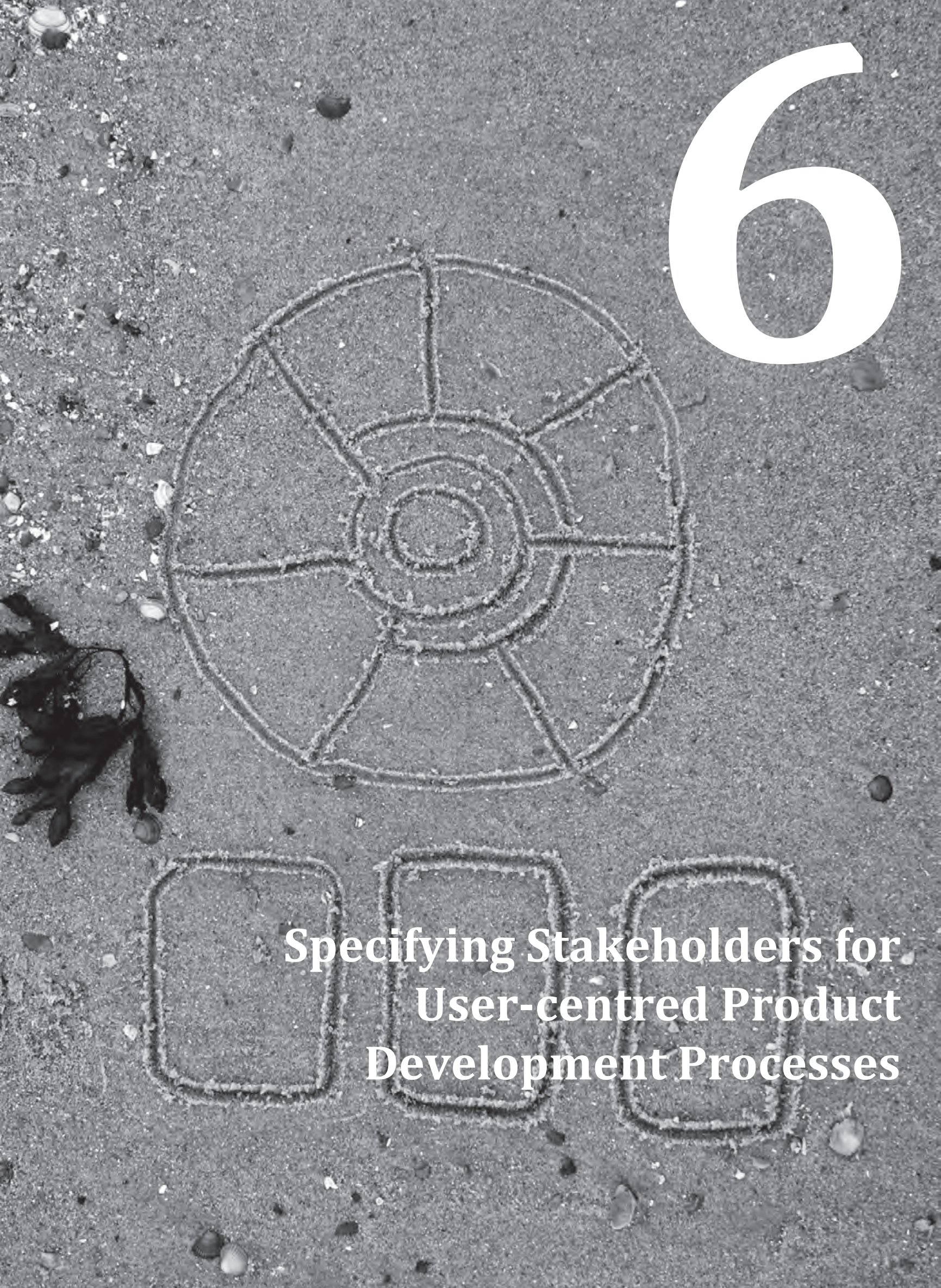




\section{6}

\section{Specifying Stakeholders for User- Centred Product Development Processes}

\subsection{Introduction}

Product development teams having a univocal and complete overview of the intended user-centred product development approach can prevent use problems with the resulting product (Deming 1986; Van Kuijk 2010). However, defining such an overview on the user-centred product development approach is not straight forward. User-centred plans of approach are generally complex since many stakeholders are involved or can influence the user-centred product development process. Stakeholders are parties inside and outside the development company who can influence the user-centred product development process. Freeman (1984) states that mapping all potential stakeholders within a project is a good starting point for defining processes. Stakeholder mapping is already done within many disciplines and stakeholder literature discusses many ways to categorise stakeholders (Friedman and Miles 2006). Unfortunately, none of these approaches is directly useful in a method that supports product development teams in defining user-centred product development approaches since they only express stakeholders in general terms. This makes it hard to express how stakeholders can influence the product development process with respect to product's use related product development activities. Therefore this chapter addresses a new approach to specify stakeholders, based on existing stakeholder theory. Before this chapter discusses this new way of stakeholder specification it first elaborates on the definition of stakeholders. It furthermore discusses existing stakeholder theory as well as what can be learned from this theory for the development of an approach to specify stakeholders that is useful in defining user-centred plans of approach. 


\subsection{State-of-the-art in stakeholder mapping}

Stakeholders are any group or individual inside or outside the company that needs to be taken into account for a successful completion of a project (Freeman and Reed 1983; Bowie 1988; Näsi 1995). Freeman's (1984) now-classic definition states that a stakeholder can affect or is affected by the completion of a project. Based on this definition there can be concluded that stakeholders have interests in a successful completion of a project as well as power and willingness to influence the course of a project. Their willingness to influence the course of a project depends on both the size of their interests as well as the consequences of their influence of the course of a project. Freeman's definition is general and therefore also applicable to user-centred product development projects for two reasons.

Firstly, within a user-centred product development project there are many parties (e.g. users or manufacturers) that have an interest in the completion of that project; in this case the development of a product. Their interests can relate to the company organisation, to the product development project organisation or the product that originates from that product development. Clarkson (1995) mentions that these interests stem from stakeholders' goals which originate from (1) risks they run in case the product development project is not done or (2) risks they run by the completion of the product development project. However, a lot of products are not developed to avoid a risk, but from an opportunity to improve something: e.g. an opportunity to increase the market share. Therefore stakeholder's interests can also relate to an opportunity to improve a certain situation.

Secondly, apart from the product development team, there are many other parties that can influence the course of the user-centred product development project and are willing to do so. These parties can influence the execution of the user-centred product development process as well as the success of the product that results from this process. In order to do this, they can decide whether or not (1) to put their resources at disposal or (2) to take decisions related to the user-centred product development process or the product that originates from that process.

Based on the trends that were discussed on section 1.1 there can be concluded that a product development project is successful when it meets the following two requirements. Firstly, the product that results from this process meets the expectations of the parties that have interests in a successful completion of the product development project. Secondly, it requires an effective and efficient organisation of the product develop development process. Meeting both requirements asks for a deep understanding of:

- Who are the stakeholders in the product development project?

- The size of their interests in the product development project? 
- Their power to influence the execution of the product development process as well as the success of the product that results from this process the project?

- To what extent are they willing to influence the project?

Stakeholders mapping supports in gaining such understandings and therefore a valuable activity in the process of organising a product development process (Freeman and McVea 2001; Babou 2004).

Well known systems that support in mapping stakeholders are Savage, Nix et al. (1991), Mendelow (1991), Cameron, Crawley et al. (2010), Murray-Webster \& Simon (2006), Turner, Kristoffer \& Thurloway (2002) and Mitchel, Agle et al (1997). However, although used terminology might differ, they all classify stakeholders based on the size of their interests, their power to influence the project and as a consequence also their rate to which they are willing to influence the product development project. Such a way of mapping stakeholders provides a good insight into which stakeholders are really important to focus on during the development of the product or to involve in the product development process. However, classifying stakeholders based on the size of their interests and power to influence the product development project is only possible when there they following characteristics are specified:

- The actual interests of stakeholders in a successful completion of the product development project;

- The actual way in which stakeholders can influence the completion of the product development project.

Moreover, gaining this understanding is also important during the actual organisation of the user-centred product development process in a user-centred plan of approach. Such a plan of approach among others specifies the main characteristics of the product that needs to be developed. In order to be successful, this product has to meet the expectations and interests of parties that have an interest in (the development of) that product. It is only possible to meet stakeholder's expectations once is known what these expectations and interests actually are. Moreover, a user-centred plan of approach specifies who will be involved in the product development process as well as how they will be involved. It is only possible to specify this when it is known who can or should be involved in the product development process, how they can influence the course of this product development process as well as their willingness to influence the product development process.

The enounced systems that support in stakeholder mapping recognise the importance of specifying stakeholders' actual interests, the way they can influence the completion of the product development project as well as their willingness to do so. However, these systems are generic and therefore applicable to a wide variety of disciples. As a result, they therefore provide less support in actually gaining such an understanding. 
More specifically, they do not discuss how to express stakeholders' interests, the way they can influence the completion of the product development project as well as their willingness to do so; let stand a user-centred product development project. Therefore the next section discusses templates that support in specifying stakeholders regarding user-centred product development processes. These templates have been developed within this research.
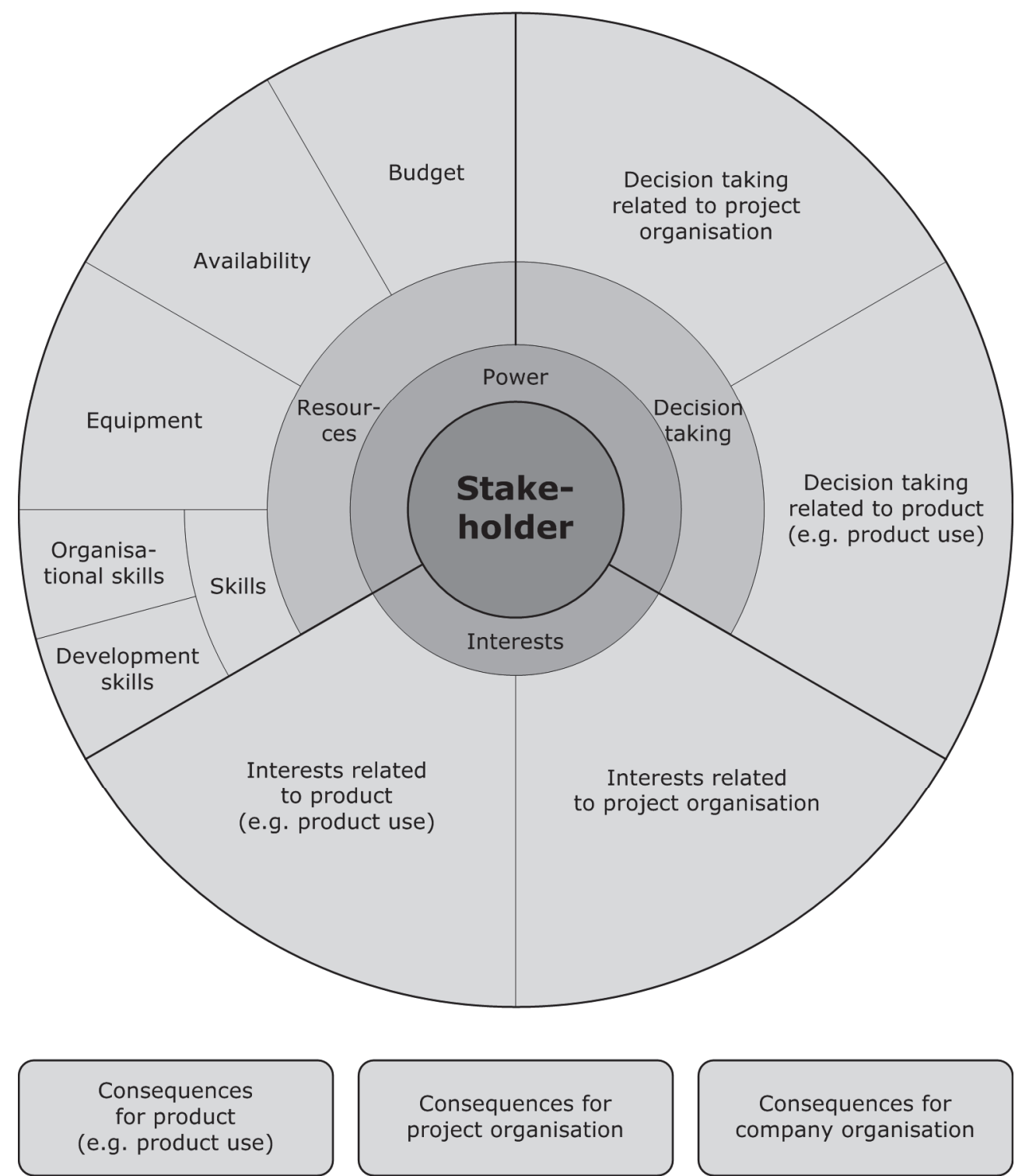

Consequences for
project organisation

Consequences for company organisation

Figure 6.1 - A template that supports in specifying stakeholder's interests, power and their consequences. 


\subsection{Templates for specifying stakeholders regarding user- centred product development processes}

Figure 6.1 shows a new template that provides practical support in describing stakeholders. It is particularly intended to be used in user-centred product development projects. In contradiction to most existing stakeholder theory, this template indicates which dimensions of stakeholder's interests, power as well as the consequences of both for the project and company are relevant to describe for usercentred product development projects. In here the framework focuses on the relation to product use aspects, but does not exclude other product aspects.

\section{Stakeholder's interests}

It is possible to divide stakeholder's interests into interests related to the product that needs to be developed as well as to the organisation of the product development project.

Stakeholder's interests related to the product refer to the kind of product that a stakeholder would like to have developed as well as how stakeholder would like to benefit from this product. Interests regarding the product can therefore relate to amongst others use aspects, technical aspects, social aspects, environmental aspects or marketing aspects.

Stakeholder's interests regarding the product development organisation refer to how the stakeholder would like to the product to be developed and how the stakeholder thinks to benefit from this project in case the interest is met. Stakeholder's interests regarding the project organisation can relate to many aspects of the product development process such as design methods, time schedules, development budgets, learning goals or collaborations.

\section{Stakeholder's power}

Stakeholders can influence the development of the product by means of making their resources available or taking decisions during the product development process.

Within product development it is possible to distinguish four types of resources, namely:

- Budget: The amount of money a stakeholder can spend during the product development process for product development activities.

- Availability: The amount of time and time slots stakeholders can spend on the product development project. 
- Equipment: Facilities (e.g. machinery, software, laboratories or workshops) that stakeholders can make available for the product development project.

- Information/knowledge/skills: Stakeholder's organisational or product development information, knowledge or skills which can be used during the product development project.

To make optimal use of stakeholder's resources during the product development process, it is necessary to have good overview of the resources itself as well as the conditions under which stakeholders will or can make their resources available.

Besides of making resources available, stakeholders can also influence the product development project by means of decision making. The framework distinguishes two kinds of decisions, i.e. decisions related to the:

- Product that needs to be developed;

- Product development process.

It is necessary to have an overview of the kind of decisions that each stakeholder can take during the product development process in order to know which stakeholders need to be taken into account during decision taking procedures.

\section{Impact}

Both stakeholders' interests as well as their power to influence the product development project have consequences. These consequences can be rather positive or negative, depending on the way in which is dealt with the stakeholders' interests and power during the product development process. Consequences can relate to the:

- Product that needs to be developed;

- Product development process;

- Company that develops the product or puts the product on the market.

When defining a plan of approach it is important to decide when and how to involve stakeholders in the product development process. This can done based on the expected impact of stakeholder's interests and power. Section 7.3 discusses how to decide this.

\section{Users}

Although many different stakeholders are involved in user-centred product development, one stakeholder deserves specific attention: the user. Just as any other stakeholder, users have interests and power regarding a specific product development project. As any stakeholder, user's interests and/or power have consequences for the product that needs to be developed, the product development process as well as the company organisation. However, the terms in which user's resources and interests are described are different. 


\section{Describing user's resources}

Stakeholder's resources are described in terms of budget, availability, equipment and skills. However, users usually do not have budget to invest in product development. Furthermore users do not possess equipment which can be used during product development activities. For this reasons user's resources are only described in terms of:

- Use knowledge, expertise or skills: What information regarding the product's use aspect can users share with product developers during the product development process?

- Availability: To what rate is it possible to involve users in product development activities (e.g. participating in use tests) from time perspective?

\section{Describing user's interests}

In contradiction to other stakeholders, users' interests restrict to the product. However, identifying expressing and understanding the product's users and their product interests, particularly regarding use aspects, is often difficult since they often depend on many non quantifiable aspects. However, Caroll (2000) states that use scenarios can support in expressing user's product needs. Expressing use needs in terms of scenarios does not only make clear what the use interest is; it also helps product developers to understand who the use interest has as well as where this interest originates from. Use scenarios are stories about people and their activities (Carroll 2000). Use scenarios describe who these people are, in which environment these people are, what happens to them in this environment and what they want to achieve within this environment.

Based on this explanation of the term 'use scenario' there can be concluded that use scenarios have characteristic elements existing out of a user, user's goal, the environment in which the user is located and the activities and possible events which takes place within this environment (Potts 1995).

\section{Defining the user}

Users have interest in a product that they can use. In user-centred product development it is important to have insight into user's abilities. According to the International Ergonomics Association (2010) it is common in ergonomics to approach users in terms of their cognitive as well as physical capacities and experience. Accordingly users can be described by means of their:

- Skills: the rate of physical experience (using a specific product) within a specific situation.

- Cognitive properties: user's mental processes and performance, such as perception, memory, reasoning and motor response, as they affect interactions with other people, objects and the environment in which they act. 
- Anthropometrical properties: user's anatomical, anthropometric, physiological and biomechanical characteristics refer to physical properties or performance as they relate to physical activity.

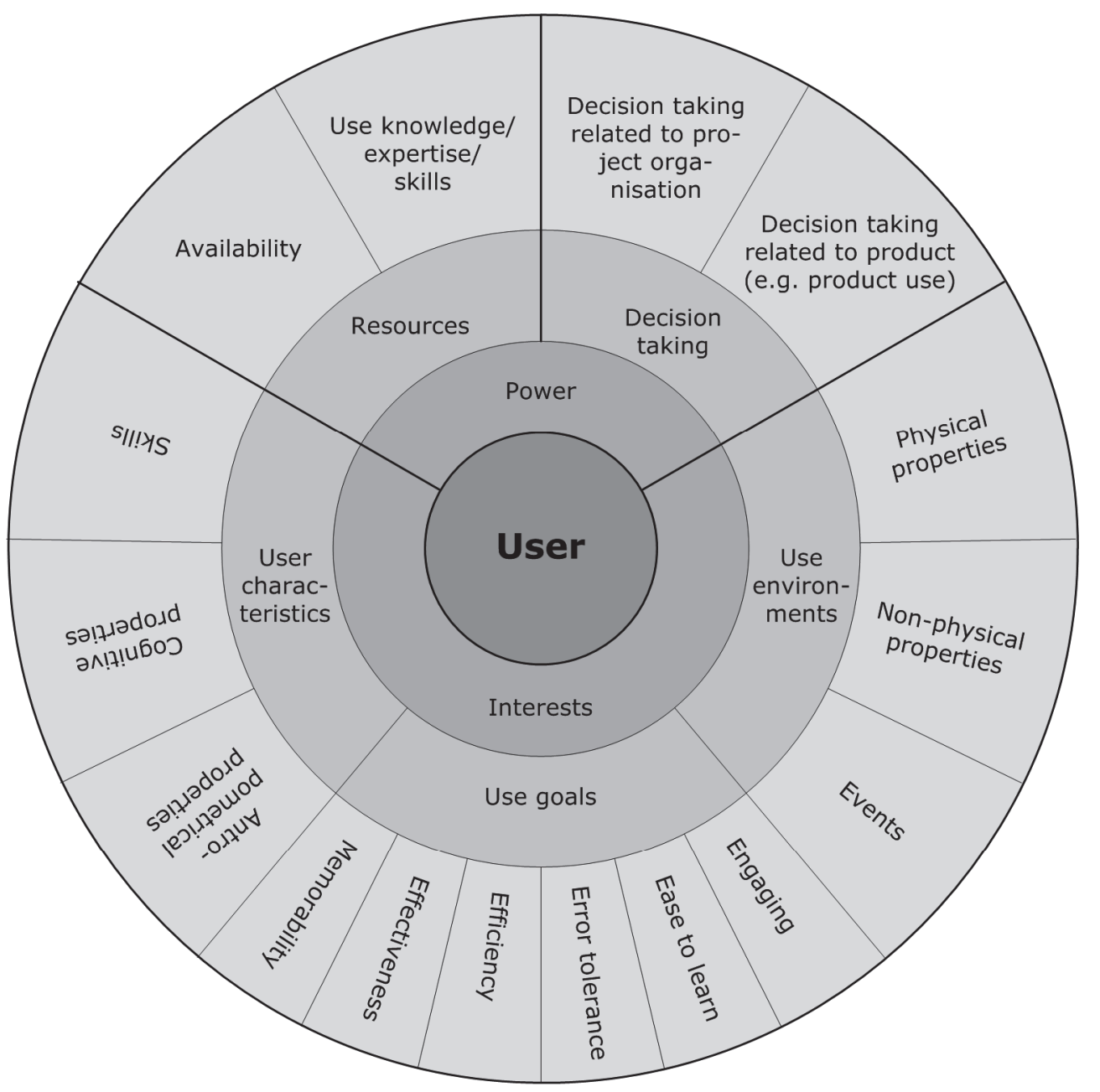

Consequences for project organisation
Consequences for company organisation

Figure 6.2 - A template that supports in specifying user's interests, power and their consequences. 


\section{Defining use goals}

According to the ISO9421 definition of usability, use goals can be expressed in terms of effectiveness, efficiency and satisfaction. Nielsen (2001) and Quesenbury (2001) furthermore discuss six characteristics which express these dimensions more precisely. These characteristics (see figure 6.2) are:

- Effectiveness: the rate to which the use of a product results in the intended effect;

- Efficiency: refers to the amount of effort that user has to spend to achieve this effect by using the product;

- Engaging: refers to how pleasant or satisfying it is to use a product;

- Error tolerance: refers to rate of errors users make and the ease to which they can recover from these errors;

- Ease to learn: refers to how difficult it is to learn to use the product in order to achieve the intended effect;

- Memorability: refers to the rate to which users can re-establish proficiency in using the product after they did not use it for some time.

\section{Defining the use environment}

Users use a product in a specific environment. Since the environment can influence the user's performance and use goals it is important to describe this environment. An environment is characterised by physical as well as non-physical properties. Physical properties refer to all physical dimensions and artefacts of and within the use environment, e.g. products, room dimensions, temperature, noise level or wind force. Non-physical properties refer to the expected or imposed way of behaviour of the user or use environment. Examples of non-physical properties of a use environment are codes of behaviour, atmosphere and working procedures. Furthermore also events which take place in an environment need to be described. Events are things that happen to the user in a specific situation. Events can influence the user, his goals or the use environment itself.

\subsection{Conclusions}

This chapter discusses what stakeholders are and why it is important to map them within product development. Furthermore this chapter discusses existing theory on stakeholder mapping.

An important conclusion of this discussion is that existing stakeholder theory is generic and focuses on classifying stakeholders based on their rate of interest in a project, power to influence the project's completion and therefore also their willingness to support a project. However, in order to make use of stakeholder mapping during the specification of user-centred product plan of approach it is also important to have a good understanding of the following aspects: 
- The actual interests of each stakeholder in a specific product development project;

- How each stakeholder can influence the course of a product development process as well as the product that results from that process;

- The possible consequences of both for the project and company.

Unfortunately, existing stakeholder mapping systems do not support in here. Therefore this chapter came up with templates that support in specifying above enounced aspects of stakeholders. These templates address the dimensions of stakeholders' interests, power and the possible consequences of both for the product development project and company in order to be useful for defining user-centred plans of approach.

However, it is only possible to use these templates once it is known which stakeholders need to be specified. Moreover, specifying a user-centred plan of approach does not restrict to specifying project's stakeholders. It also involves result planning, development method selection and development method specification. Therefore chapter seven addresses a method that supports in specifying a usercentred plan of approach and discusses how stakeholder specification supports in here. This discussion also addresses how the stakeholders that need to be specified can be determined. 


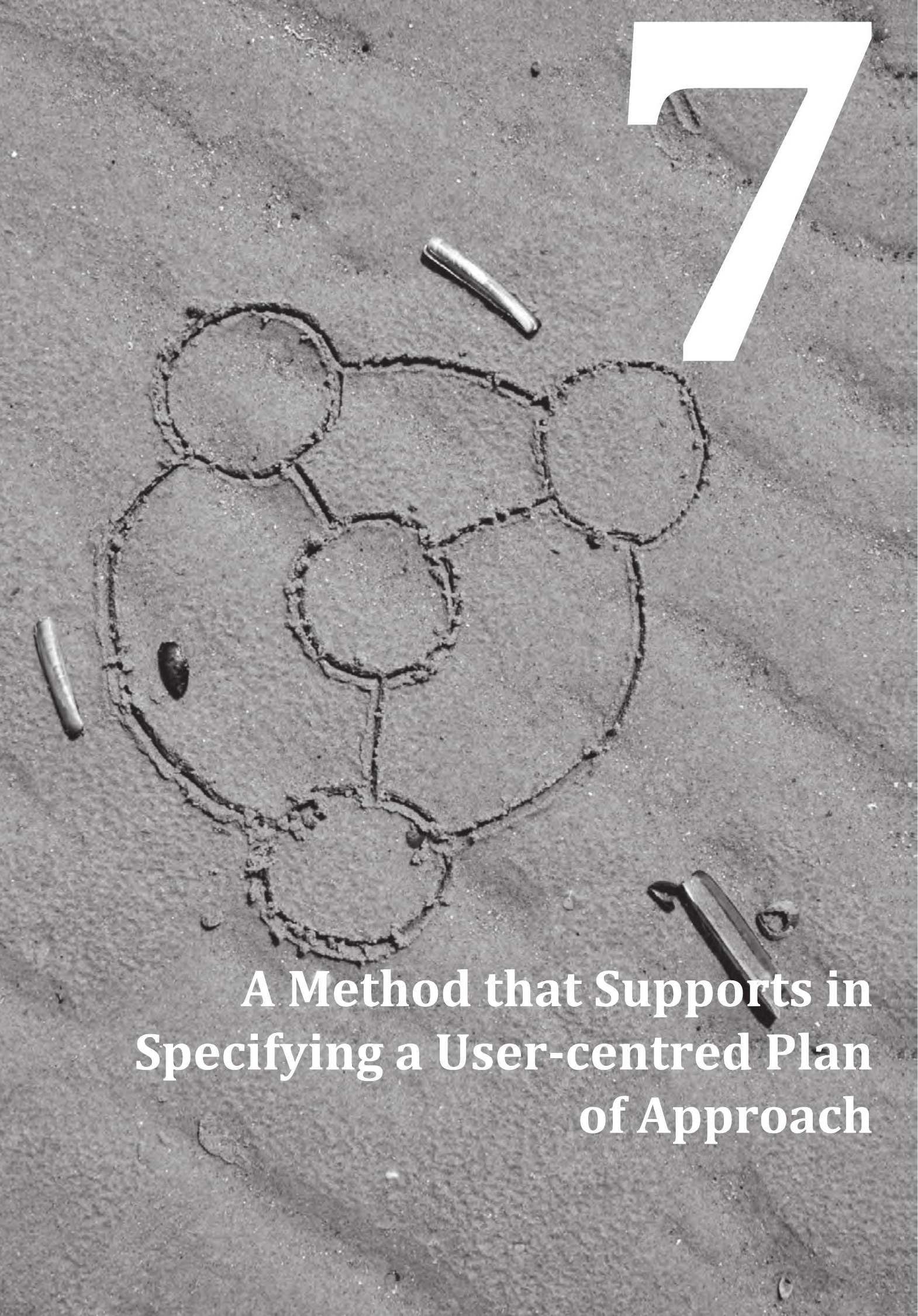




\section{7}

\section{A Method that Supports in Specifying a User-centred Plan of Approach}

\subsection{Introduction}

Practice based research shows that user-centred plans of approach are currently specified based on experience (Van Kuijk 2010; Van Eijk, Van Kuijk et al. 2012). There are no methods available to support product development teams in defining a univocal, effective and complete user-centred plan of approach. Therefore this chapter introduces a method that supports product development teams in specifying a detailed user-centred plan of approach in four steps, the UCD kick-off method. The UCD kick-off method will be elucidated in several steps. Section 7.2 first addresses aspects to consider while defining a user-centred plan of approach. Afterwards, section 7.3 will elaborate on the UCD kick-off method itself. Section 7.3.1 first discusses the UCD kick-off method's structure. In here discussion focuses on the main objectives and added value of the UCD kick-off method's four iterative steps. It furthermore discusses the characteristics of input which is required for using the method as well as the characteristics of the user-centred plan of approach which originates from it. Next sections 7.3.2 to 7.3.5 will address each of four iterative steps in detail.

\subsection{Aspects of a user-centred plan of approach}

According to Kerzner (2001) and PMI (2000), a detailed plan of approach should specify the following aspects: (1) elaborate product specification, (2) product conditions, (3) contextual conditions, (4) milestones, (5) development activities specifying (5a) development methods, (5b) development tasks and (5c) resources. Other project management related theory addresses similar aspects to specify in a plan of approach and provides a general definition of these aspects. Unfortunately, such general definitions do not provide sufficient support when defining a user- 
centred plan of approach since they do not address what should be specified per aspect regarding product use. Therefore this section introduces a use-related definition for each of these aspects and addresses what should be specified regarding product use for each of them.

\section{Elaborate product specification}

An elaborate product specification provides an objective interpretation of a future situation's image (Hekkert, M. et al. 2003; Hekkert, Van Dijk et al. 2011). In here a future situation may directly refer to the new product itself (features, functions, technology platforms, etc.) or the context in which the product is used, the users, the use environment, the interaction of the users and use environment with the product. According to Hekkert (2011) a product specification includes:

- A view on the essence of the problem in general and with respect to product use in particular

- A general idea about the expected solution direction:

o What kind of product will be developed?

o What are its main characteristics that influence its use, e.g. use of technology platforms, corporate identity and compatibility with other product or facilities?

- An insight or understanding of the product-user-use environment interaction:

o Who will use the product?

o Why will users use the product?

o Where and under which circumstances will users use the product?

An elaborate product specification supports development teams in their search for ideas during the development process. According to Hekkert (2003) and Cross, Christiaan et al. (Cross, Christiaans et al. 1996) it furthermore gives direction and therefore steers the user-centred development process. An elaborate product specification should be effectively sharable and inspiring for the whole development team e.g. by means of textual or visual representations.

\section{Product conditions}

Roozenburg \& Eekels (1996) state that product conditions are requirements and wishes which relate to the future use of the product as well as aspects that influence product use. Product use related conditions take the user, user's goals, the environment in which the product is used and the use situations into account. In here use situations can refer to both, normal use situations and extreme use situations in which the product is used. Product conditions can be qualitative or quantitative and must be met by the product. Just as a product vision, product conditions give direction to the user-centred development process. Roozenburg \& Eekels (1996) state that product conditions form a base for verification of design solutions during the user- 
centred development process. There are multiple ways to represent product conditions such as a written list of product criteria and wishes or use scenarios.

\section{Contextual conditions}

Kleinsmann (2006), Dorst (2008) and Van Kuijk (2010) state that contextual conditions influence the user-centred development process. However, most product development methods such as Pahl \& Beitz (1996) or VDI 2221 (1986), seem to neglect these conditions. Contextual conditions are boundary conditions evolving out of the development environment sketching limitations and possibilities to organise the user-centred development process. Boundary conditions are procedures, agreements, policies, rules, provisions or protocols which can refer to a wide range of company or product related aspects (e.g. product use) such as shown in table 7.1 (Van Kuijk, Hoolhorst et al. 2010).

Process level: User-centred product development methodologies, methods, techniques and tools

Project level: Planning, resources, innovativeness

Team level: Organisation, communication, attitude

Company level: Long-term orientation, innovation, organisation, company culture, management \& control, product line, brand position

Table 7.1 - Examples of company or product related aspects to which contextual conditions can relate (Van Kuijk, Hoolhorst et al. 2010).

\section{Milestones}

Cross (2006) discusses that, besides a detailed insight into the desired product characteristics, also a detailed insight into milestones within the development process is needed in order to define a user-centred plan of approach. Milestones subdivide the major project deliverables into smaller, more manageable components. Kernzer (2001) and PMI (2000) mention that milestones describe which and when intermediate results to deliver during the development process. Regarding product use, intermediate development results relate to both the information that should be provided with respect to product use aspects as well as the format in which the information needs to be available? In here information regarding product use can be expressed in terms of:

- User(s): What information should a milestone provide about the product's users in terms of:

o Skills: The rate of physical experience (using the specific product) within a specific situation.

o Cognitive properties: User's mental processes and performance, such as perception, memory, reasoning and motor response, as they affect interactions among humans and other elements of a system. 
o Anthropometrical properties: User's anatomical, anthropometric, physiological and biomechanical characteristics refer to physical properties or performance as they relate to physical activity.

- Use goal(s): What information should a milestone provide about users' reasons to use the product? Expressing use goals can be done in terms of:

o Effectiveness: The intended effect of using the product (functionality)

o Efficiency: What information must be provided regarding the way and effort by which user wants to achieve this intended effect by using the product

o Engaging: Product's rate of use satisfaction or pleasance

o Error tolerance: The rate of errors users make and the ease to which they can recover from these errors

o Ease to learn: How difficult it is to learn to use the product in order to achieve the intended effect

- Use environment(s): What information should a milestone provide about the environment and circumstances in/ under which the user(s) will use the product? This can be done in terms of:

o Physical properties: The physical dimensions and artifacts of and within the use environment. Examples of physical properties are (symbiotic) products, room dimensions, temperature, noise level or wind force.

o Non-physical properties: The expected or imposed way of behavior of the user or use environment. Examples of non-physical properties of a use environment are codes of behavior, atmosphere and working procedures.

- Other product specifications: What information must the milestone provide about other relevant product specifications that might influence product's use characteristics? In here one e.g. can think of required:

o Interaction of the users and use environment with the product

o Use of technological platforms or UI standards

o Compatibility with other existing products or facilities

\section{User-centred development activities}

PMI (2000) states that user-centred development activities refer to specific activities that must be performed to produce the various milestones. User-centred development activities need to be sequenced based on their identified interactive dependencies. To specify each (set of) user-centred development activity one should address:

- User-centred product development methods: Which method will be used to achieve the (set of) milestones? More detailed information about user-centred product development method's characteristics can be found in section 2.5

- User-centred development tasks: Sequence of scheduled actions which need to be done by the development team to achieve a milestone. It is important to define user-centred development tasks since they indicate how to apply a 
selected user-centred development method in the user-centred product development process. User-centred development tasks refer to actions which are needed to (1) prepare application of the user-centred development method, (2) to apply the user-centred development method or (3) to process data which are gathered during application of the user-centred development method.

- Required input: Input refers to information or sub-results (content as well as format), which are needed to (1) prepare application of the user-centred development method or development task, (2) to apply the user-centred development method or perform development task or (3) to process data which are gathered during application of the user-centred development method or development task in order to achieve the intended milestone. Required input can relate to:

o The selected user-centred development method itself: What should be known about the user-centred development method itself to be able to apply it?

o The context in which the selected user-centred development method will be applied: What should be known about the environment in which the selected user-centred development method will be applied, events that take place in this environment, the people who will be involved in application of the user-centred development method or the product that will be examined?

o Intended intermediate result: Input that is achieved as a result of the execution of previous product development activities.

- Resource allocation: PMI (2000) mentions that resources refer to any physical or virtual entity of limited availability that needs to be consumed to obtain a benefit from it. Project management literature distinguishes the following types of interrelating resources (Kerzner, 2001):

o Budget: The amount of money which stakeholders make available for development activities.

o Equipment: Tools, sources, disposables, hardware, software and facilities which can be used for development activities

o Time: Availability of stakeholders during a development project

o Knowledge/skills/information: Stakeholder's knowledge, skills and information which can be used during development activities.

Kerzner (2001), Wheelright \& Clark (1992), Joglekar \& Ford (2005) and Meyer \& Utterback (1995) state that resource allocation is important for several reasons. Resource allocation enables:

o Verification of the actual feasibility of the scheduled development activities in development practice.

o Managing the user-centred development process since an overview of scheduled resources enables identification of potential development 
process organisational problems or risks. It is possible to consider alternative development activities or objectives and streamline the usercentred development process based on the overview of potential development process organisational problems or risks.

o Product developers to get insight into which resources are available for the execution of each development activity.

A complete user-centred plan of approach includes the specification of all above mentioned aspects. However, it is only possible to specify these aspects when it is known how to specify them. Therefore the next section discusses a method that supports product development teams in four main steps in specifying these aspects towards a detailed user-centred plan of approach based on the specific characteristics of the product as well as the development environment.

\subsection{The UCD kick-off method}

\subsubsection{UCD Kick-off method's structure}

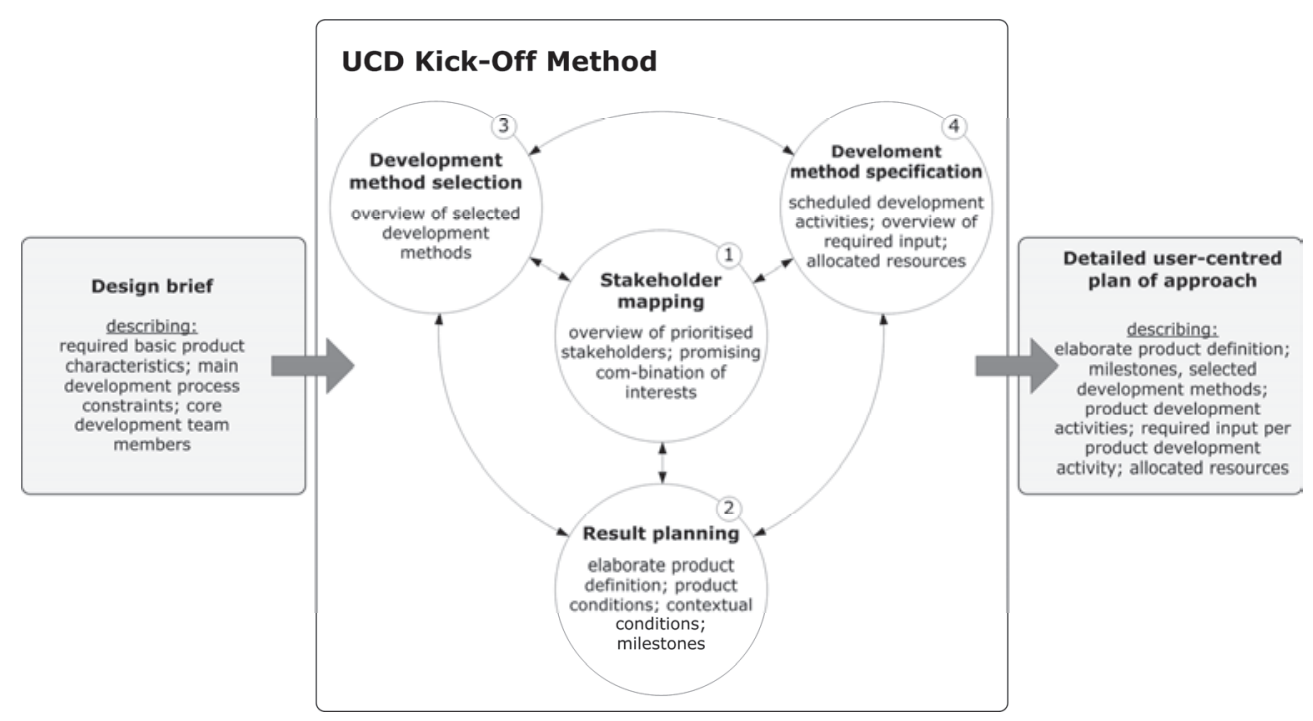

Figure 7.1 - Overview of the UCD Kick-off method describing four iterative steps.

The UCD kick-off method (see fig. 7.1) supports product development teams in defining a detailed user-centred plan of approach based on the specific characteristics of the product to be developed as well as the development environment. Since product use is only one out of many aspects to consider in product development (Boivie, Gulliksen et al. 2006; Gulliksen, Boivie et al. 2006; Van Kuijk 2010), this method focuses on product use, but does not exclude other product aspects. The UCD kick-off 
method supports in considering all relevant aspects while defining a user-centred plan of approach. Input for the method is a design brief describing the desired basic product characteristics, process and project constraints and the core development team. Output of the method is a detailed user-centred plan of approach describing the intended product characteristics, intermediate development results, selected development methods, development activities, input per development activity and allocation of resources. The UCD kick-off method provides support regarding four interrelating steps. Each of these main steps focuses on one of the following four main questions which need to be answered while defining a user-centred plan of approach:

1) Stakeholder mapping: Who are stakeholders in the product development project with respect to product use?

2) Result planning: Which product use needs must the product meet and which user-centred milestones need to be achieved during the product development process to satisfy the stakeholders?

3) Development method selection: Which user-centred development methods will be used to achieve the defined milestones?

4) Development method specification: How to apply the selected user-centred development methods in the product development process?

The following sections describe these four main themes and discusses which steps need to be taken in order to answer these questions.

\subsubsection{Stakeholder mapping}

Stakeholder mapping, exists out of two sub-steps, respectively (1) Mapping stakeholders and (2) Combining stakeholders' interests (see fig. 7.2). The first step, Mapping stakeholders, focuses on making a complete overview of stakeholders for the product development project. Concluding Van Kuijk (2010), this is important since product developers' lack of a complete overview of stakeholders is an important aspect that causes of use problems (see also Chapter 6). The second step, Combining stakeholders' interests, focuses on making a promising combination of focus interests for the product development project based on a prioritised stakeholder overview. Making a promising combination of focus interests is important since it is often not possible or needed to satisfy all stakeholders' interests within a product development project for technical, project organisational or market reasons. Both, the overview of stakeholders and the promising combination of focus interests support the next steps of the UCD Kick-off method, i.e. defining a product vision and milestones as well as the contextual conditions regarding the user-centred product development process. 


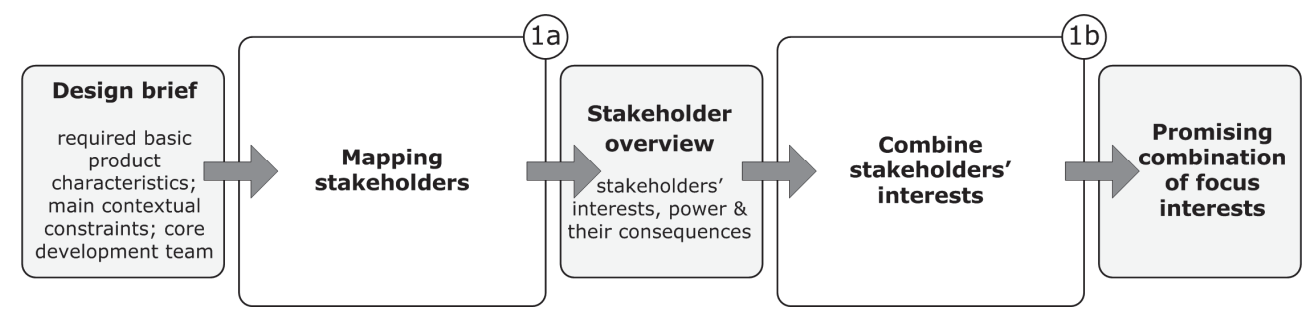

Figure 7.2 - Step 1: Stakeholders mapping.

\section{1a) Mapping stakeholders}

The first sub-step focuses on making a complete overview and specification of stakeholders for the product development project. Making such an overview and specification minimizes the risk that important stakeholders are overseen.

Based on the design brief, mapping stakeholders starts with listing stakeholders who possibly have interests in project. In here their interests can relate to the user-centred product development process or the use related aspects of the product that originates from it. Table 7.2 shows that within user-centred product development processes two types of stakeholders can be distinguished: external stakeholders and internal stakeholders (1983; Freeman 1984; 1990; 2001). In here, external stakeholders refer to parties or individuals outside the company; internal stakeholders refer to parties or individuals inside the company.

\begin{tabular}{l|l} 
External stakeholders & Internal stakeholders \\
Users: & Team: \\
- Professionals & $\bullet \quad$ Core team \\
- Consumers & - extended team (e.g. department \\
Buyers: & representatives) \\
- Buyer-to-buyer & Company: \\
- Buyer-to-consumer & $\bullet \quad$ Corporate as a collective \\
Clients (e.g. retailers, service providers) & $\bullet \quad$ Upper management \\
Suppliers (e.g. technological platform) & $\bullet$ Departments
\end{tabular}

Table 7.2 - Overview of external and internal stakeholders in a product development project (Van Kuijk 2010).

Afterwards, once an overview of external and internal stakeholders has been made, each of them needs to be specified. Specification of each stakeholder can be done by means of the templates that are discussed in section 6.5. The templates support in specifying stakeholder's (product use related interests) interests in the product development project, power to influence the project and the consequences of both for the product, user-centred product development process and the company. This substep results in a specified overview of all project stakeholders. 


\section{1b) Combining stakeholders' interests}

The second sub-step focuses on making a promising combination of focus interests for the product development project based on the complete overview of the stakeholders and their interests. Making such a promising combination is done by means of four iterative steps (see fig. 7.3).

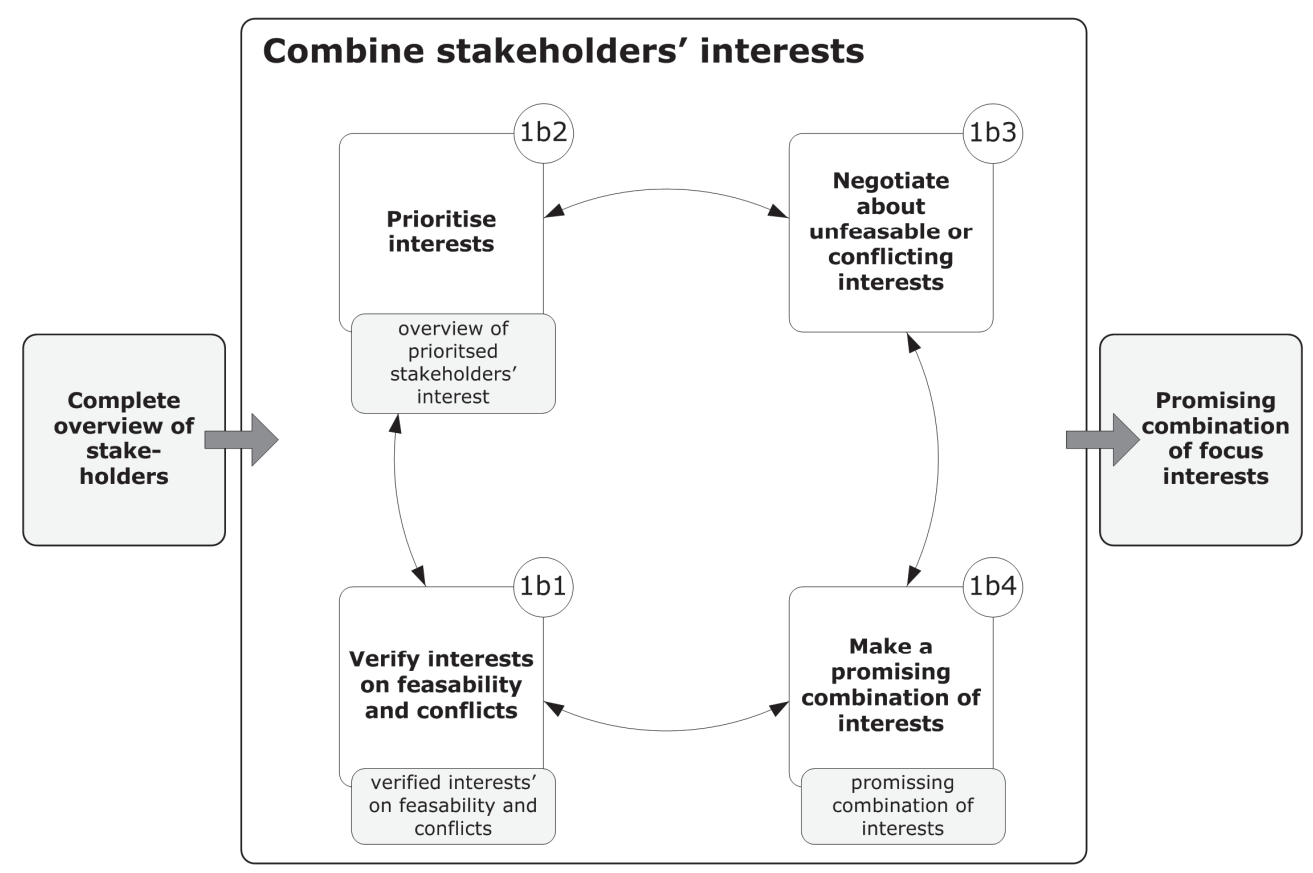

Figure 7.3 - Sub-step 2: Combine stakeholders' interests.

1b1) Verify interests on feasibility and conflicts: Dealing with a variety of stakeholders' interests can be problematic or impossible during a product development process. Some stakeholders' interest might conflict each other or are unfeasible to be met during the product development process. To avoid or calculate risks related to product use and the user-centred product development process, it is necessary to have insight into which extent stakeholders' interests regarding product use are expected to conflict each other or are expected to be unfeasible from a product technical, project organisational or market perspective.

1b2) Prioritise interests: Some stakeholders' interests are more important for the product development project than others. Focusing on their impact, prioritising stakeholders' interests can therefore help in making a promising 
combination of stakeholders' interests. Prioritising interests can possibly been done based on the following two questions:

1) What are the adverse consequences regarding product's usability, the project organisation and the company in case a stakeholder interest is not met?

2) How beneficial is it for product's usability, the project organisation and the company to meet an interest?

1b3) Negotiate about unfeasible or conflicting interests: In some cases negotiation with stakeholders ensures that conflicting interests become more in line with each other or increases their feasibility within the product development project. Insight into conflicting or unfeasible stakeholders' interests supports in determining which stakeholders' interests need to be negotiated. Before negation it is important to determine which stakeholders' interests can be negotiated and if they are worthwhile to negotiate. In here the following questions are important to answer.

- Is the conflicting or unfeasible interest of a stakeholder of enough importance for the product development project to negotiate on?

- Is it possible to contact the stakeholder?

- To what extent are these stakeholders willing to negotiate on their interests?

Afterwards, agreements stakeholder interest negotiation activities need to be made among workshop participants based on the results of above enounced questions. In here it is important to agree on who will negotiate stakeholders' interests as well as when the results of these negotiations need to be available.

1b4) Make a promising combination of interests: Specify the combination of interests that at least need to be met for a successful completion of the product development project. In here the product development project refers to the product development process as well as the product that originates from it. Making a promising combination should be based on the results of the previous steps, i.e.:

- Insight in feasibility and conflicts of interests

- Prioritisation of interests

- Results of negotiations about unfeasible and conflicting in interests

When selecting stakeholders' interests, one should not automatically restrict to selecting stakeholders' interests which are indicated as important. Some stakeholders might be indicated as less important to the project. However, they can share a similar interest. These stakeholders as a set might be important and therefore valuable to select. Furthermore, automatically selecting non-conflicting stakeholders' interests should be 
avoided. Although a challenge, a product which meets conflicting interests might be very successful on the market. Finally there should be mentioned that making a promising combination of focus interests does not involve that interests of stakeholders that are not selected are not valuable to be met during the product development process. However, these interests do not need to be met in order for the project to succeed.

The prioritised overview of stakeholders and their interests as well as the promising combination of interests can be used as input for the second step of the UCD kick-off method: Result planning.

\subsubsection{Result planning}

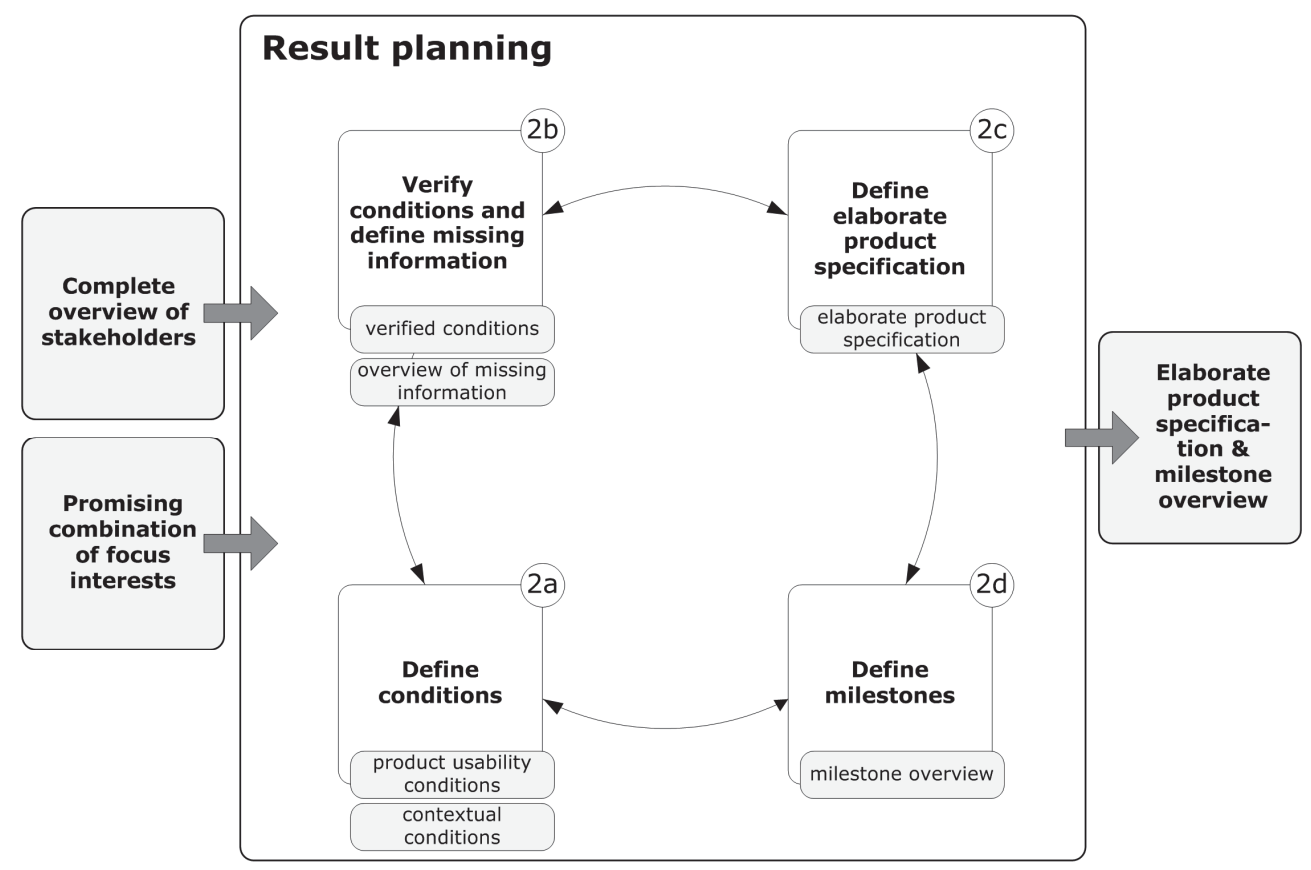

Figure 7.4 - Step 2: Result planning.

Cross (2006) states that, due to the product-process relation, detailed insight into the desired product characteristics as well as the milestones of the development process is needed in order to define a user-centred plan of approach. Furthermore contextual conditions, such as available time and budget, influence the specification of the usercentred product development process (Kleinsmann 2006; Dorst 2008; Van Kuijk 2010). However, most product development methods, such as Pahl \& Beitz (1996) or VDI 2221 (1986), seem to neglect these conditions. Therefore the second step (see fig. 
7.4) aims at making a detailed overview of (1) desired product characteristics by means of (1a) product conditions and (1b) an elaborate product specification, (2) milestones and (3) contextual conditions by means of the following sub-steps.

2a) Define conditions: Make overviews of (use related) product conditions and contextual conditions based on the design brief, the overview of described stakeholders and the promising combination of focus interests.

2b) Verify conditions and define missing information: Make a reliability assessment of the product use conditions, contextual conditions as well as the information both kinds of conditions are based on. In here the following systematic steps need to be taken:

1) Make an overview of known or assumed information about the product, its intended use characteristics and product development context based on the design brief, the elaborate product specification, the overview of product conditions and overview of stakeholders.

2) Indicate to which extent the collected information is reliable and relevant to realise a product which meets the intended product characteristics.

3) Decide which of the available information regarding the product, its intended use characteristics and product development context needs to be verified on reliability based on its reliability and relevance indication.

4) List which relevant information regarding the product, its intended use characteristics and product development context is missing.

A reliability assessment of existing information and an overview of missing relevant information regarding the product, its intended use characteristics and product development context can support in defining an elaborate product specification and milestones.

2c) Define elaborate product specification: Make an elaborate product specification based on the design brief, the overview of selected and specified stakeholders and the overview of verified product conditions. Compared to the overview of verified product conditions, the elaborate product specification provides a coherent, concrete and univocal view on the product that needs to be developed as well as the circumstances under which this product will be used. The elaborate product specification forms a starting point for defining milestones. An elaborate product description needs to be realistic and expected to be feasible within the given product development context. Therefore the contextual conditions, such as time or budget restrictions, need to be taken into account while writing the elaborate product description. 
2d) Define milestones: Define and schedule milestones which need to be achieved during the product development process based on the elaborate product definition, the overview of product conditions and the overview of missing relevant information regarding the product, its intended use characteristics and product development context. Milestones need to be realistic and feasible to achieve during the product development process. Therefore the contextual conditions which e.g. prescribe required milestones or time and budget limitation, need to be taken into account when defining milestones.

Roozenburg \& Eekels (1996) state that overviews of product conditions and contextual conditions, missing information, product vision and milestones are dynamic documents which require updating during the user-centred development process based on insights regarding product's usability and the user-centred development process. The updated documents should subsequently be used to adjust the user-centred plan of approach.

\subsubsection{Development method selection}

Daalhuizen (2008) states that product developers automatically tend to stick to development methods they are familiar with without questioning if these development methods fit the desired milestones. Therefore the third step supports in explicitly exploring and selecting appropriate and feasible development methods which lead to the desired development results. Based on the overview of scheduled (intermediate) product development results, exploring and selecting development techniques is done by means of the following three sub-steps.

3a) (Pre-)select development methods: Explicitly explore and (pre)select development methods which are expected to lead to the obtained development results. To reduce product use problems exploration and selection of development methods is preferably done based on the desired milestones. Finally, it must, in principle, be possible to achieve the desired milestones by means of the application of the selected method Since product developers tend to stick to development methods they are familiar with, wider exploration of development methods might lead to selecting development methods which fit better to the desired quality of the milestones (Daalhuizen, Badke-Schaub et al. 2008). In here quality refers to the quality of result's content as well as result's format. There are many user-centred design focused (web) tools available which support in wider exploring and selecting development methods. Examples of such tools are such as IDEO Methods Cards (2002), Generic Process 1.0 (2006) or UsabilityNet (2006). 


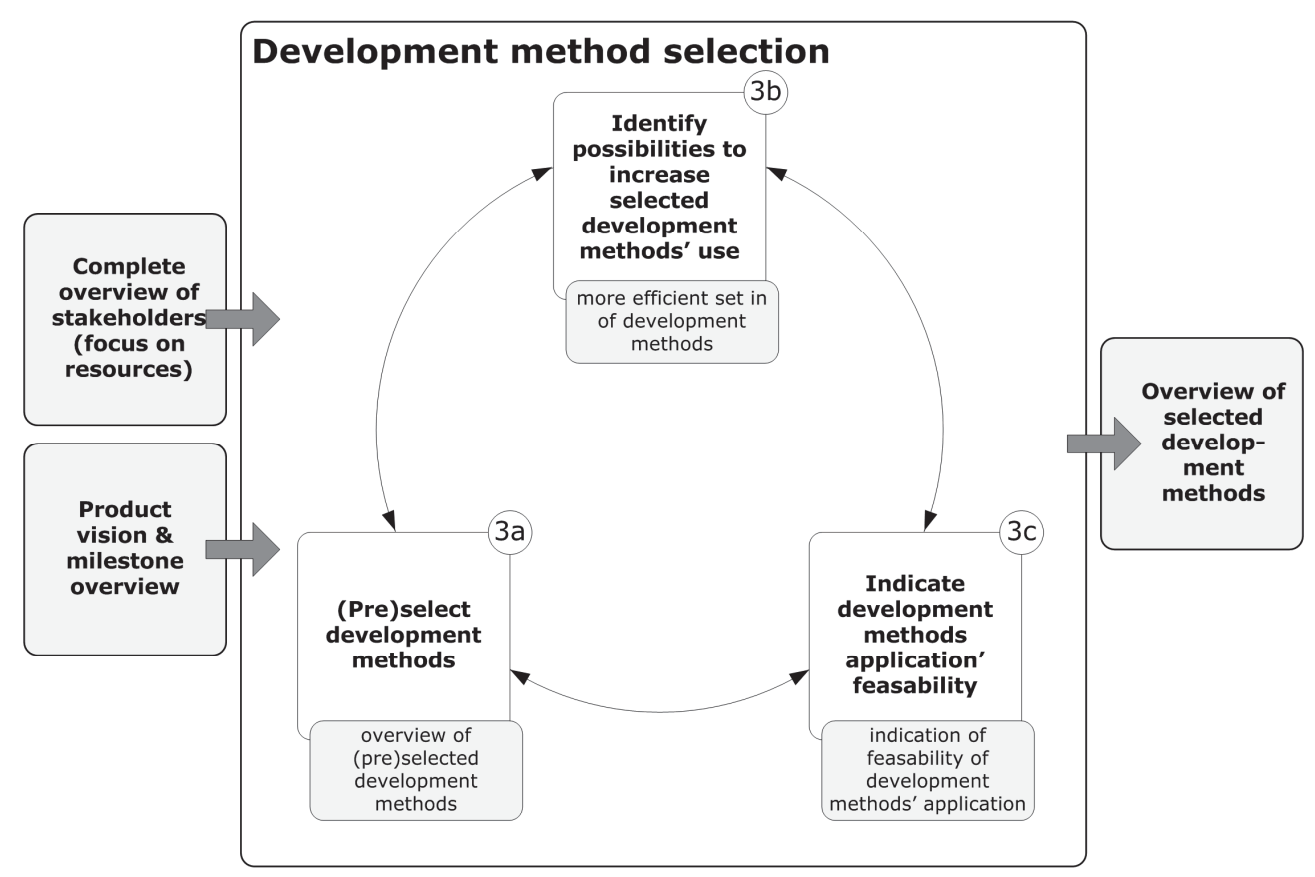

Figure 7.5 - Step 3: Development method selection.

3b) Identify possibilities to increase selected development methods' use: Verify to which extend the selected development techniques' use efficiency during the development process can be optimised based on the desired milestones. It is possible to distinguish the following two types of efficiency within the development process:

- Parallel efficiency: To which extend is it possible to obtain different intermediate development results at the same time using one development method?

- Sequential efficiency: To which extend is iterative use of a development method during the user-centred development process possible?

Optimising development method's efficiency shortens the development process since it allows achieving multiple development results at the same time or shortens preparative development activities needed to apply the chosen development technique.

3c) Indicate application feasibility of selected development methods: Indicate to which extend it is feasible to practically apply selected development methods in the user-centred development process. It is possible to indicate development methods' application feasibility from several perspectives, such as: 
- Economical: To what extend is expected that resources are available to apply a selected development method. In here resources refer to budget, time, skills, information and knowledge, people, equipment and environment.

- Product development contextual: Is it feasible to apply the development method within the product development context? Considering this aspect can be done based on the overview of contextual conditions which e.g. relate to corporate development methods or company culture (also see table 7.1).

- Ethical: Are there ethical drawbacks to use a development method? It is possible to approach ethical drawbacks from many perspectives such as social, environmental, financial, physical, mental or historical.

This sub-step provides an overview of issues which would need attention during the development method specification step.

Chosen development methods are input for the fourth step of the UCD Kick-off method: Development method specification. This fourth step addresses how chosen development methods will be applied during the user-centred product development process.

\subsubsection{Development method specification}

Only selecting a development method does not guarantee that intended milestones will be achieved during the user-centred development process (Van Kuijk 2010). Further specification of the actual application of the selected development technique is needed since it is still not clear how to apply the selected development method (Hoolhorst 2010; Van Kuijk 2010). This specification step exists out of two iterative steps. The first step focuses on describing required development activities; the second sub-step on allocation of resources. Defining required development activities gives insight into what steps will be executed during the product development process and their sequence. Allocating resources gives insight into required time, budget, equipment and people to execute each development activity.

\section{4a) Define required development activities}

Determine product development activities. In here product development activities can refer to activities that need to be undertaken to:

- Prepare application of the development method;

- Apply the development method;

- Process data which are gathered during application of the development method.

Determining product development activities starts with making an overview of input that is required to be available per product development method/milestone 
combination. This input refers to information that is required to be available in order to actually apply the selected product development method and can refer to the:

- Selected development method: What should be known about the selected development method itself to be able to apply it?

- Application context: What should be known about the environment in which the selected development method will be applied, events that take place in this environment, the people who will be involved in application of the development technique or the product or that will be examined?

- Intended intermediate results: Which information or knowledge is required to apply the selected development method in terms of content, detail level and format?

Then define product development activities per development method/milestone combination based on the overview of required input per development method/milestone combination.

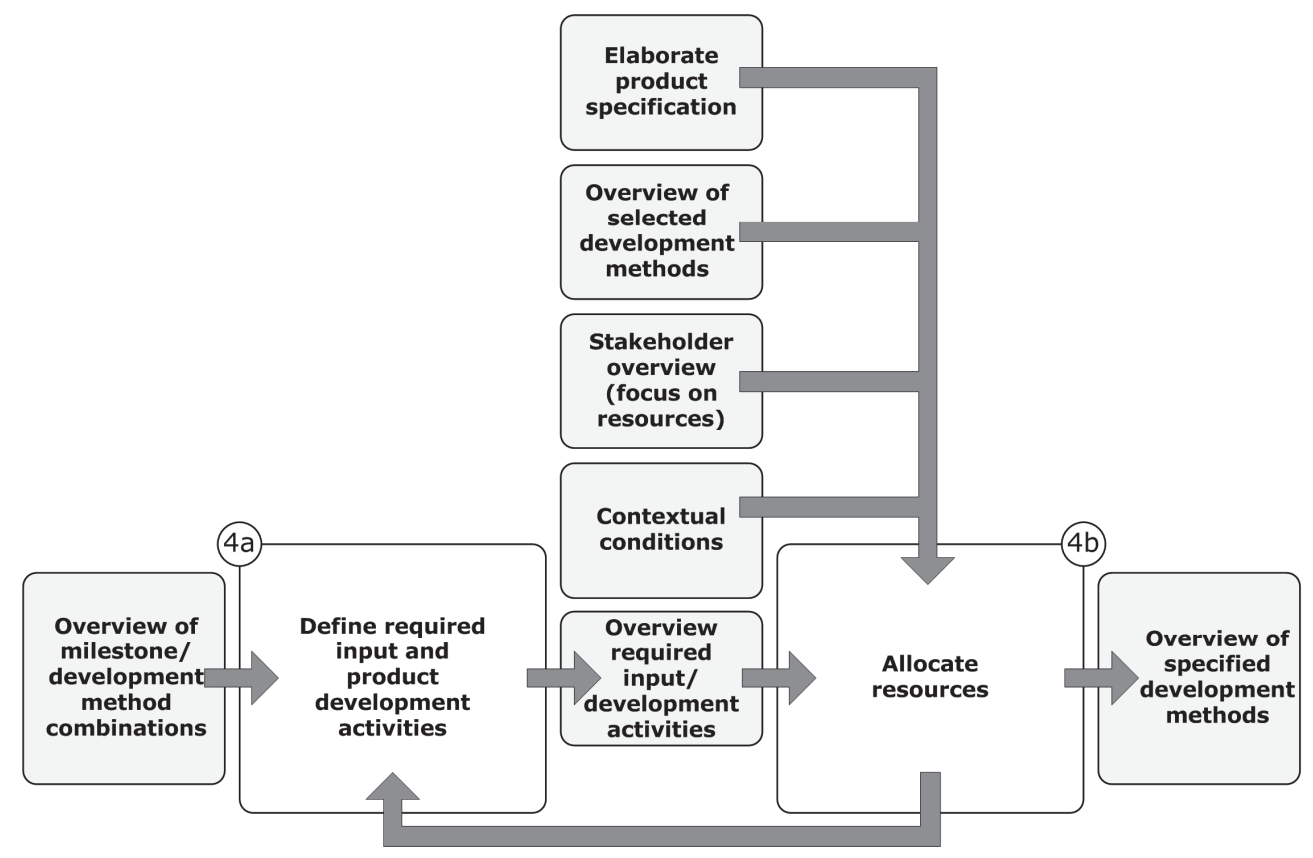

Figure 7.6 - Step 4: Development method specification.

\section{4b) Allocate resources}

The PMI (2000) states that resource allocation is planning the use of available resources to achieve goals for the future. The challenge in resource allocation is to determine what resources are needed in which quantity to execute a development activity. 


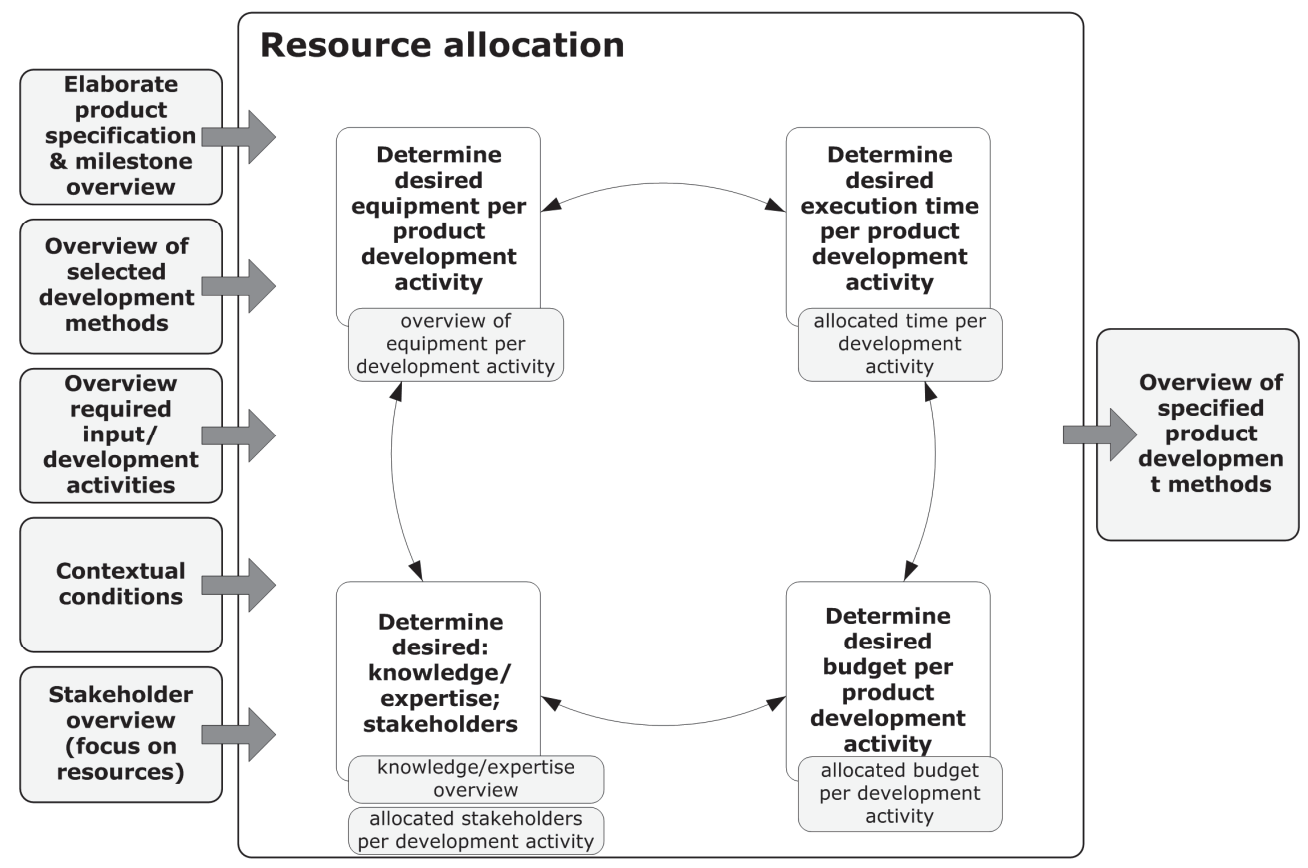

Figure 7.7 - Sub-step 2: Resource allocation.

Based on the overview of available resources it is possible to allocate resources to each of the scheduled development activities. This resource overview is output of the stakeholder mapping which has been discussed in section 7.3.2. Figure 7.7 shows that allocating resources can be done by means of the following four iterative steps:

- Determine desired knowledge/expertise per product development activity and allocate stakeholders;

- Determine desired equipment per product development activity;

- Determine desired execution time per product development activity;

- Determine desired budget per product development activity.

The sequence in which these steps are executed depends on the resource type that is leading in the allocation of resources. Furthermore, these iterative steps do not have a finite sequence. Allocating resources gives the product development team insight into the resources that are available for each of the product development activities that need to be executed.

\subsection{Conclusions}

This chapter discussed the UCD Kick-off method; a reference method that supports product development teams in specifying a user-centred plan of approach for their product development assignment. Input for the method is a design brief describing desired basic product characteristics, process and project constraints and the core 
product development team. Output of the method is a detailed user-centred plan of approach describing intended product characteristics, intermediate development results, selected development methods, development activities, input per development activity and allocation of resources. The method focuses on product use, but also allows the inclusion of focus on other product aspects in the plan of approach. The UCD Kick-off method supports in achieving the following four main objectives regarding the specification of a user-centred plan of approach.

\section{Stakeholder mapping}

The lack of a complete overview of stakeholders is an important aspect that causes of use problems. Therefore the method supports in identifying all stakeholders to the product development process (including the product development team members) in the process of writing the plan of approach. For each of them their interests as well as their possible contribution in the form of expertise/skills, decision taking, equipment, availability and budget is defined.

\section{Result planning}

Detailed insight into the desired product characteristics as well as the intermediate results of the development process is needed in order to define a user-centred plan of approach. Furthermore contextual conditions, such as procedures, agreements, policies, rules or protocols, influence the specification of the user-centred product development process. Therefore, the UCD Kick-off method supports in specifying the expected end results of the project as well as all milestones needed to achieve these end results in terms of content and format. It furthermore supports in gaining insight into the contextual conditions as well as their implications for the product development process and the product's use characteristics in the process of writing the plan of approach.

\section{Development method selection}

Product developers tend to stick to development methods they are familiar without questioning if these development methods fit the intended development results. The UCD Kick-off method supports product development teams in investigating a wide range of methods and tools that can be applied to realise the needed intermediate results.

\section{Development method specification}

Only selecting a development method does not guarantee that intended development results will be achieved during the product development process. Further specification of the actual application of the selected development method is needed. The UCD Kick-off method therefore also supports products in specifying when, how, by whom and with what means they will be applied. 
Furthermore, application of the UCD Kick-off method is expected to have an additional advantage. The UCD Kick-off method is expected to support team collaboration. In current product development practice, plans of approach are usually specified by only one person, in most cases the project manager. However, the method that has been developed within this research stimulates to specify the user-centred plan of approach as a team. In this way each product development team member gets familiar with the full plan of approach. As a result team members are more aware of which role(s) they have during the product development process and which deliverables are expected from them during each product development activity in terms of content and format and where they are used for. Furthermore, they have a good overview of the budget, time as well as equipment that can be used per product development activity.

The UCD kick-off method has been developed based on the development statement and specifications which were formulated in Chapters 2 to 4 . Next step in the development of the method is to validate and assess the UCD kick-off method in product development practice in order to gain insight into its actual applicability scope as well. The next chapter will therefore discuss the assessment and validation of the UCD kick-off method. 


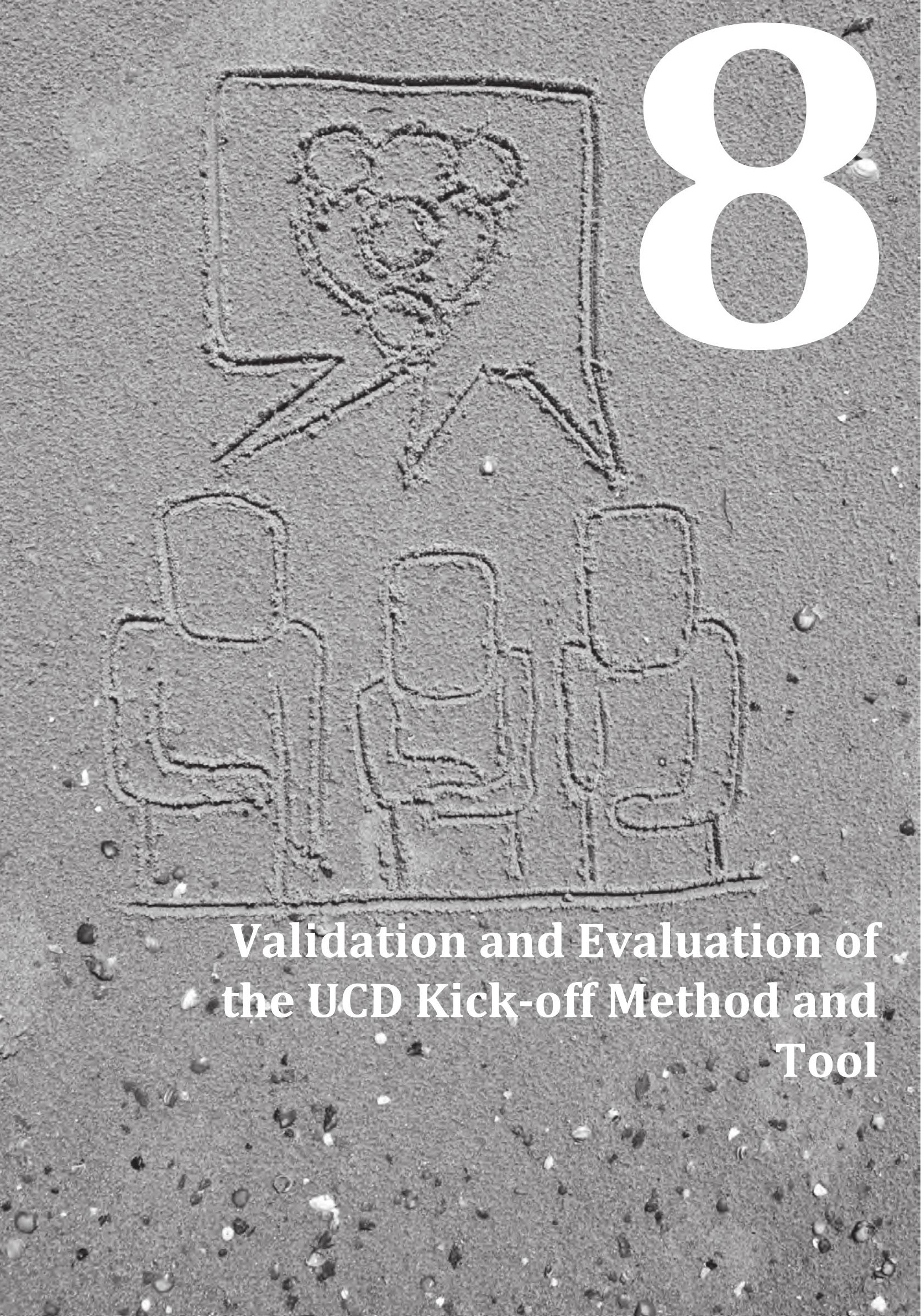




\section{8}

\section{Validation and Evaluation of the UCD Kick-off Method and Tool}

\subsection{Introduction}

Chapter 7 discussed a method that supports product development teams in systematically defining user-centred plans of approach for their specific product development assignment: the UCD Kick-off method. The next step in this research focussed on gaining insight in the actual viability of the UCD Kick-off method in product development practice. To this aim a study was conducted in the form of a workshop at the DfU symposium 2011- Usability Methods and Tools. In two individual assignments, workshop participants were asked to reflect on twelve principles which represented the main characteristics of the UCD Kick-off method. The results of both assignments gave insight in the extent to which plans of approach are defined and communicated at this moment in product development practice as well in workshop participants' opinion towards the expected added value of the UCD Kick-off method in their product development practice.

In order to make the UCD Kick-off method applicable and accessible for product development practice, the content of the method as described in Chapter 7 is made available in the form of a workshop. A workshop manual, the UCD Kick-off tool, will be composed to support product development teams in preparing and executing the UCD Kick-off workshop. A validation study was conducted to gain insight into the practical support (both content and format) that the workshop manual should provide to make the UCD Kick-off method applicable in design practice. Another aim of this validation study was to investigate to what extent product developers understand the UCD Kickoff method's methodical template. Furthermore the validation study was performed to gain insight into the actual expected applicability scope of the UCD Kick-off method and tool in daily product development practice. 
The validation study was conducted during two workshops in which employees of three industrial partners participated. In here, workshops participants were asked to reflect on preliminary version of the UCD Kick-off tool. This preliminary version of the workshop manual was made to trigger discussion regarding the research aims rather than it had to be seen as a final concept for the UCD Kick-off tool. Besides of insight into the comprehensibility of the UCD Kick-off method's template and expected applicability scope, the validation study resulted in an overview of advises and suggestions for a usable and understandable UCD Kick-off tool.

Based on these advises and suggestions, the UCD Kick-off tool was developed. To assess this workshop manual, an evaluation study consisting of another series of workshops was organised. The employees of both design agencies that also participated in the validation research were asked to reflect on the UCD Kick-off tool. They were asked to reflect on the usability of this workshop manual by means of a UCD Kick-off tool walkthrough. The workshop resulted in suggestions for improvements based on which the UCD Kick-off tool was updated.

\subsection{Insight into UCD Kick-off method's viability}

This research introduced a method that supports product development teams in systematically specifying user-centred plans of approach for their specific product development assignment: the UCD Kick-off method. The development statement as well as the verified criteria, which were formulated in Chapters 2 to 4, were used as a frame of reference for the development of this method. However, although the UCD Kick-off method meets this development statement as well as the verified criteria, this does not automatically involve that it is actually viable in product development practice. Therefore a viability study was conducted that provides insight into the method's viability in product development practice.

The development of the UCD Kick-off method resulted in a method that meets twelve main principles regarding specifying a user-centred plan of approach. Table 8.1 shows these twelve main principles. The method is expected to be viable in case it adds value compared to the way in which user-centred plans of approach are currently defined and communicated in product development practice. Therefore the first goal of the viability study was to gain insight into what actual value the UCD Kick-off method adds to the way in which user-centred plans of approach are defined and communicated currently. A measure for this is the extent to which the way in usercentred plans of approach are currently formulated and communicated is consistent with the main principles of the UCD Kick-off method. The second goal was to gain insight into the extent product developers expect that the UCD Kick-off method could improve their plans of approach and thereby also the organisation of their product development process. 
Principles:

1. For each product development process a dedicated user-centred plan of approach is formulated.

2. Each member of the product development team is familiar with the full plan of approach.

3. The plan of approach explicitly addresses the expectations regarding the usability of the product to be designed and its use situations.

4. The project team is dynamically defined as members are added or withdrawn from the team during the product development process based on the need for their contribution.

5. In the process of writing the plan of approach team members are aware of the contextual conditions (such as procedures, agreements, policies, rules or protocols) as well as their consequences on the product development process and the product usability.

6. In the process of writing the plan of approach all stakeholders to the product development process (including the development team members) have been identified. For each of them their interests as well as their possible contribution in the form of expertise/skills, decision taking, equipment, availability and budget is defined.

7. The plan of approach states not only the expected end results of the project, but also indicates all intermediate results needed to achieve these end results in terms of content and format.

8. In the process of writing the plan of approach a wide range of methods and tools that can be applied to realise the needed intermediate results have been investigated (i.e. beyond the range of methods and tools team members are most familiar with).

9. Methods and tools included in the plan of approach have been selected based on their effectiveness and efficiency to generate the required results as well as on their fit to the resources and skills available for this specific project.

10. The plan of approach not only defines the methods and tool to be applied, but also specifies when, how, by whom and with what means they will be applied.

11. Team members know which role(s) they have during the product development process and which deliverables are expected from them during each design activity in terms of content and format and where they are used for.

12. Team members have a good overview of the budget, time as well as equipment that can be used per design activity.

Table 8.1 - Overview of twelve main principles that are met by the UCD Kick-off method.

\subsubsection{Setup viability study}

The viability study was conducted during a workshop at the DfU symposium 2011 Usability Methods and Tools in Utrecht, The Netherlands. In total 43 employees from a wide variety of large, mid-size or small companies or design agencies participated in this workshop. Workshop participants all had at least some experience in usercentred product development or project management related to user-centred product development. The workshop allowed collecting the opinions of a wide range of potential users regarding the UCD Kick-off method's viability.

Based on the discussed goals of this viability study, the following research questions were formulated to gain insight into the formulation of user-centred plans of approach in the current product development practice:

1) To what extent do product development teams currently formulate usercentred plans of approach according the UCD Kick-off method's twelve main principles? 
2) To what extent are user-centred plans of approach communicated and available for product developers during the product development process in accordance with the UCD Kick-off method's twelve main principles?

3) To what extent do workshop participants think that their user-centred plans of approach, and therefore also the organisation of their product development process, can be improved?

The workshop started with a short introduction to familiarise workshop participants with the workshop's aim and importance of formulating user-centred plans of approach within product development projects. Next, to gain insight into UCD Kick-off method's viability and answer the above mentioned research questions, workshop participants were asked to make two assignments in which they were asked to reflect on the twelve main principles of the UCD kick-off method. They had to reflect on the twelve principles from the perspective of the organisation of their own product development practice. Since participants were employed within different companies and the organisation of product development within each of these companies has its own unique characteristics, workshop participants were asked to make both assignments on an individual basis.

\section{Assignment I}

The first assignment related to the first two research questions. Workshop participants were invited to give insight into the extent to which user-centred plans of approach were formulated, communicated and available within their product development practice. In here, each workshop participant received a form which listed the twelve principles of table 8.1. Workshop participants were asked to rate the extent to which each statement was applicable to their own product development practice by ascribing a number between 0 and 10 . Workshop participants rated a principle with a 0 in case this statement was completely not applicable and with a 10 in case a statement was very applicable for their product development practice. Workshop participants were asked to hand in their form after rating the principles.

\section{Assignment II}

The second assignment related to the third research question. Within this assignment workshop participants were asked to indicate the three principles that were least applicable to their product development practice. These principles indicated the aspects of their process organisation that could be improved in order to optimise their user-centred product development process and therewith reduce product development process delays or use problems for the products. Workshop participants were asked to anonymously indicate their selected principles on posters in front of the workshop room. The results on these posters were discussed once all participants finished the assignment. 


\subsubsection{Research results}

This section discusses the outcome of the workshop. As a first step the data that was collected during both workshop assignments was processed.

\section{Data processing assignment I}

Finally 40 out of 43 workshop participants completed the first individual workshop assignment successfully.

Next, the scores that were given to each principle were coded. A statement was labelled as 'never applicable' to their product development practice in case participants indicated this principle with a score between 0 and 2. Principles were labelled as 'sporadic applicable' in case participants indicated this statement with a score from 3 to 5 . Principles were labelled as 'often applicable' in case participants indicated this principle with a score of 6,7 , or 8 . in case principles were 'always applicable' to participants product development practice, they were indicated with a score of 9 or 10 .

Next the percentage of the stakeholders that labelled each principle as respectively 'never applicable', 'sporadic applicable', 'often applicable' or 'always applicable' for their product development practice was calculated. Figure 8.1 gives an overview of these percentage distributions for each statement.

\section{Data processing assignment II}

The second assignment was successfully completed by 43 workshop participants. For each principle it was calculated which percentage of workshop participants indicated that principle as an aspect of their product development organisation that could be improved in order to optimise their user-centred product development process. Figure 8.2 shows an overview of these percentages.

\section{Results for assignment I}

A percentage of $75 \%$ of the workshop participants indicated that a dedicated usercentred plan of approach was never or just sporadically defined for each project within their product development organisation (see principle 1). Although 68\% participants indicated that team members know their role and tasks in the product development process (principle 11), only 34\% of the workshop participants indicated that each team member often or always is familiar with the complete user-centred plan of approach in case such a plan is available in their product development practice (principle 2). Furthermore 65\% of the workshop participants indicated that, in their daily practice, product development team members do most of time not have a good overview of the available budget, time and equipment that is available for their product development activities (principle 12). 
Of the workshop participants 58\% indicated that, in their daily practice, there was never or sporadically a good insight into all project stakeholders when defining a user-centred plan of approach (principle 6). Above all, 66\% of the workshop participants indicated that there is never or sporadically awareness of the contextual conditions as well as their consequences for the product when defining a user-centred plan of approach (principle 5). Furthermore, only 53\% of the workshop participants indicate that user-centred plans of approach often or always define characteristics of the expected end results as well of the intermediate results in terms of content and format (principle 7).

A percentage of $88 \%$ of the workshop participants indicate that in their process of writing a plan of approach never or sporadically a wide range of methods and tools that can be applied to realise the needed project results have been investigated (principle 8). Furthermore, 65\% of the workshop participants indicate that in, their practice, methods and tools are not or sporadically selected based on their effectiveness and efficiency to generate the required results as well as on their fit to the resources and skills available for this specific project (principle 9). Above all, $68 \%$ of the workshop participants indicate that selected methods and tools do not or sporadically get specified in a user-centred plan of approach in terms of when, how, by whom and with what means to apply these methods and tools (principle 10).

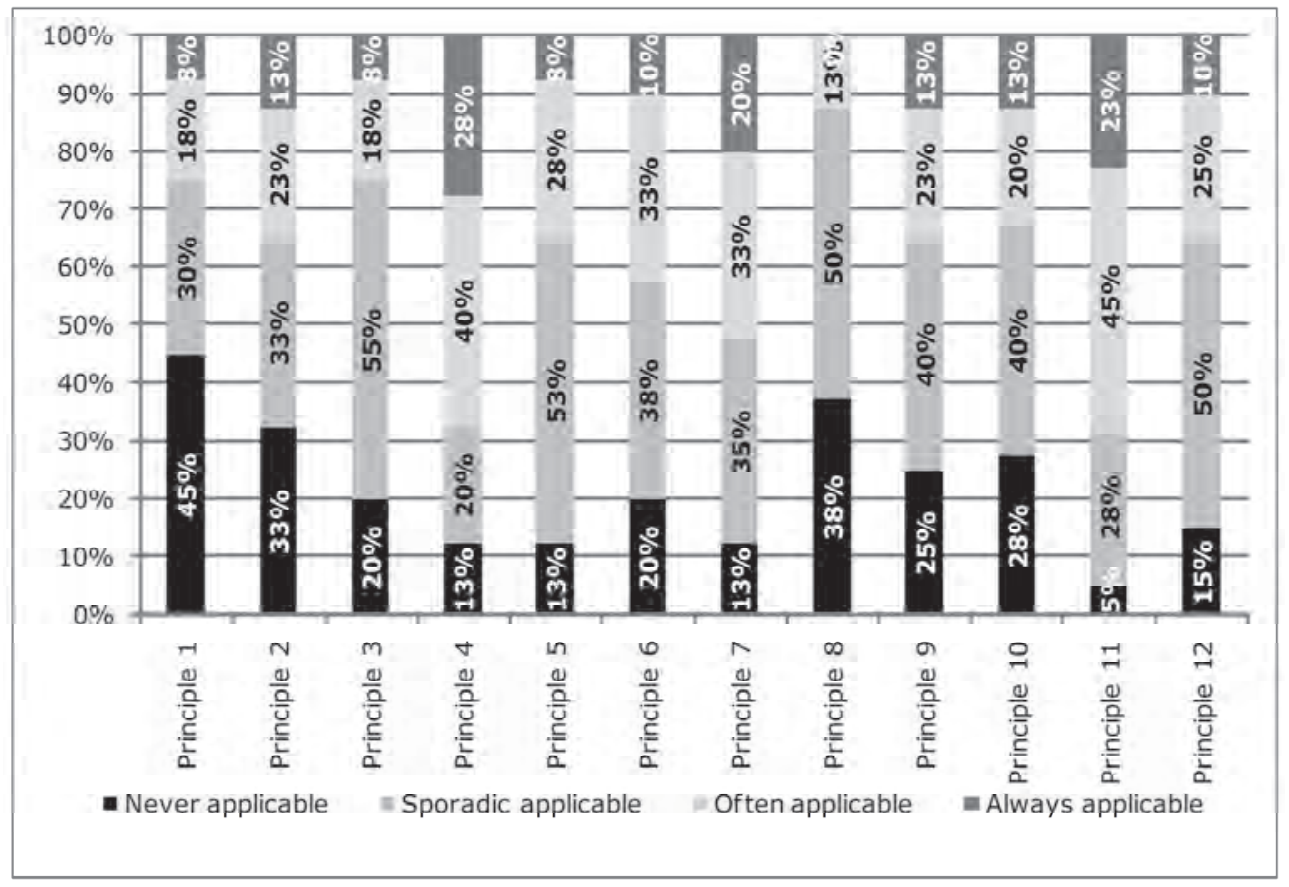

Figure 8.1 - Percent distributions of applicability rate of principles in practice. 


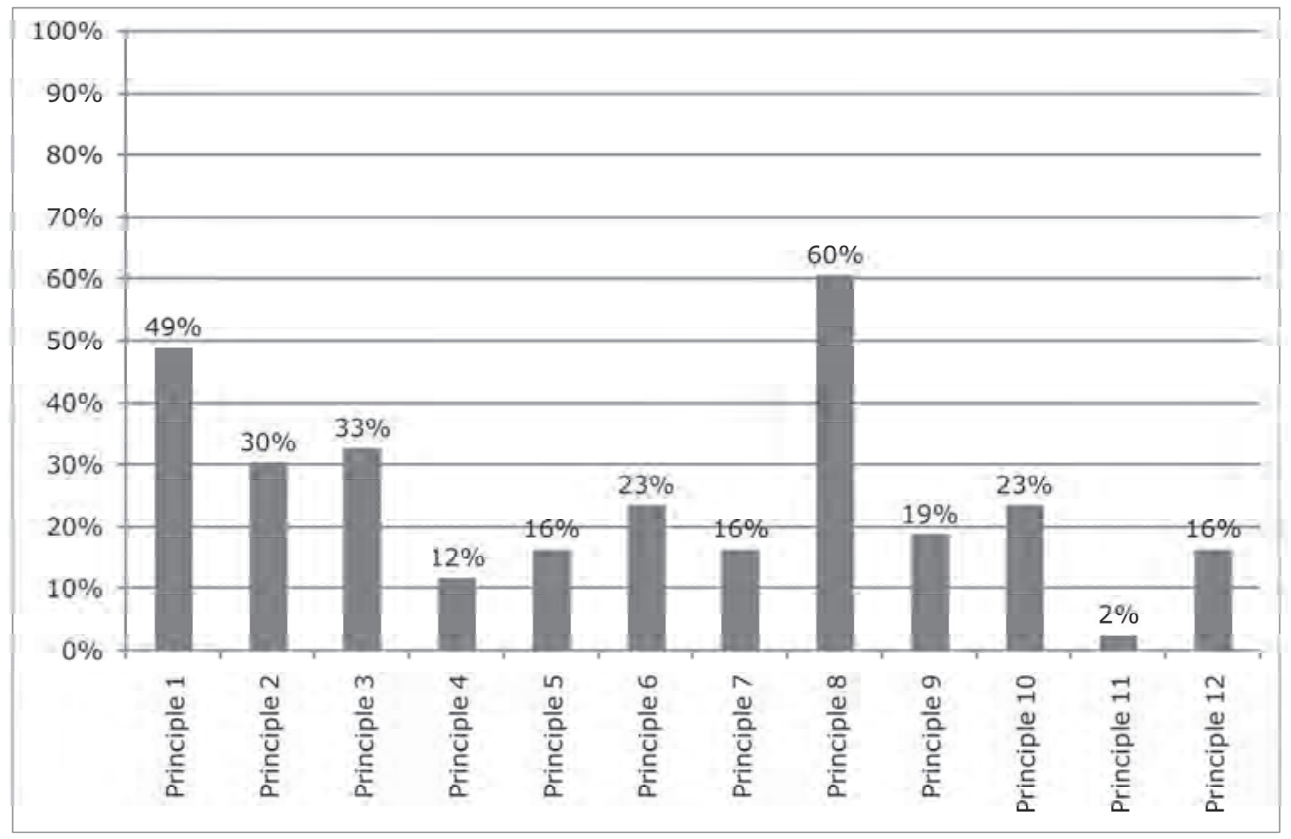

Figure 8.2 - Workshop participants that indicated a principle as an aspect to improve.

\subsubsection{Conclusions}

Based on the results of the viability study, it can be concluded that the UCD Kick-off method is expected to be viable in product development practice. Results of the study indicate that, compared to the current way in which user-centred plans of approach are specified, applying the UCD Kick-off method in product development practice particularly has added value since it supports in:

- Specifying expectations regarding the use of the product and its use situations as well as the intermediate results which are needed to achieve during the product development process;

- Specifying when, how, by whom or with what means product development activities will be executed;

- Exploring and selecting product development methods and tools based on their effectiveness and efficiency to generate required results as well as their fit to the product development context;

- Making the entire product development team familiar with the full plan of approach.

Asked for their expectations, workshop participants also indicated these principles of the UCD Kick-off method as the main aspects of their product development organisation that could be improved in order to optimise their user-centred product development process. 


\subsection{Validation study}

Section 8.2 concludes that the UCD Kick-off method is expected to be viable in product design practice. Next step is to make the UCD Kick-off method available for product developers in a comprehensible and accessible way. This requires an insight into the needs regarding a practical support of the UCD Kick-off method in product development practice. A validation study was performed with the aim to gain insight into the following topics:

- Comprehensibility of the UCD Kick-off method. The UCD Kick-off method is developed to be used by product developers. These product developers only can (and are willing to) apply the method correctly if they understand its aim, structure, (sub) steps and their interrelations.

- Actual expected applicability scope of the UCD Kick-off method. To this aim more knowledge needs to be gained regarding the contextual conditions under which the UCD Kick-off method is actually expected to be applied as well as the kind of product development assignments for which the method is expected to be applied.

- Needs regarding practical support of the UCD Kick-off method in product development practice. The initial idea is to make the UCD Kick-off method available as a workshop which will be described in a workshop manual. Product developers must be able to prepare and execute this workshop with the help of this workshop manual. More knowledge is required on how such a workshop manual should support product developers in preparing and executing the workshop.

The next section discusses how the validation study was conducted in order to gain these insights.

\subsubsection{Setup validation study}

The validation study consisted out of a series of workshops in which one or two industrial design engineers or project managers of three industrial partners participated. The first two partners were midsize design agencies whose employees have experience in the development of user-focussed, mainly healthcare, products. The third industrial partner was a large multinational, producing a wide range of food products and products for personal care. This multinational holds a large multidisciplinary R\&D department which is concerned with the development of all food and personal care products as well as all products and packaging which support the sale, distribution and use of the food and personal care products. Due to the divergence in the product development expertise of the three industrial partners, the composition of their product development team as well as the characteristics of the context in which the participating partners develop products, it should be possible to gain a broader view and insight regarding above enounced topics. 
The UCD Kick-off tool was reviewed during a workshop at each of the three industrial partners. These workshops took approximately three hours and existed out of the following parts: (1) introduction and the (2) UCD Kick-off method walkthrough.

\section{Part I - Introduction}

After a short acquaintance, the setup of the workshop was introduced to all workshop participants. This introduction enabled to explain workshop participants what they could expect during the workshop. The introduction provided background information regarding the validation research in general, workshop's aim, research questions, workshop setup, as well as participants' workshop tasks.

\section{Part II: Walkthrough}

The second workshop part existed out of a top-down walkthrough of the UCD Kick-off method. This was done by means of a preliminary version of the UCD kick-off tool (see section 8.3.2). During this walkthrough participants were asked to give their opinion and expectations regarding the comprehensibility and the expected applicability scope of the UCD Kick-off method in its entirety as well as for each of its individual (sub-) steps. Furthermore they were asked to indicate which practical support the workshop manual should provide to enable them to apply the UCD Kick-off method in their product development practice. In here practical support refers to the information that the workshop manual should provide as well as workshop manual's structure and format.

Since most workshop participants were unfamiliar with the UCD Kick-off tool, each part started with an introduction explaining the UCD Kick-off tool or each of its steps' objective, relevance, required input, expected output, overview and relation of substeps. Afterwards participants gave the opinion and expectations they are asked for.

The workshops were captured by means of video recordings. Through the use of video registration, discussions during the workshop were captured without disturbance. Afterwards the video recordings were analysed. As part of this analysis, transcripts of relevant quotes of workshop participants were made. Furthermore a comment was added to each transcribed quote in order to make this quote understandable (for outsiders). This comment summarized the context in which the quote was made, the discussion's topic as well as the intermediate conclusion that could be drawn from the quote.

\subsubsection{Preliminary workshop manual}

A preliminary workshop manual for the UCD Kick-off method was made as input for the validation study. This manual should be seen as a means to trigger workshop participants to give the opinions and expectations they were asked for rather than a concrete workshop manual's concept. The content of the preliminary workshop 
manual was limited, but provided the workshop participants sufficient insight into its structure and content.

The preliminary workshop manual started with an introduction in which the background and main functionality of the UCD Kick-off method is discussed. This introduction furthermore discusses how to read the manual. Afterwards, the workshop manual goes further into the layered structure and content UCD Kick-off method in its entirety as well as each of its individual steps. Figures 8.1 and 8.2 provide an impression of how the workshop manual discusses a specific step of the UCD Kick-off method. Each section starts with a schematic overview of the addressed step (Figure 8.1). Figure 8.2 shows the corresponding page that provides a textual explanation to this schematic overview. Each textual explanation starts with clarifying the goal and added value of the specific steps or sub-step (see 1). At the left side of the right page, it explains the sub-steps that need to be taken in order to achieve the goal of that phase as well as how to take each sub-step (see 2). At the right side of the page practical tips and tricks are given which support in taking each of the sub-steps (see 3). 


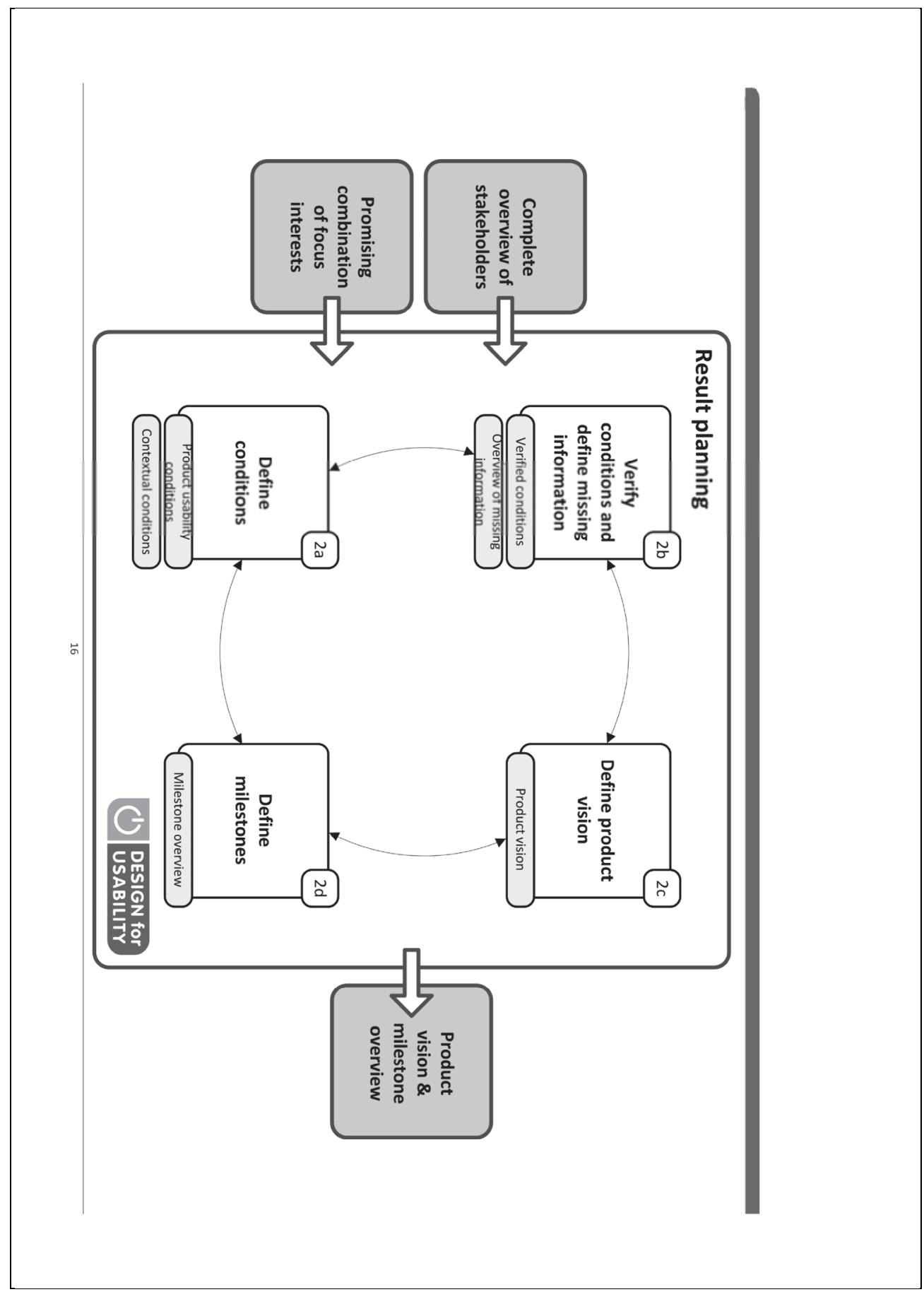

Figure 8.1 - Example of a page of the preliminary workshop manual. The page shows a schematic overview of a specific step. 


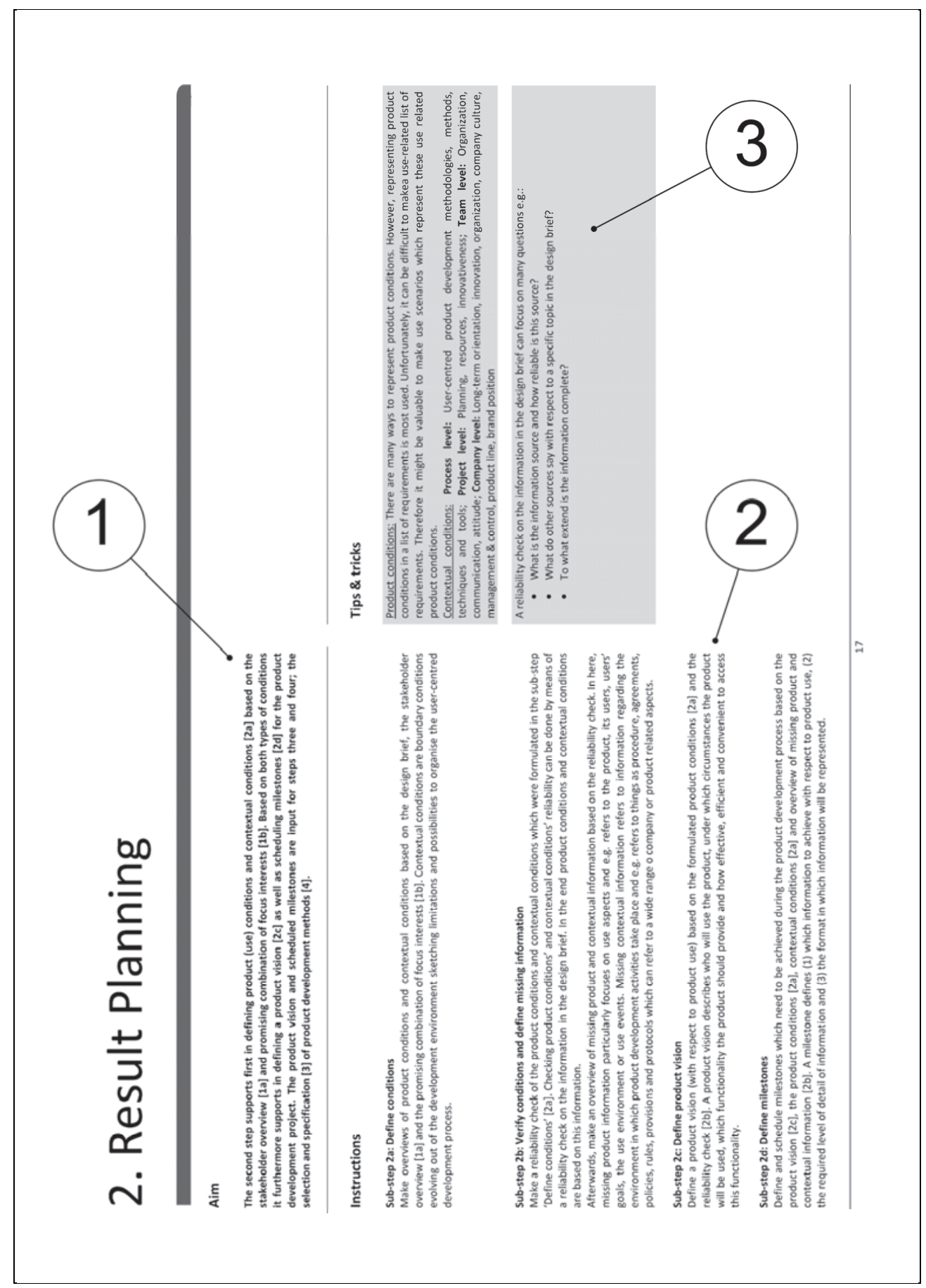

Figure 8.2 - Example of a page of the preliminary workshop manual. The page provides a 
textual explanation to this schematic overview of the workshop step which is shown in figure 8.1

\subsubsection{Discussing research results}

This section discusses the results regarding the three focus points that were formulated for this validation research. Discussing these results will be done based on the transcripts.

\section{Comprehensibility of the UCD Kick-off method.}

It is important to focus on the UCD Kick-off method's content as well as its structure in order to answer this question. In here 'content' refers to the question whether product developers understand the method's application area as well as the objectives and added value of all UCD Kick-off method's phases and (sub-) steps. The term 'structure' refers to the question whether product developers understand the relations between the phases and (sub-) steps.

\section{Regarding the method's content}

At the end of the workshop, participants were asked whether they understand the UCD Kick-off method's objective as well as the method's steps that support in achieving this objective. Finally all participants responded affirmatively to this question. The following quote illustrates this. During the workshop at one of the participating design agencies, one of the participants said: "I think that the method as a whole as well as each of its individual phases and steps are well-founded from a scientific point of view. The method seems to be complete and I do not think that aspects are overlooked."

Nevertheless, one of the participants of the workshop at the design agency made some remarks regarding the fourth phase of the UCD Kick-off method: Development method specification. He said: "For me personally, the second and third phase of this method are most valuable. The fourth phase of the method is just regular project management. Above all, the support that is provided in this phase is just one way in which chosen development methods can be specified. However, project management literature provides many more methods and tools that support in here. I agree with you that the method should mention that it is important to specify chosen development methods. However, I would advise you to restrict to providing both (1) an overview of aspects that need to be specified within this phase as well as an overview of some well-known project management resources which support in specifying these aspects." This remark is appropriate. Specifying development methods is not an activity that specifically belongs to user-centred product development. Furthermore, there is indeed a lot of project management literature available that supports in here. The new workshop manual will therefore restrict to providing an overview of aspects that need to be 
specified within this phase as well as an overview of well-known project management resources which support in here.

\section{Regarding the method's structure}

For most participants it took some time to understand the layered structure of the UCD Kick-off method. Particularly, the layered structure of the method's first phase Stakeholder mapping - was found difficult to grasp. One participant of the workshop at one of the design agencies for example asked: "Why do I need to make a description of the product's users? Users are stakeholders to the projects. One of the previous steps of the method already asked to describe stakeholders." This quote illustrates that the participant did not understand that he was looking at a more detailed instruction for the sub-step 'Define stakeholder' which is part of the phase 'Stakeholder mapping'. In order to avoid this confusion, the new workshop manual should leave this layered structure and describe all UCD Kick-off method's steps at the same level.

\section{Actual expected applicability scope of the UCD Kick-off method}

This question can be answered by focusing on both the characteristics the product development assignments for which application of the method is expected to be valuable as well as the characteristics of product development team that would benefit most from application of the method.

Characteristics of product development projects

Overall, workshop participants expect to apply the method to both small as well as large product development assignments. Discussion during the workshop at one of the design agencies revealed that small product assignments were defined as assignments with a short lead time, concrete and known deliverables and a limited amount of stakeholders. The team that executes small assignments exists out of a maximum of three product developers. Large product development assignments were defined as projects with a long lead time. Its deliverables are not known or vaguely described. There is a big variety in stakeholders which need to be taken into account. The product development team is described as large (up to more than 100 persons) and multidisciplinary.

However, the way in which the method is expected to be used differs. As one of the participants during the workshop at one of the design agencies said: "I think I will use this method for each assignment. However, I do not think that I will always execute all of its steps. Okay, for big assignments I would, because I have time for that. In small projects I do not have much time to spend on specifying a plan of approach. Nevertheless, the method provides good overviews of aspects that need to be considered when specifying a plan of approach. This makes the method also very useful as a mnemonic to 
small projects. In that case I would first specify the plan of approach and use the method afterwards to check if all required aspects have been considered."

This quote illustrates that there is less time to define a user-centred plan of approach in small product development projects. This was also confirmed by participants of the workshops at the other participating companies. Instead of applying the UCD Kick-off method step-by-step, the user-centred plan of approach is first intuitively defined based on experience by one single product developer. Afterwards the method is used to check if all required elements of the user-centred plan of approach are defined and if all relevant aspects for defining a user-centred plan of approach have been considered.

In large product development projects there is often more time available to define a user-centred plan of approach. One of the participants of the workshop at the multinational illustrates this by telling that, for some of their assignments, a team participates in a series of workshops in order to specify only the main characteristics of the assignment's approach. This series of workshops may take more than three days. This participant furthermore argues that the added value of a method that supports in specifying a user-centred plan of approach is expected to be bigger for these kind of projects since here defining a user-centred plan of approach is more complex. This complexity is caused by the big variety of stakeholders and product developers who need to be taken into account during the product development process as well as the unknown or vaguely described brief. Workshop participants therefore indeed expect to use the workshop manual, i.e. the UCD Kick-off tool, to systematically specify and detail the project deliverables as well as the user-centred plan of approach during a UCD Kick-off workshop.

\section{Experience of the product development team}

All workshop participants mention that the UCD Kick-off tool will be used by less experienced as well as experienced project managers. The UCD Kick-off tool is seen as a learning tool for less experienced project managers. One of the participants during the workshop at one of the design agencies said: "Although less experienced project managers do not have elaborate knowledge in defining user-centred plans of approaches and available product development methods, I expect that the UCD Kick-off method enables them to take well-funded decisions with respect to the organisation of a usercentred plan of approach. The method and accompanying tool teaches them to define an adequate user-centred plan of approach together with the other product development team members."

More experienced project managers will particularly use the UCD Kick-off tool as a mnemonic. It is expected that most experienced project managers are familiar with the steps and sub-steps of the UCD Kick-off method. One of the workshop participants 
said: "Organizing a user-centred plan of approach is an activity which is now based on experience. In here, I often take short cuts, combine steps and take decisions regarding the plan of approach implicitly. However, this does not mean that all the steps that are distinguished by the tool are useless. I can use this overview of steps in order to check if I did not oversee some aspects that needed to be considered." The UCD Kick-off tool therefore first of all reminds experienced project managers which steps to take during specification of a user-centred plan of approach. It furthermore supports them in taking more explicit decisions regarding the user-centred plan of approach's organisation by reminding them of the aspects which need to be taken into account in here.

\section{Needs regarding practical support of the UCD Kick-off method in product development practice}

\section{UCD Kick-off tool's structure}

After reading and discussing the UCD kick-off tool, workshop participants indicated to understand the workshop manual. Nevertheless workshop participants during the workshop at the multinational said to miss the following sections in the workshop manual:

- Workshop setup: A section which supports users of the UCD Kick-off tool in preparing the UCD Kick-off workshop. This section at least should give an example of a possible workshop program and time table. It furthermore should give an overview of information, workshop materials and templates that must be available for the workshop participants during for the workshop.

- Using the user-centred plan of approach: This section should discuss how to deal with the user-centred plan of approach once it has been defined. In here dealing refers to topics as updating the user-centred plan of approach, responsibility for the user-centred plan of approach and its use during the product development process or communication of user-centred plan of approach to the product development team.

\section{Execution of steps and sub-steps}

Workshop participants said to understand the goal of each individual phase and (sub-) step. However, despite of the practical tips and tricks which were added to each (sub-) step, they unanimously stated to need help in actually executing each of the (sub-) steps. A solution here was seen in adding templates and examples to each (sub-) step. These templates and examples should:

- Give insight into:

o What results exactly to generate in each step;

o The required level of detail for results;

o The format in which results need to be defined; 
- Give an overview of the aspects to consider during execution of a particular (sub-) step.

Templates furthermore enable to shorten the preparation and execution time of the UCD Kick-off workshop since developing workshop material is not needed and workshop participants immediately can start filling in their results.

During the validation workshops also the number of steps the UCD Kick-off tool consists of was discussed. Although most participants did not see the current number of (sub-) steps as a problem, participants of the workshop of one of the design agencies said: "The tool contains many steps. This makes me somewhat reluctant to use the tool, since I expect that the execution of all these steps is quite time consuming. I do not always have the time for doing this. However, I think that it is possible to combine some steps. This makes the use of the tool more efficient." Concluding from this, combining steps could make the use of the tool more time efficient. However, making the user-centred plan of approach definition process explicit and systematic was one of the fundamental principles for the development of the UCD Kick-off method. Combining steps would most probably make user-centred plan of approach definition process less explicit and systematic. Therefore one should be reluctant in reducing the number of (sub-) steps.

\subsubsection{Intermediate conclusions}

The research results indicate that in small product development assignments the UCD Kick-off tool will most likely be used as a mnemonic for an individual product developer. Within large product development assignments the UCD Kick-off tool is expected to be used as a means to group wise define in a structural way a usercentred plan of approach.

Furthermore the UCD Kick-off tool is expected to be used by the full range of project managers, i.e. less experienced as well as experienced project managers. Less experienced project managers will use the UCD kick-off tool as a learning tool. Experienced project managers will use the UCD Kick-off tool as a mnemonic.

Some workshop participants had difficulties to grasp the UCD Kick-off method's layered structure of phases, steps and sub-steps. Based on the advices of the involved project managers, it was decided to introduce a flat tool structure for the UCD kick-off tool. Through this structure all steps of the UCD Kick-off tool will be described on the same level.

Furthermore the workshop manual should no longer provide an overview of substeps which support in specifying selected product development methods since this is a regular project management activity for which many existing methods and tools can be consulted. The workshop manual should restrict to providing information 
regarding the aspects which need to be specified within a detailed user-centred plan of approach. In addition, some references will be provided for project management related literature regarding this topic.

The participating project managers furthermore advised to include the following additional sections:

- A section which support in preparing the UCD Kick-off workshop;

- A section which discusses how to deal with the user-centred plan of approach once it has been defined.

Besides it was advised that each UCD Kick-off method's step in the manual should be supported with templates and examples to increase its comprehensibility. These templates and examples should provide insight into:

- What results exactly to define in each step;

- The aspects to consider during execution of a particular (sub-) step;

- The required level of detail for results;

- The format in which results need to be defined.

Above discussed conclusions were used as input for the development of the UCD Kickoff tool.

\subsection{Workshop manual: The UCD Kick-off tool}

The workshop manual, i.e. the UCD Kick-off tool, was developed based on the results and conclusions of the validation research. This section will discuss the main characteristics of this workshop manual.

The UCD Kick-off tool describes the following three workshops in which a product development team applies the UCD Kick-off method.

- Workshop 1: Stakeholder mapping: Focus on listing stakeholders, defining stakeholders, prioritising, verifying and negotiating stakeholders' interests.

- Workshop 2: Result planning \& product development method selection: Focus on selecting focus interests, making overviews of product and contextual conditions, making an elaborate product description, defining milestones and selecting development methods.

- Workshop 3: Development method specification: Focus on formulating product development activities as well as allocating resources.

This division in three workshops makes it possible to actually negotiate with project stakeholders in the field (is part of one of the workshop steps) after the first workshop. Furthermore it enables product managers to process the results of the first two workshops towards a proposal or draft of a coherent and detailed user-centred plan of approach after the second workshop. 
For product developers it is important to estimate whether a tool is suitable for the execution of their tasks. Therefore the workshop manual starts with a chapter which introduces the UCD Kick-off method (see figure 8.3 and 8.4). Within this chapter, the manual goes further into the background of the UCD Kick-off method. In here it discusses why the method has been developed. Furthermore, the introduction addresses the UCD Kick-off method's main objectives and added value. Within this part, the manual also provides further information regarding the UCD Kick-off method's main characteristics, the required input and (3) the main characteristics of the output (user-centred plan of approach). Finally the introduction contains a section that goes further into the method's application domain. This section discusses to what kind of product development assignments the UCD Kick-off method and tool can be applied as well as under which circumstances application of the UCD Kick-off method is most beneficial.

As revealed by the validation research, it is important to know how to prepare and execute the workshops. Therefore, the workshop manual's next chapter, Workshop setup, supports product development teams in preparing and executing the workshops in which the UCD Kick-off method is applied. It discusses which persons should participate in the workshops, how to prepare the workshops, the role of the workshop moderator as well as some rules for workshop participants regarding the execution of each workshop. It furthermore provides an example workshop setup (see figure 8.5) which among others gives estimated times for each of the workshops as well as its steps.

The next three parts of the UCD Kick-off tool go further into each of the workshops. In here the tool discusses, per workshop, the steps that need to be executed. Addressing these steps is done according to a standard format (see figure 8.6 and 8.7). Furthermore for each step templates are available which support product development teams in executing the specific step. The format starts by discussing the goal of the specific step (see figure 8.7). In here discussion goes further into what the product development team is expected to do as well as why it is important to do this. Afterwards, the format provides overviews of input that is required as well as workshop materials that should be available for execution of the specific step. Furthermore, an overview of points of interests discusses (1) more background information to the step and (2) suggestions regarding the execution of the specific step. As shown in figure 8.6, the UCD Kick-off tool provides an example to each step. This example provides insight into how the result of a specific step should look like and in particular into the kind as well as the level of detail of results that are expected.

The execution of the workshops results in a user-centred plan of approach. However, such a plan of approach is only useful when it is known how to deal with it in the 
actual product development practice. Therefore the last chapter of the UCD Kick-off tool goes further into this topic and provides an overview of recommendations regarding the use of the user-centred plan of approach during the product development process. 


\section{introduction}

\section{Introduction}

The number of complaints regarding use problems with electronic consumer goods increases since the mid-nineties. Research indicates that a lot of these complaints find their origin in the organisation of the product development process.

Most companies use their own specific product development method in order to make the product development process as effective and efficient as possible. Further specification of the intended usability-focused product development process in a detailed plan of approach is however needed to apply these corporate product development methods. Our research unfortunately showed that currently product development teams often have an un-univocal or incomplete overview of such a user-centred plan of approach. The lack of a detailed and user-centred overview of the approach will, based on the productprocess relation, most certainly not lead to a product design that meets the intended use characteristics.

Practice based research revealed that currently user-centred plans of approach are defined based on experience. There are no tools available to support product development teams in this. This workshop manual therefore provides a tool that supports product development teams in specifying a detailed user-centred plan of approach, the UCD kick-off tool.

\section{Objectives and added value}

The UCD kick-off tool, existing out of three workshop parts, supports product development teams in explicitly defining a detailed user-centred plan of approach based on the specific characteristics of the product as well as the development environment. Since usability is only one out of many aspects to consider in product development, this tool focuses on usability, but does not exclude other product aspects. The UCD kick-off tool is the practical implementation of the UCD Kick-off method. This method supports in addressing the aspects which need to be considered while defining a usability and user-centred plan of approach. The method is based on the assumption that an explicit and detailed definition of a user-centred plan of approach prevents usability problems. Input for the method is a design brief describing desired basic product functionality, the main characteristics of its user, process and project constraints and the core development team. Output of the method is a detailed user-centređ plan of

Figure 8.3 - Example pages of the introduction chapter of the workshop manual. 
approach describing project stakeholders, intended product characteristics, intermediate development results, selected development methods, development activities, input per development activity and allocation of resources.

Stakeholder mapping

The lack of a complete overview of project stakeholders is an important aspect that causes usability problems. Therefore the method supports in making a complete overview and specification of project stakeholders (including the product's users) and prioritising their stakes.

\section{Product characteristics and intermediate results}

A detailed insight into the desired product characteristics as well as the needed intermediate results of the development process is required in order to define a user-centred plan of approach. Furthermore contextual conditions, such as available time and budget, influence the specification of the user-centred product development process. This method focuses on making a detailed overview of product characteristics, scheduled intermediate development results and development process conditions.

\section{Development method selection}

Product developers tend to stick to development methods they are familiar with without questioning if these development methods fit the intended development results. This method supports in explicitly exploring and selecting appropriate and feasible development methods which lead to the desired development results.

\section{Development method specification}

Only selecting a development method does not guarantee that intended development results will be achieved during the product development process. Further specification of the actual application of the selected development method is needed. The fourth step therefore focuses on describing required development activities, required input per activity, development techniques and allocation of resources.

\section{Application domain}

Using the UCD Kick-off tool has most added values in large user-centred product development projects. Large user-centred product development projects refer to projects which are done by large (sets of) product development teams. There are many project stakeholders that need to be taken into account and the knowledge regarding required product's main characteristics, especially regarding product's use aspects, is limited at the start of the project. The project's lead time is expected to be long.

The UCD Kick-off tool is preferably used at the start of a user-centred product development project by the complete core development team to systematically define a univocal and detailed user-centred plan of approach. Afterwards, the

Figure 8.4 - Example pages of the introduction chapter of the workshop manual. 


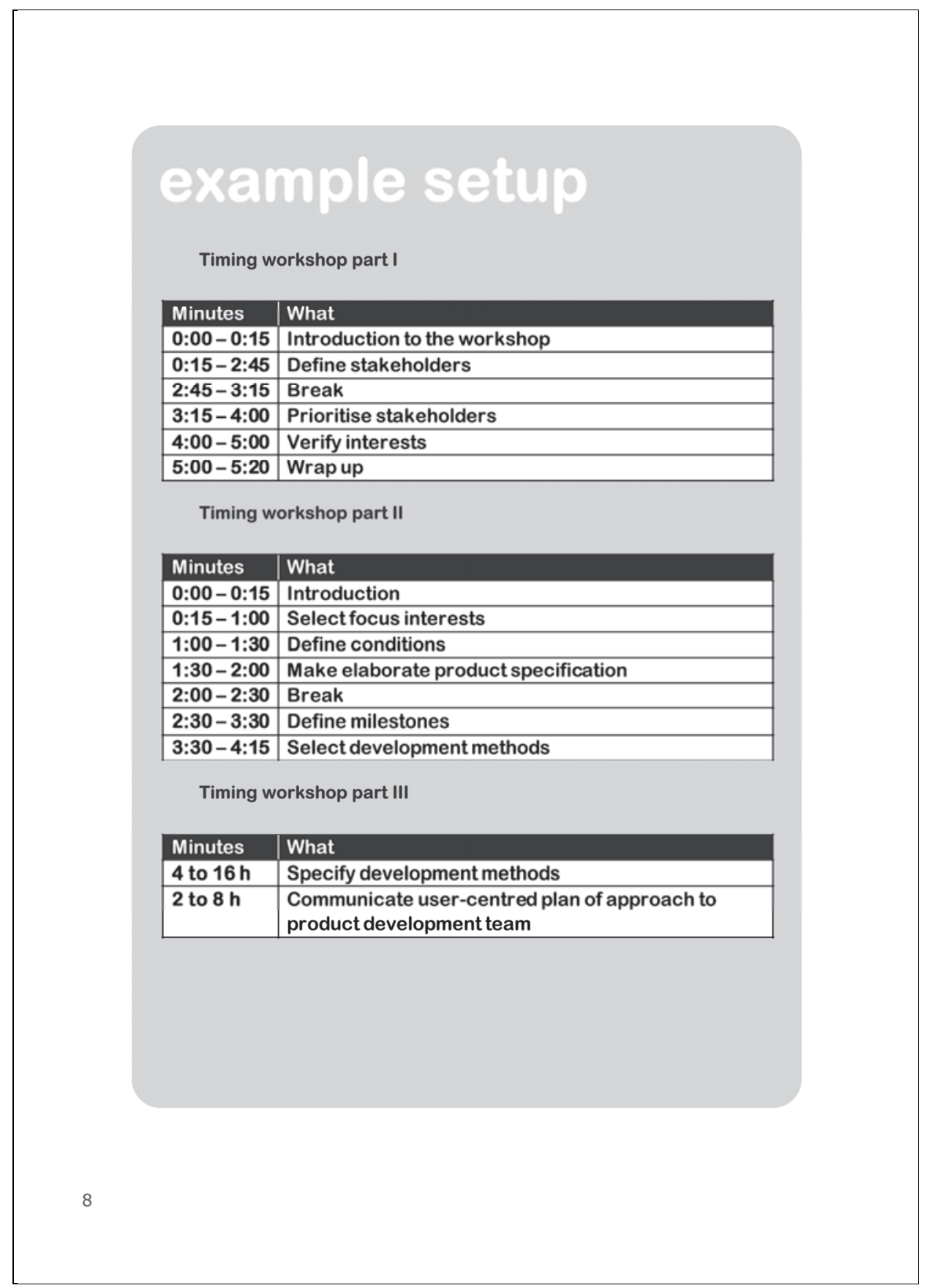

Figure 8.5 - The example workshop setup. In here the workshop manual provides an example of a times schedule for the workshops and provides an overview of the steps that need to be taken during each workshop. 


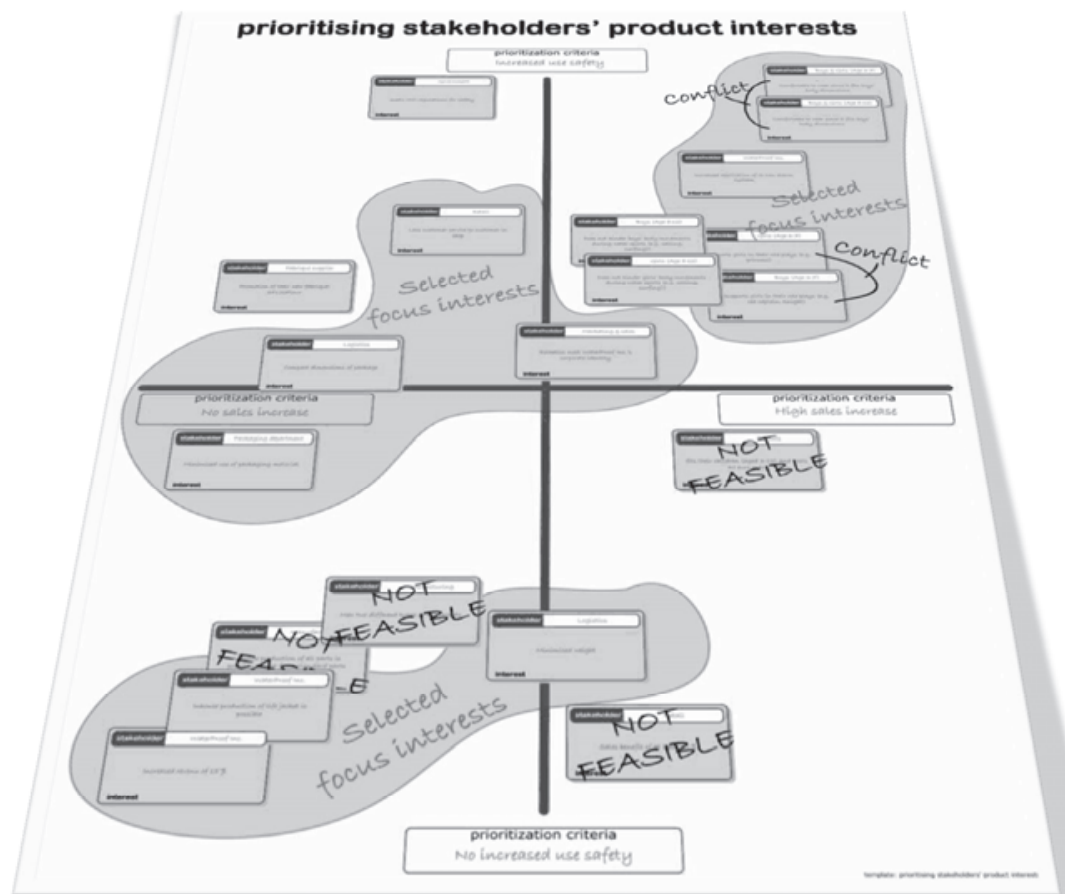

Figure 6 - Prioritising stakeholders' product interests

Figure 8.6 - Example of a page of the workshop manual. The example shows how the result of a specific step could look like. 


\section{select focus interests}

\section{Goal}

Not all stakeholders' interests are equally important and can be met during the product development project. It is necessary to be aware of the stakeholders' interests that at least need to be met for a successful completion of the product development project. Therefore make a promising combination of stakeholders' interests that at least have to be met. These are in the first place, though not necessarily, the stakeholders' interests which are indicated as important for ensuring the success of the product development project. In here the product development project refers to the product development process as well as the product that originates from it. Furthermore, these are stakeholder's interests which are indicated as feasible and which do not conflict each other. Selecting focus interests can be done by indicating the selected interests with a coloured marker in the 'Prioritised and verified overviews of stakeholders' interests with respect to the product as well as product development process'.

\section{Required input}

The 'Prioritised and verified overviews of stakeholders' interests with respect to the product as well as product development process' is needed to make a promising combination of focus interests.

\section{Materials}

Coloured markers are needed to make a promising combination of focus interests.

\section{Points of interest}

Do not automatically only select stakeholders' interests which are indicated as important. A group of similar, but as less important indicated, stakeholders' interests as a set might be important as well and therefore valuable to select.

Do not automatically avoid a selection of focus interests which conflict each other. Although a challenge, a product which meets conflicting interests might be very successful on the market.

Figure 8.7 - Example of a page of the workshop manual. It discusses the goal of a specific step, required input and the points of interests discussing (1) more background information to the step and (2) suggestions regarding the execution of the specific step. 


\subsection{Evaluation study}

Although the UCD Kick-off tool is based on the results of this research it does not automatically mean that the workshop manual is actual comprehensible and meets the expectations of product developers. Therefore the UCD Kick-off tool was evaluated in order to gain insight into the extent to which this tool is comprehensible and meets the expectations of product developers.

Workshop participants who were involved in the validation study also participated in this evaluation study. This study existed out of a workshop in which the complete UCD Kick-off tool was discussed step-by-step in an informal way. Due to its informal though structured character, the discussion allowed the participants both to express their opinion regarding the UCD Kick-off tool as well as to indicate the parts of the tool that were not clear for them. Furthermore, the discussion enabled workshop participants to give suggestions for further improvement of the UCD Kick-off tool. Workshop participants were asked to read the workshop manual as a preparation in order to make the workshop as effective and efficient as possible.

Based on the results of the evaluation workshop it can be concluded that workshop participants generally responded positively to the UCD Kick-off tool. Workshop participants of both participating design agencies judged the UCD Kick-off tool as a good learning tool for product developers and project managers since it explains stepby-step how a user-centred plan of approach can be specified in a systematic way. Participants were particularly positive regarding the following aspects of the UCD Kick-off tool.

\section{Examples and templates}

Each of the workshop steps is provided with a template and an example. Workshop participants indicated that the templates and examples make the execution of a specific step concrete. The following quote of one of the workshop participants illustrates this: "Both the templates and the examples provide me a good insight into how a specific step of your method needs to be executed. The templates will support me in actually executing each of the steps of your method since they provide me an overview of aspects I have to consider within each step. Furthermore, the examples in the workshop manual are inspiring. They concretely show what kind of result I am expected to achieve in terms of its content, detail level and format." The templates and examples therefore provide support and insight into how a specific step actually needs to be executed in product development practice.

\section{Workshop setup section}

The workshop manual contains the section 'Workshop setup'. This section goes further into how the workshops in which the UCD Kick-off method will be applied 
could be organised and executed. Workshop participants found section useful. They indicated that a section like this will particularly support them in determining (1) the persons who need to be invited for the workshops, (2) appropriate time schedules for the workshops as well as (3) materials that need to be available during the workshops.

\section{Using the user-centred plan of approach section}

The workshop manual finishes with the section 'Using the user-centred plan of approach'. This section discusses how to deal with a user-centred plan of approach during the product development process. Workshop participants indicated that a section like this is useful since it makes them aware of the boundary conditions regarding the use of a user-centred plan of approach during the product development process. As one of the workshop participants stated: "This section makes me aware of the fact that a user-centred plan of approach is a 'living' document. It is only useful to specify a user-centred plan of approach when it is actually used and regularly updated during the product development process. This section provides me valuable information regarding the way in which a user-centred plan of approach should use and treated."

However, although workshop participants reacted positively on the workshop manual, they also came up with the following recommendations for further improvement.

\section{Contextual conditions}

Within of the workshop at one of the participating design agencies, workshop participants indicated that, despite of the short explanation at page 28 of the UCD Kick-off workshop manual, it was still hard for them to understand what contextual conditions exactly are and how they can influence the user-centred product development process. Therefore textual explanation in the workshop manual regarding the definition of contextual interests was updated as well (see figure 8.8).

\section{Prioritising interests}

One of the steps of the UCD Kick-off tool focuses on prioritising stakeholders interests (UCD Kick-off tool pages 18 and 19). The evaluation workshops show that some workshop participants did not understand why it is important to prioritise stakeholders' interests. One of the workshop participants said:"OK, for me it is clear that I have to prioritise stakeholders' interests. However, can you explain me why I should do this? I do not see it! I mean, they are all stakeholders, they all have interests in the project and they all have power to influence it. After all, I think I have to satisfy them all so therefore they are all equally important to the project." Therefore the textual explanation in the workshop manual regarding the step 'Prioritise interests' was updated regarding the importance of prioritising stakeholders. This new textual explanation is shown in figure 8.9. 


\section{Selecting stakeholder interests}

One of the steps of the UCD Kick-off tool focuses on selecting focus interests (UCD Kick-off tool page 24 and 25). During the workshop at both participating design agencies, workshop participants indicated not to understand how stakeholders' focus interests could be selected. The textual explanation in the workshop manual regarding this step was therefore updated. This new textual explanation is shown in figure 8.10

The UCD Kick-off tool has been updated based on these recommendations and published on the following website: www.designforusability.org. It is now possible to download the UCD Kick-off tool and accompanying templates from this website.

\footnotetext{
Contextual conditions

Most companies benefit from an effective and efficient product development. Therefore they create an environment that enables product developers to develop products in such way. This environment consists of both physical components (e.g. test facilities, workshops or budgets) as well as organisational components (e.g. corporate product development methods, staffing structure, mission statement). Within most companies, product developers are required to (to a greater or lesser extent) take account of these physical and organisational components during the user-centred product development process. E.g. Product developers are required to apply the corporate product development method during the user-centred product development process or are restricted to all kinds of budgets. These physical and organisational components therefore sketch boundary conditions (limitations as well as possibilities) regarding the organisation of the user-centred product development process. Within this workshop manual this kind of conditions are called 'contextual conditions'. Contextual conditions can refer to the following levels within a development environment:

- Process level: User-centred product development methodologies, methods, techniques and tools

- Project level: Planning, resources, innovativeness

- Team level: Organization, communication, attitude

- Company level: Long-term orientation, innovation, organization, company culture, management $\&$ control, product line, brand position
}

Figure 8.8 - Section of the updated UCD Kick-off tool. The textual explanation in the workshop manual regarding the definition of contextual conditions was updated. 


\section{prioritise interests}

\section{Goal}

For various reasons it is not always possible to meet the complete set of stakeholders' interests during a product development project. E.g. some stakeholder's interests might conflict each other in such a way that meeting the both of them is hardly possible. In that case it is inevitable to select stakeholder interests to focus on during user-centred product development process. However, in here it is important to select stakeholder's interests that are important to meet in order to ensure the project's rate of success. This requires insight into the importance of stakeholders' interests for the success of the project. Therefore it is important to prioritise the stakeholders' interests. In here two prioritizations need to be made; a prioritization of stakeholders' product interests and a prioritization of stakeholders' interests regarding the project organisation.

Prioritising stakeholders' interests can easily end up in an unstructured confusing discussion. However, the following sub-steps give more structured support in prioritizing stakeholders' interests:

1. Chose for each prioritization one or more criteria to prioritise on.

2. Select for each prioritization a template and fill in the chosen prioritization criteria on these templates. In here, the following templates can be selected: 'Prioritising stakeholders' product interests I'; 'Prioritising stakeholders' product interests II'; 'Prioritising stakeholders' interests regarding project organisation I'; 'Prioritising stakeholders' interests regarding project organisation II' $^{\prime}$

3. Write each stakeholder's interest on template 'Stakeholder's interest'.

4. Prioritise stakeholders' interests by positioning each stakeholder's interest on the template.

A selection of focus interests for the product development project can be made in workshop part II based on this prioritized overview of prioritized stakeholders' interests.

\section{Required input}

The overview of described stakeholders is required input to prioritise stakeholders' interests.

\section{Materials}

The following materials are needed to prioritise stakeholders' interests:

Figure 8.9 - Section of the updated UCD Kick-off tool. The textual explanation in the workshop manual regarding the step 'Prioritise interests' was updated regarding the importance of prioritising stakeholders. 


\section{select focus interests}

\section{Goal}

Not all stakeholders' interests are equally important and can be met during the product development project. It is necessary to be aware of the stakeholders' interests that at least need to be met for a successful completion of the product development project. Therefore make a promising combination of stakcholders' interests that at least have to be met. These are in the first place, though not necessarily, the stakeholders' interests which are indicated as important for ensuring the success of the product development project. In here the product development project refers to the product development process as well as the product that originates from it. Furthermore, these are stakeholder's interests which are indicated as feasible and which do not conflict each other. Selecting focus interests can be done by indicating the selected interests with a coloured marker in the 'Prioritised and verified overviews of stakeholders' interests with respect to the product as well as product development process'.

\section{Required input}

The 'Prioritised and verified overviews of stakeholders' interests with respect to the product as well as product development process' is needed to make a promising combination of focus interests.

\section{Materials}

Coloured markers are needed to make a promising combination of focus interests.

\section{Points of interest}

Do not automatically only select stakeholders' interests which are indicated as important. A group of similar, but as less important indicated, stakeholders' interests as a set might be important as well and therefore valuable to select.

Do not automatically avoid a selection of focus interests which conflict each other. Although a challenge, a product which meets conflicting interests might be very successful on the market.

Figure 8.10 - Section of the updated UCD Kick-off tool. The textual explanation in the workshop manual regarding selecting stakeholder interests was updated. 


\subsection{Conclusions}

This chapter first proved that the UCD kick-off method is expected to be viable in product development practice. Afterwards, this chapter described the process of making the UCD Kick-off method applicable for product development practice. This process started with a validation study which provided insight into:

- $\quad$ Comprehensibility of the UCD Kick-off method;

- Actual expected applicability scope of the UCD Kick-off method;

- Needs regarding practical support of the UCD Kick-off method in product development practice.

Next a workshop manual that supports product development teams in applying the UCD Kick-off method during three workshops in product development practice has been developed based on these insights. This workshop manual, the UCD Kick-off tool, was evaluated in collaboration with industrial partners during an evaluation study. This evaluation study provided insight into the extent to which the workshop manual meets the actual expectations of product development practice. Finally, the UCD Kickoff tool was updated based on the results of this evaluation study. Overall, the validation and evaluation studies revealed that the UCD Kick-off method and tool are assessed to be of added value to and applicable in product development practice. Within small product development projects, the UCD Kick-off tool will most likely be used as a mnemonic by an individual product developer. Whereas within large projects the UCD Kick-off tool is expected to be used as a means to group wise define in a structured way a user-centred plan of approach.

Furthermore, design practitioners expect the UCD Kick-off tool to be used by less experienced as well as experienced project managers. Less experienced project managers will use the UCD kick-off tool as a learning tool. Experienced project managers will use the UCD Kick-off tool as a mnemonic to remind them of the aspects which need to be taken into account while defining the user-centred plan of approach. The UCD Kick-off tool will thereby support them in taking more explicit decisions regarding the user-centred plan of approach's organisation.

The next, and final, chapter of this thesis will provide an overview of as well as reflect on the outcome of this research. 


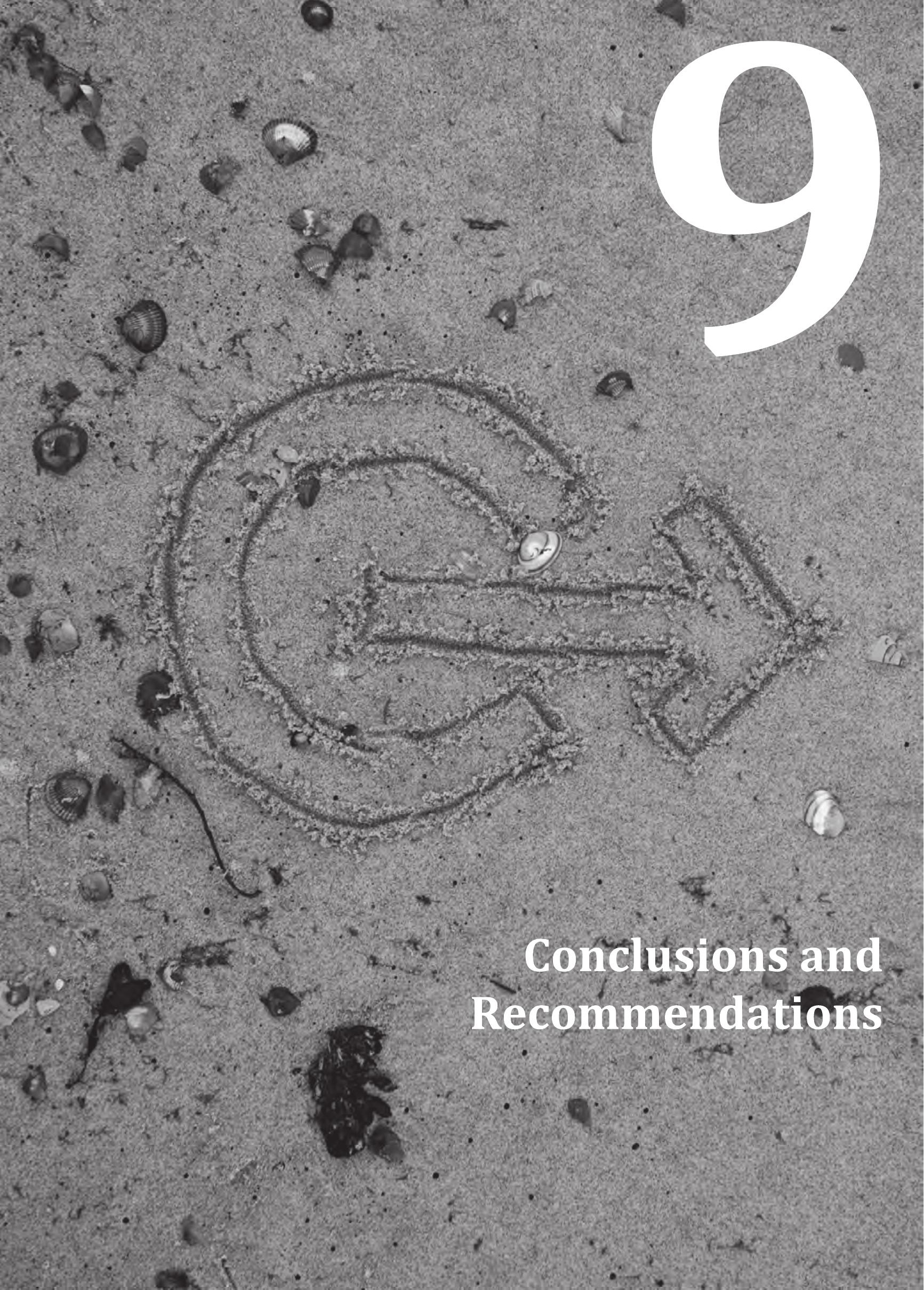




\section{9}

\section{Conclusions and Recommendations}

\subsection{Summary of research results}

Main objective for this research was to develop a support that enables product development teams to systematically specify a detailed user-centred plan of approach for their project. The following results have been achieved during this research in order to achieve this objective.

\section{Development statement and overview of criteria}

Literature research resulted in a development statement and overview of criteria regarding the support that needed to be developed during this research. According to the development statement and criteria there is a need for a method that supports product development teams in specifying a detailed and univocal user-centred plan of approach for the product development process. In here the method focuses on addressing product use, but does not exclude addressing other product aspects. The user-centred plan of approach is based on the design brief and takes all aspects within and outside the organisation that influence product's use characteristics (and therefore the execution of the product development process) into account.

\section{Insight into the method's expected application area}

Two case studies were executed to verify whether the identified need was recognised by the product development practice that will use this support. These case studies provided insight into the expected circumstances under which the support would be used. Based on the results of these case studies it is expected that the method is particularly expected to be useful within complex product development assignments in which product use is seen as a key aspect to take into account during the product development process. In here complex refers to assignments that are divided into sub-assignments, in which a large number of design aspects need to be considered 
during the product development process' (usually long) lead time. These assignments are generally executed by large, complex-structured, multidisciplinary teams.

\section{Impact model regarding product use}

Many aspects on several levels within and outside the product development organisation have influence on a product's use characteristics and on the execution of the user-centred product development process. Product development teams therefore have to consider these aspects when specifying a user-centred plan of approach. This research resulted in an impact model that provides an overview of the influence levels within and outside the company that can distinguished and discusses the aspects that need to be considered when specifying a user-centred plan of approach.

\section{Stakeholder mapping templates}

It is important to have insight into all stakeholders within a specific product development project since they can influence the execution of the user-centred product development project as well as the results that stem from this process. However, despite the fact that much stakeholder mapping theory is available, is not easy to gain this insight. Unfortunately, most available theory is generic and describes stakeholder's interests and power on a level that is too abstract to be useful when specifying user-centred product development processes. Within this research templates have been developed that supports product development teams in specifying stakeholder's interests, power as well as the consequences of both for the project and company that are relevant to describe for user-centred product development projects.

\section{Method that supports in specifying user-centred plans of approach}

A method has been developed that supports product development teams in explicitly specifying a detailed user-centred plan of approach for product development based on the specific characteristics of the product as well as the development context. Input for the method is a design brief describing desired basic product functionality, the main characteristics of its user, process and project constraints and the core development team. Output of the method is a detailed user-centred plan of approach describing project stakeholders, product's intended use characteristics, intermediate development results, selected product development methods, development activities, input per development activity and allocation of resources. The method is characterised by the following four iterative steps in order to define a user-centred approach that specifies these aspects.

\section{Stakeholder mapping}

The lack of a complete overview of project stakeholders is an important aspect that causes usability problems. Therefore the method supports in making a complete 
overview and specification of project stakeholders (including the product's users) and prioritising their stakes.

\section{Product characteristics and intermediate results}

A detailed insight into the desired product characteristics as well as the needed intermediate results of the development process is required in order to define a usercentred plan of approach. Furthermore contextual conditions, such as available time and budget, influence the specification of the user-centred product development process. This method focuses on making a detailed overview of product characteristics, scheduled intermediate development results and development process conditions.

\section{Development method selection}

Product developers tend to stick to development methods they are familiar with without questioning if these development methods fit the intended development results. This method supports in explicitly exploring and selecting appropriate and feasible development methods which lead to the desired development results.

\section{Development method specification}

Only selecting a development method does not guarantee that intended development results will be achieved during the product development process. Further specification of the actual application of the selected development method is needed. The fourth step therefore focuses on describing required development activities, required input per activity, development techniques and allocation of resources.

\section{Workshop manual}

Developing a support that is directly applicable in product development practice is one of the main objectives of this research. Therefore a workshop manual that supports in executing a series of workshops in which product development teams apply the method was developed. Execution of this series of workshops enables product developers to jointly specify a detailed user-centred plan of approach.

\subsection{Reflection on the research}

The research objective was to develop a method that supports product development teams in specifying a detailed user-centred plan of approach for their project. This implies that application of the method should result in a plan of approach that, besides user-centred, is specific for their product development assignment, their team as well as the development context. This section reflects on the extent to which the developed method meets these four main principles. 


\section{User-centredness}

The method supports in the determination of the (use) expectations of the users as well as the desired and attainable use characteristics of the product by offering usercentred templates that support in identifying and prioritising all project stakeholders. However, determining the (use) expectations of the user and the desired use characteristics of a product does not guarantee a successful completion of the product development assignment. Specifying and following an approach that leads to a product that meets these desired (use) characteristics and expectations of the user is just as important. The developed method supports in specifying a plan of approach that increases the chance to develop a product that meets the desired use characteristics based on an overview of these characteristics and an elaborate product specification.

\section{Assignment}

The content of the method as well as the format in which this method has been made available was developed in close collaboration with product development practice. As a result product developers judge the method to be viable as well as applicable to a wide range of product development assignments. However, it is not only the question whether the method is applicable to an assignment. Application also has to be valuable. Whether the application of the method is valuable depends on both the improvement it brings to the quality of the process versus the time and effort needed to invest. In here quality of the process refers to its efficiency as well as to the quality of the products that result from this process. According to the research results, application of the method is most advantageous to complex product development assignments in which product use is seen as a key aspect to take into account during the product development process. In general, these kinds of projects are characterised by a large amount of interrelating and repetitive product development activities that need to be done in order to complete the assignment. Due to these interrelations, the effects of an inefficient and ineffective organisation of one or more of these activities can influence the execution of other product development activities and result in serious delay in the product development process. However, to precisely reveal the most valuable application domain of the method, application of the method to a wide range of product development processes is required.

\section{Teams}

Developing and validating the method in cooperation with product development practice, resulted in a method that product developers judged to be directly applicable in design practice. In contradiction to other methods, this method does not just prescribe the steps that need to be taken in order to specify a user-centred plan of approach. By means of providing examples, techniques and templates, its workshop manual also explains how steps can be executed in product development practice. An 
additional benefit of the method is that it allows its application to be adapted to the expertise of the appliers, i.e. the product development teams. Depending on the product development team's level of experience, the workshop manual provides both the opportunity for following steps of the method literally as well as the opportunity for adjusting particular steps to the context in which the plan of approach needs to be specified. However, further research should determine the extent to which this feature of the method can and is applied in product development practice. This will depend on whether (1) (inexperienced) teams are able to apply the method autonomously and (2) (experienced) teams find it feasible as well as valuable to adapt the method to their specific needs.

Furthermore, the developed method is expected to support team collaboration. In current product development practice, plans of approach are usually specified by only one person, in most cases the project manager. However, the method that has been developed within this research stimulates to specify the user-centred plan of approach as a team. By doing so, the entire team obtains a complete and univocal overview of the user-centred plan of approach. It furthermore reduces the change to oversee important aspects in the plan of approach and offers the opportunity to make use of expert knowledge regarding specific aspects or topics that need to be specified in the user-centred plan of approach.

\section{Context}

Product development is an iterative process cycle of problem definition and solution generation. The plan of approach should evolve accordingly. The validation study revealed that design practice recognised the ability to repeatedly apply the method during the product development process. Further research should reveal whether the utilisation of the method can be adjusted to its application cycle similar to the adaptation to product development experience.

Furthermore, a useful plan of approach is based on the specific characteristics of the context in which the product development assignment needs to be executed (Van Kuijk, 2010). The developed impact model and stakeholder mapping templates enable product development teams to gain both a more detailed picture of the product development context as well as a more detailed overview of the stakeholders. Nonetheless, in here product development teams always have to deal with a certain degree of uncertainty. It will never be evident whether all relevant aspects of the product development context have been mapped or all relevant stakeholders have been identified. 


\subsection{Directions for future research}

Most of the reflective points of the previous section relate to the fact that the method needs to be applied in product development practice over a longer period of time in order to fully and thoroughly asses its added value to user-centred product development processes. For future research, three related studies are proposed to gain this insight into the method's actual added value to user-centred product development processes.

Assessing the added value of a new method to a product development process is however always challenging. Firstly, the variety in product development assignments, composition of product development teams and product development context is endless. Empirically asses the full application domain of a method is therefore often infeasible. Secondly, product development is a process that is not reproducible. This makes it difficult to reliable assess the impact of the application of the method through a comparison of product development processes with and without application of the method. The three studies proposed below should therefore face these challenges.

\section{Study 1 - Autonomous application of the method}

The first study addresses the autonomous applicability of the method. In here product development teams are asked to apply the method at the start of one of their assignments in order to specify a user-centred plan of approach. In addition - since product development is an iterative process cycle of problem definition and solution generation - product development teams are also asked to accordingly update the user-centred plan of approach with support of the method. This study will provide insight into the extent to which a) product development teams understand the workshop manual, b) can apply and even adapt the method as well as c) they are able to autonomously specify and update a user-centred plan of approach.

\section{Study 2 - Efficiency and effectiveness of the product development process}

The second study focuses on gaining insight into the method's efficiency and effectiveness. The study should be conducted within one company. Within this study, product development teams of that company are asked to apply the method over a longer period of time to several product development projects. By comparing the outcome of these projects to previous projects, it is possible to reveal a possible trend of improvements in both product development process as well as products that originate from this process.

\section{Study 3 - Application domain}

Finally, the third study attends to the application domain of the method and should be conducted at several companies of a longer period of time. In here product development teams of the participating companies are asked to apply the method to 
several product development assignments. The fact that the method is applied in a varying product development context, by teams that vary in composition and organisation, to different kinds of product assignments, will provide better insight into the application domain in which application of the method is expected to be most valuable.

Another remaining question in respect to this research is whether applying the developed method leads to products that better meet the wide variety of (use) expectations of their users. Answering this question was beyond the scope of this research. Conducting the proposed future research, in particular the studies 2 and 3, is strongly recommended as they will enable the answering of this question as well. After all, providing users with products that meet their expectations is the main reason behind this research. 


\section{References}

(1986). Methodik zum entwickeln und konstruieren technischer Systeme und

Produkte. V. D. Ingenieure. Düsseldorf, VDI.

(2006). "Generic work process version 1.0." Retrieved 8 July, 2011.

Andreasen, M. and L. Hein (1985). Integrated product development. Bedford, IFS (Publications) Ltd.

Asimov, M. (1964). Introduction to design. New York, Prentice-Hall.

Association, I. E. (2010). "What is ergonomics?" Retrieved 5 April 2010, 2010.

autor, C. (2011). Retrieved 27 July, 2011, from http://openlearn.open.ac.uk/course/category.php?id=13\&perpage=15\&p age $=1$.

Babou, B. (2004) "What is stakeholder analysis." 2011.

Bailey, R. W. (1996). Human performance engineering, 3rd edition. Englewood Cliffs, New York, PTR Prentice Hall.

Bevan, N. (2006). "UsabilityNet." Retrieved 8 July, 2011.

Bias, R. (1991). "Walkthroughs: Efficient collaborative testing." IEEE Software 8(5): 94-95.

Blanchard, B. S. and W. J. Fabrycky (1990). Systems engineering and analysis. Englewood Cliff, NJ, Prentice Hall.

Boivie, I. C., J. Gulliksen, et al. (2006). "The lonesome cowboy: A study of the usability designer role in systems development." Interacting with computers 18(4): 601-634.

Bowie, N. (1988). The moral obligations of multinational corporations. Problems of international justice. S. Luper-Foy. Boulder, CO, Westview press: 97113.

Buijs, J. and A. Valkenburg (1997). Integrale productontwikkeling. Utrecht, LEMMA.

Buijs, J. and R. Valkenburg (2005). Integrale productontwikkeling. Utrecht, Uitgeverij Lemma.

Butler, K. A. (1996). "Usability engineering turns 10." Interactions 3(1): 58-75.

Buxton, B. (2007). Sketching user experiences: Getting the design right and the right design, Morgan Kaufmann.

Cameron, B. G., T. Seher, et al. (2010). "Goals for space exploration based on stakeholder network value considerations." Acta Astronautica doi:10.1016/i.actaastro.2010.11.003.

Caroll, J. (2000). "Five reasons for scenario-based design." Interacting with computers 13: 43-60. 
Carroll, J. M. (2000). "Five reasons for scenario-based design." Interacting with computers 13: 43-60.

Christiaans, H. (1992). Creativity in design. Industrial design engineering. Delft, TU Delft. PhD.

Clarkson, M. B. E. (1995). "A stakeholder framework for analyzing and evaluating corporate social performance." Academy of Management Review (Academy of Management) 20: 92-117.

Cross, N. (1994). Engineering design methods. Chichester, John Wiley \& Sons.

Cross, N. (2006). Designerly ways of knowing. Basel, Boston, Berlin, Birkhäuser.

Cross, N., H. Christiaans, et al. (1996). Analysing design activity. Chichester, John Wiley and Sons Ltd.

Cross, N. and N. Roozenburg (1993). "Modelling the design processes in engineering and in architecture." Journal of engineering design 3(4): 325 337.

Daalhuizen, J., P. Badke-Schaub, et al. (2008). Community based design support. TMCE 2008 conference. I. Horváth and Z. Rusak. Izmir, Tukey.

Deming, W. E. (1986). Out of the Crisis. Cambridge, Massachusetts, The MIT Press.

Den Ouden, P. H. (2006). Development of a design analysis model for consumer complaints: Revealing a new class of quality failutes. Eindhoven, TU Eindhoven. PhD.

Dix, A., J. Finlay, et al. (1993). Human-computer interaction. englewood Cliffs, NJ, Prentice Hall.

Dorst, K. (2006). "Design problems and design paradoxes." Design issues 22(3): 417.

Dorst, K. (2008). "Design research: a revolution-waiting-to-happen." Design studies 29: 4-11.

Evbuomwan, N. and S. Sivaloganathan (1996). "A survey of design philosophies, models, methods and systems." Proceedings of the institution of mechanical engineers 210(4): 301-320.

Finger, S. and J. Dixon (1989). "A review of research in mechanical engineering design. Part II: Representations, analysis, and design for the life cycle." Research in engineering design 1: 121-137.

Freeman, R. E. (1984). Strategic Management: A stakeholder approach. Boston, Pitman.

Freeman, R. E. and J. McVea (2001). "A Stakeholder Approach to Strategic Management." SSRN eLibrary.

Freeman, R. E. and D. L. Reed (1983). "Stockholders and stakeholders: A new perspective on corporate governance." California management review 25(3): 93-94.

Freeman, R. E. and E. W.M. (1990). "Corporate governance: A stakeholderinterpretation." Journal of behavioral economics 19(337-359). 
French, M. J. (1971). Engineering design: The conceptual stage. London, Heinemann Educational Books.

Friedman, A. L. and S. Miles (2006). Stakeholders: Theory and practice. New York, Oxford University Press Inc.

Gould, J. D. and C. Lewis (1985). "Designing for usability: key principles and what designers think." Communication of the ACM 28(3): 360-411.

Grudin, j. (1991). "Obstacles to user involvement in software product development, with implications for CSCW." International journal of manmachine studies 34: 435-452.

Gulliksen, J. I., I. C. Boivie, et al. (2006). "Usability professionals--current practices and future development." Interacting with computers 18(4): 568-600.

Hedeman, B. and G. Vis van Heemst (2005). Project management based on PRINCE 2 - PRINCE2 edition 2005. Zaltbommel, NL, Van Haren Publishing.

Hekkert, P. P. M., M. M., et al. (2003). Dancing with a machine: A case of experience-driven design'. DPPI conference Pittsburgh USA.

Hekkert, P. P. M., M. B. Van Dijk, et al. (2011). Vision in product design, BIS Publishers

Hoolhorst, F. W. B. (2010). Research project 'Insight in design practics': Insight into the user-centred design method's applicability in design practice. Enschede, Universiteit Twente.

Hoolhorst, F. W. B. and v. d. M. C. Voort (2009). A concept for a usability focused design method. IASDR 2009. Seoul.

Hubka, V. (1983). Design tactics = methods + working principles for design engineers. International Conference on Engineering Design, ICED. Kobenhavn: 16-34.

IDEO (2002). IDEO Method cards. San Francisco USA, William Stout Architectural Books

ISO (1998). ISO 9241-11 (1998): Ergonomic requirements for office work with visual display terminals (VDTs) -- Part 11: Guidance on usability. I. o. f. S. (ISO), International organization for Standarization (ISO).

ISO (1999). ISO 13407 - Human-centred design processes for interactive systems. Geneva, Switserland.

Jiao, J., T. Simpson, et al. (2007). "Product family design and platform-based product development: A state-of-the-art review." Journal of intelligent manufacturing 18(1): 5-29.

Joglekar, N. R. and D. N. Ford (2005). "Product development resource allocation with foresight." Auropean journal of operational research 160: 72-87.

Kahn, M. J. and A. Prail (1994). Formal usability inspections. Usability inspection methods. J. Nielsen and R. L. Mack. New York, USA, John Wiley \& Sons: 203-232. 
Kerzner, H. (2001). Project management: A systems approach to planning, scheduling and controlling. Berea, Ohio USA, John Wiley \& Sons, Inc.

Kleinsmann, M. (2006). Understanding collaborative design. Industrial design engineering. Delft, TU Delft. PhD.

Koller, R. (1976). Konstruktionsmethode für den Machinen-, Geräte und Apparatebau. Berlin, Springer.

Kreifeldt, J. (1992). Ergonomics of product design. Handbook of industrial engineering. G. Salvendy. New York, John Wiley \& Sons.

Krishnan, V. and S. Gupta (2001). "Appropriateness and impact of platform-based product development." Management science 47(1): 52-68.

Lauesen, S. (1997). Usability engineering in industrial practice. INTERACT'97, Discovering new worlds of $\mathrm{HCl}$, Sydney, Australia, Chapman \& Hall.

Lloyd, P. and P. Scott (1994). "Discovering the design problem." Design studies 15(2): 125-140.

Luckman, J. (1984). An approach to management in design. Developments in design methodology. N. Cross. New York, Wiley.

MacCormac, R. (1976). Design is ... (Interview with N. Cross). United Kingdom, BBC/Open University TV programme.

Meister, D. (1987). System design, development, and testing. Handbook of human factors. G. Salvendi. New York, Wiley: 17-41.

Mendelow, A. (1991). Stakeholder Mapping. 2nd International Conference on Information Systems. Cambridge.

Meyer, M. H. and J. M. Utterback (1995). "Product development cycle time and commercial succes." IEEE Transactions on engineering management 42(4): 297-303.

Mitchell, R. K., B. R. Agle, et al. (1997). "Toward a Theory of Stakeholder Identification and Salience: Defining the Principle of Who and What Really Counts." Academy of Management Review (Academy of Management) 22(4): 853-886.

Murray-Webster, R. and P. Simon (2006). "Making sens of stakeholder mapping." PM World today 8(6).

Näsi, J. (1995). What is stakeholder thinking? A snapshot of a social theory of the firm. Understanding stakeholder thinking. J. Näsi. Helsinki, LSR-Julkaisut Oy: $19-32$.

Nemeth, C. (2004). Human factors methods for design, Making systems humancentered. Boca Raton, CRC Press LLC.

Newell, A. (1983). The heuristic of george Polya and its relation to artificial intelligence. Methods of heuristics. R. Groner, M. Groner and W. F. Bischof. London (UK), Lawrence Erlbaum associates Publishers: 203-204.

Nielsen, J. (1992). "The usability engineering lifecycle." IEEE Computer 25(3): 1222. 
Pahl, G. and W. Beitz (1986). Konstruktionslehr; Handbuch fur Studium und Praxis. Berlin, Springer.

Pahl, G. and W. Beitz (1996). Engineering design. London, Design Counsil.

Person, O., J. P. L. Schoormans, et al. (2008). "Should new products look similar or different? The influence of the market environment on strategic product styling." Design studies 29(1): 30-48.

Peters, A., E. Rooney, et al. (1999). "New product design and development: a generic model." The TQM Magazine 11(3): 172-179.

PMI (2000). A guide to the project management body of knowledge (PMBOK Guide). Newtown Square, Pennsylvania USA, PMI.

PMI (2004). A Guide to the Project Management Body of Knowledge (Pmbok Guide)Third Edition. Zaltbommel, Van Haren Publishing.

Potts, P. (1995). Using Schematic Scenarios to Understand User Needs. Designing Interactive Systems (DIS'95), Ann Arbor.

Preece, J., H. Sharp, et al. (2007). Interaction design: Beyond human-computer interaction, John Wiley \& Sons Inc.

Pugh, S. and D. G. Smith (1978). Design teachin 10 years on.

Quesenbury, W. (2001). What does usability mean: Looking beyond 'ease of use'. 48th Annual conference, Society for Technical Communication. Chicago.

Restrepo, J. (2004). Information processing in design. Delft, DUP Science.

Restrepo, J. and H. Christiaans (2003). Problem structuring and information access in design. Design thinking research symposium.

Rittel, H. and M. Webber (1973). "Dilemmas in a general theory of planning." Policy sciences 4: 155-169.

Roozenburg, N. and J. Eekels (1996). Productontwerpen, structuur en methoden (derde druk). Utrecht, Uitgeverij LEMMA.

Roozenburg, N. F. M. and J. Eekels (1996). Produktontwerpen, structuur en methoden (derde druk). Utrecht, NL, Uitgeverij Lemma BV.

Roth, K. (1982). Konstruieren mit Konstruktionskatalogen. Berlin, Springer.

Savage, G. T., T. W. Nix, et al. (1991). "Strategies for assessing and managing organizational stakeholders." Academy of Management Executive 5(2): 61-75.

Sawhney, M. S. (1998). "Leveraged high-variety strategies: From protfolio thinking to platform thinking." Journal of the academy of marketing science 26(1): 54-61.

Shewhart, W. (1939). Statistical method from the viewpoint of quality control. Washington D.C. USA, The Graduate School, the Department of Agriculture.

Shneiderman, B. (1992). Designing the user interface: Strategies for effective human-coputer interaction (2nd edition). Reading, MA, Addison-Wesley. 
Simon, H. (1973). "The ill structure of ill-structured problems." Artificial intelligence 4: 181-204.

Sundgren, N. (1999). "Introducing interface management in product family development." Journal of production innovation management 16(1): 4051.

Tjalve, E. (1979). A short course in industrial design. London, The Butterworth Group.

Turner, J. R., V. Kristoffer, et al. (2002). The Project Manager as Change Agent. London, McGraw-Hill Publishing Co.

Ullman, D. G. (1992). The mechanical design process. New York, McGraw-Hill Inc.

Ullrich, K. T. and S. D. Eppinger (1995). Product design and development. New York, Mcgraw-Hill Inc.

Ulrich, K. T. and S. D. Eppinger (2004). Product design and development. New Yorl, McGraw-Hill.

Van den Kroonenberg, H. H. and F. J. Siers (1998). Methodisch ontwerpen: ontwerpmethoden, voorbeelden, cases en oefeningen. Houten, Educatieve Partners Nederland BV.

Van Eijk, D., J. Van Kuijk, et al. (2012). Design for usability; Practice-oriented research for user-centered product design. IEA2012.

Van Kuijk, J. I. (2010). Managing product usability: How companies deal with usability in the development of electronic consumer products. Industrial design engineering. Delft, TU Delft. PhD.

Van Kuijk, J. I. (2010). Managing product usability: How companies deal with usability in the development of electronic products. Industrial design engineering. Delft, TU Delft. PhD.

Van Kuijk, J. I., F. W. B. Hoolhorst, et al. (2010). Vision on integration: Towards a coherent DfU methodology and positioning of new knowledge, methods and tools. TU Eindhoven.

VDI (1985). Methodik zum Entwickeln und konstruieren technischer Systeme und Produkte. Düsseldorf.

Verbeek, P. P. C. C. (2005). What things do. University Park, The Pennsylvania State Press.

Vredenburg, K., S. Isensee, et al. (2002). User-centered design; An integrated approach. New Jersey, USA, Prentice-Hall.

Vredenburg, K., J. Y. Mao, et al. (2002). A survey of user-centered design practice. SIGCHI 2002 Conference on human factors in computing systems: Changing our world, changing ouselves. Minneapolis, Minnesota, USA.

Wheelright, S. C. and K. B. Clark (1992). Revolutionizing product development: Quantum leaps in speed, efficiency, and quality. New York, The free press. 
Wickins, C., S. Gordon, et al. (1998). An introduction to human factors

engineering. New York, Reading, Menlo Park, Harlow, Don Mills, Sydney, Mexico City, Madrid, Amsterdam, Addison Wesley Longman. 